\title{
LIGHTNING ENVIRONMENT IN THE VICINITY OF THE CN TOWER DURING MAJOR STORMS
}

\author{
by \\ Norhan Mansour \\ B.Sc., Ain Shams University, Cairo, Egypt, 2011 \\ A thesis \\ presented to Ryerson University \\ in partial fulfillment of the \\ requirements for the degree of \\ Master of Applied Science \\ in the Program of \\ Electrical and Computer Engineering
}

Toronto, Ontario, Canada, 2017

(C) Norhan Mansour 2017 


\section{AUTHOR'S DECLARATION FOR ELECTRONIC SUBMISSION OF A THESIS}

I hereby declare that I am the sole author of this thesis. This is a true copy of the thesis, including any required final revisions, as accepted by my examiners.

I authorize Ryerson University to lend this thesis to other institutions or individuals for the sole purpose of scholarly research.

I further authorize Ryerson University to reproduce this thesis by photocopying or by other means, in total or in part, at the request of other institutions or individuals for the sole purpose of scholarly research.

I understand that my thesis may be made electronically available to the public. 


\author{
Abstract \\ Lightning Environment in The Vicinity of The CN Tower During Major Storms \\ Norhan Mansour \\ Master of Applied Science \\ Electrical and Computer Engineering \\ Ryerson University \\ 2017
}

Based on the North American Lightning Detection Network data and the return-stroke currents recorded at the $\mathrm{CN}$ Tower, the lightning environment within $100 \mathrm{~km}$ from the $\mathrm{CN}$ Tower is thoroughly investigated, especially while the tower was struck with major storms in 2011 and 2005. On Aug 24, 2011, video records showed that the tower was struck with 52 flashes within about 84 minutes, pointing out to the most intense storm that has ever been observed at the tower. During this most intense storm, the tower's current measurement system recorded 32 flashes, containing 161 return strokes, resulting in an average flash multiplicity of 5 , which is $80 \%$ higher than the average multiplicity of flashes occurring in the vicinity of the tower. Since the tower is repeatedly hit by lightning and its flashes produce markedly higher number of strokes, then it definitely poses an electromagnetic interference risk to nearby sensitive installations, including those in downtown Toronto. 


\section{Acknowledgements}

First and foremost, I would like to sincerely thank my loving parents Samia and Mostafa Mansour for their love, encouragement, and everlasting moral support throughout my undergraduate and graduate education.

My deepest appreciation goes to my beloved husband, Mohamed Hussein, for his constant encouragement, for believing in me and always pushing me towards greatness. And to my babies; Ali and Layla.

I would like to express my deep gratitude and appreciation to my thesis supervisor Prof. Dr. Ali Hussein for his guidance, support and advice during my research work on this thesis. His expertise, knowledge and professionalism are highly valued; it was my pleasure working with him.

I would like to acknowledge with appreciation the contributions of M. Anwar, M. Yousuf and P. Liatos for the installation of the NI PCI 5114 digitizer, which was pivotal for the recording of the current derivative data of the most intense storm that hit the tower on August 24, 2011.

I would like to also acknowledge with appreciation Dr. S. Kazazi for his help in the acquirement and the analysis of the recorded current derivative data of August 242011 storm.

Furthermore, many thanks go to Mr. P. Weiss and Mr. W. See-Tho for providing lightning images of August 24, 2011 strikes to the Tower.

I would like to thank Environment Canada for providing lightning data from the Canadian Lightning Detection Network. This work was supported by the Natural Sciences and Engineering Research Council of Canada, NSERC Discovery Grant: 2012-2017, which is gratefully acknowledged.

And finally, I would like to thank the Department of Electrical and Computer Engineering

and the School of Graduate Studies at Ryerson University for giving me the opportunity to participate in such an interesting research. 


\section{Contents}

Author's Declaration for Electronic Submission of A Thesis ......................................................... ii

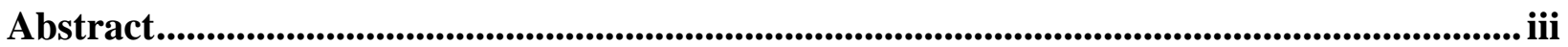

Acknowledgements .................................................................................................................................. iv

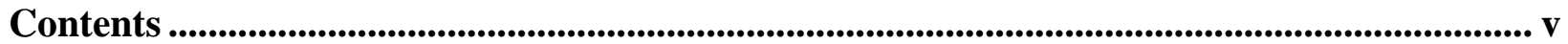

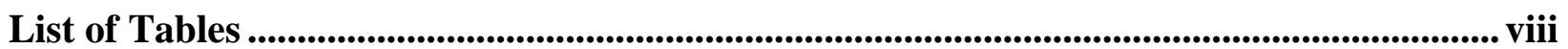

List of Figures............................................................................................................................................................ ix

Chapter 1 Introduction............................................................................................................................ 1

Chapter 2 Lightning Phenomenon ...................................................................................................... 4

2.1 History of Lightning Studies .....................................................................................

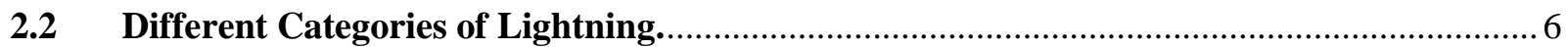

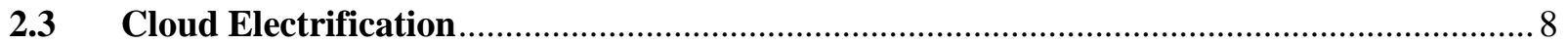

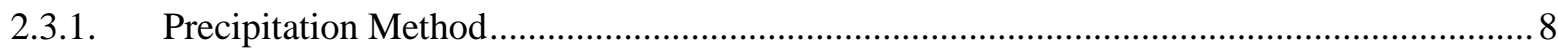

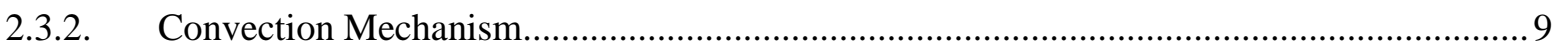

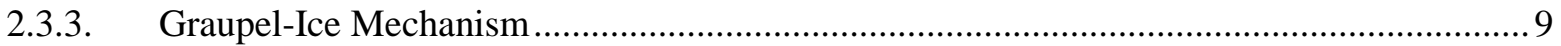

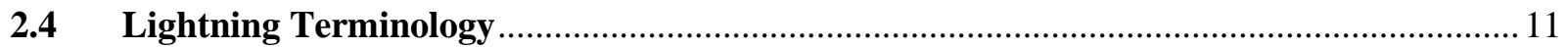

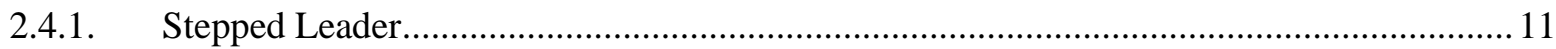

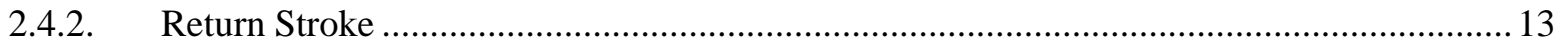

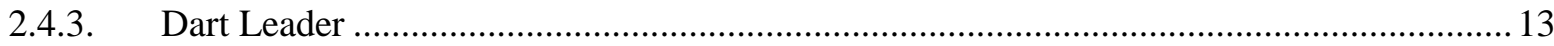

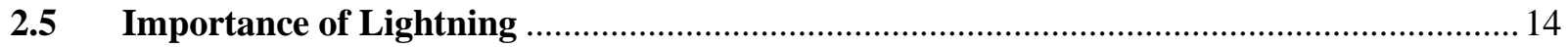

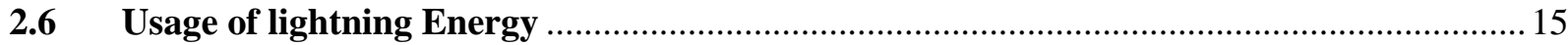

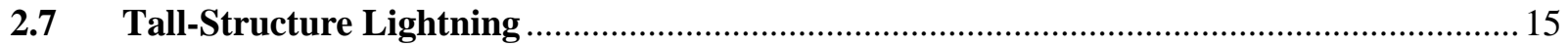

Chapter 3 Lightning Detection ............................................................................................................. 18

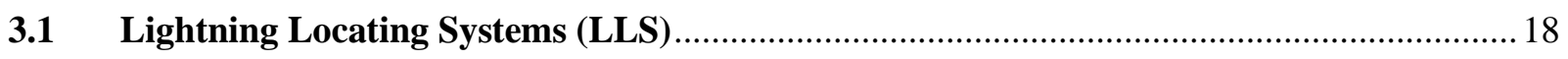

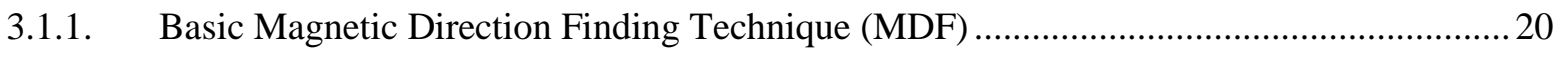




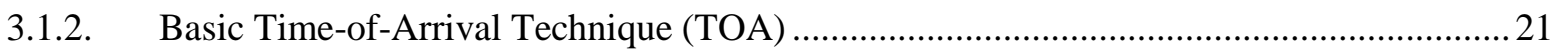

3.1.3. Improved Accuracy from Combined Technology (IMPACT) ........................................23

3.2 North American Lightning Detection Network (NALDN) ............................................... 24

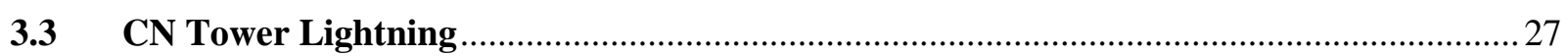

Chapter 4 CN Tower Lightning Current Measurement Systems ........................................ 28

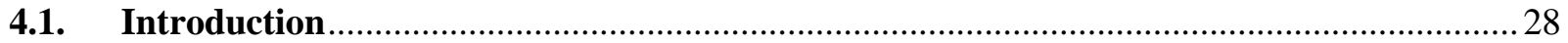

4.2. Current Derivative Measurement Systems....................................................................29

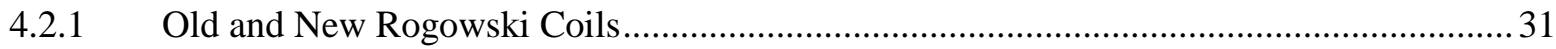

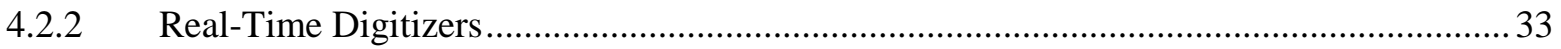

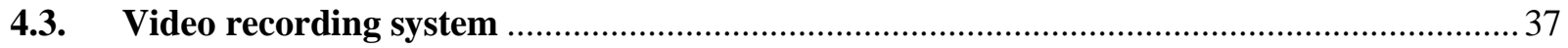

4.4. Current Derivative Measurement System Records ........................................................ 37

Chapter 5 Lightning in the Vicinity of the Tower ........................................................................ 42

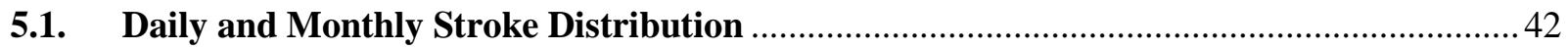

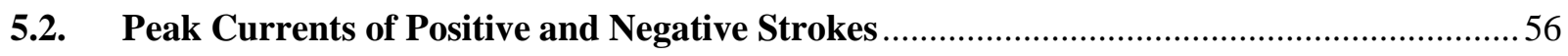

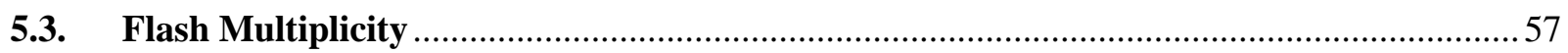

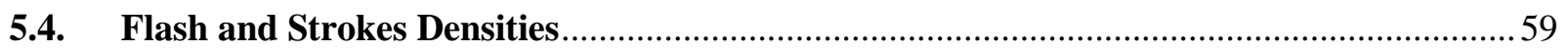

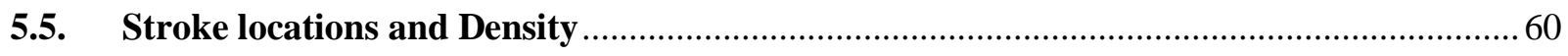

Chapter 6 Major Storms at the CN Tower.........................................................................6 63

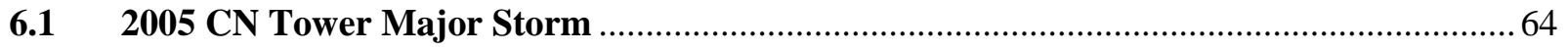

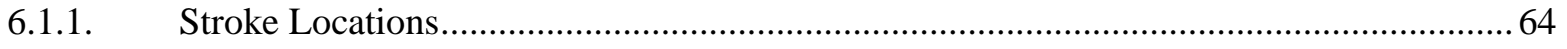

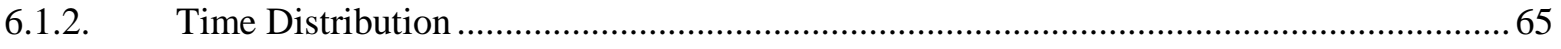

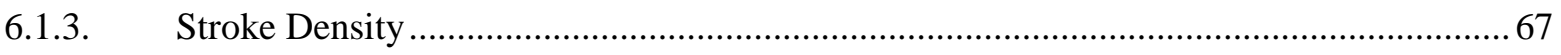

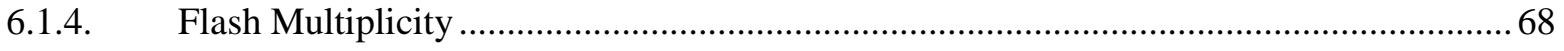

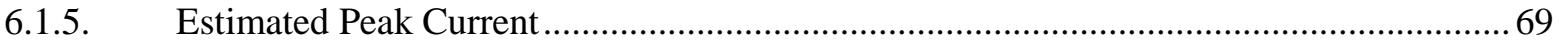

6.1.6. Estimated Stroke Locations within $5 \mathrm{~km}$ from the tower ........................................... 71

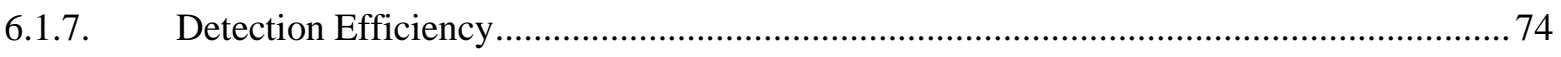

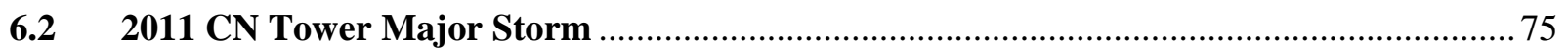

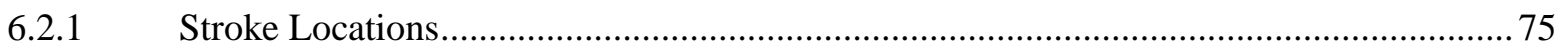

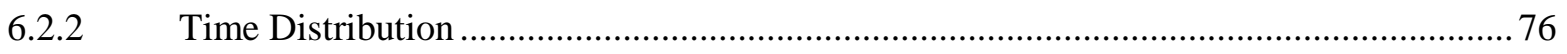

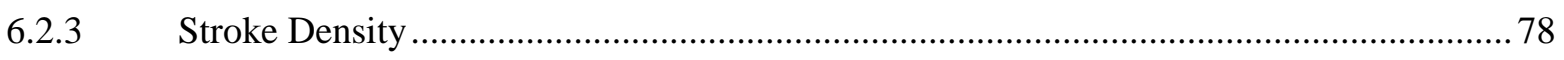

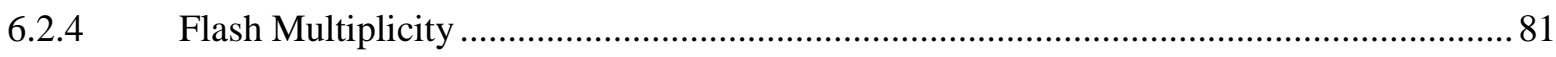

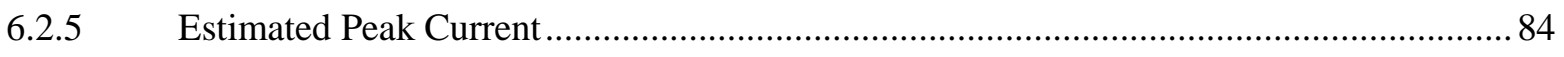

6.2.6 Estimated Stroke Locations within $5 \mathrm{~km}$ from the tower.............................................. 86 


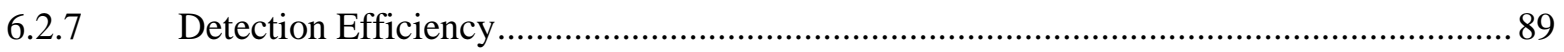

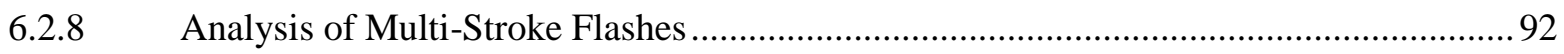

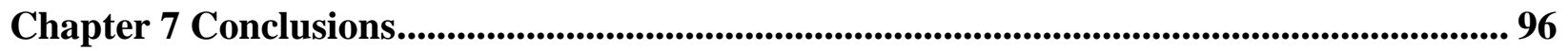

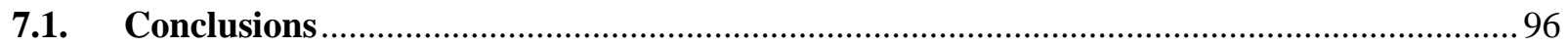

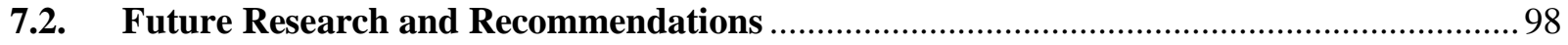

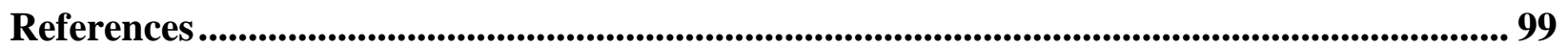

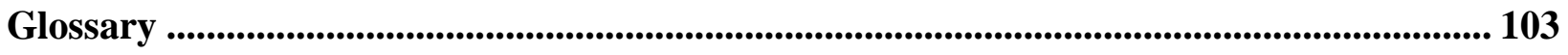




\section{List of Tables}

Table 4.1 - Technical specifications of the old and new Rogowski coils ................................ 32

Table 4.2 - Technical specifications of the LeCroy LT342L, NI PCI 5114, and NI PXIe 5160

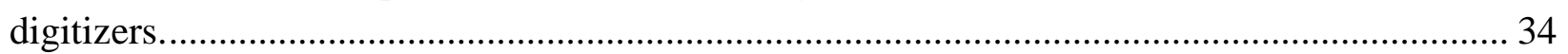

Table 5.1 - Monthly number of cloud-to-ground strokes and their peak current values, 2000.... 43

Table 5.2 - Monthly number of cloud-to-ground strokes and their peak current values, 2001... 44

Table 5.3 - Monthly number of cloud-to-ground strokes and their peak current values, 2002... 45

Table 5.4 - Monthly number of cloud-to-ground strokes and their peak current values, 2003... 46

Table 5.5 - Monthly number of cloud-to-ground strokes and their peak current values, 2004... 47

Table 5.6 - Monthly number of cloud-to-ground strokes and their peak current values, 2005... 48

Table 5.7 - Monthly number of cloud-to-ground strokes and their peak current values, 2009... 49

Table 5.8 - Monthly number of cloud-to-ground strokes and their peak current values, 2010... 50

Table 5.9 - Monthly number of cloud-to-ground strokes and their peak current values, 2011... 51

Table 5.10 - Monthly number of cloud-to-ground strokes and their peak current values, 2012.. 52

Table 5.11 - Monthly number of cloud-to-ground strokes and their peak current values, 2013.. 53

Table 5.12 - Total number of strokes for each year ......................................................... 55

Table 5.13 - Total number of positive and negative strokes and their percentage per year........ 56

Table 5.14 - Summary of the total number of positive and negative strokes detected by NALDN per year along with the average, maximum and minimum values of their estimated peak current.

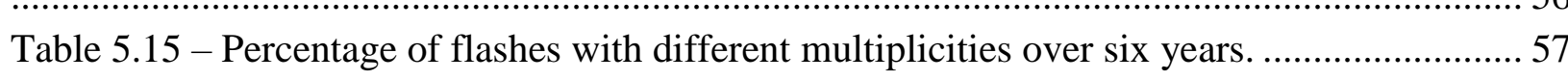

Table 5.16 - Average flash multiplicity per year. ............................................................ 58

Table 5.17 - Flash and stroke densities each year based on an area of $31,415.93 \mathrm{~km}^{2} \ldots \ldots \ldots \ldots . . .59$

Table 6.1 - Number of NALDN-detected and CN Tower-measured strokes........................... 74

Table 6.2 - Number of NALDN-detected and CN Tower-measured strokes........................... 90 


\section{List of Figures}

Figure 2.1 - Franklin's experiment to prove that lightning is electrical [1] ............................... 5

Figure 2.2 - Franklin's electrical kite experiment [1] .................................................... 6

Figure 2.3 - The four lightning categories [5] ............................................................. 7

Figure 2.4 - The Precipitation method explaining the electrical structure of a thundercloud [6]. . 8

Figure 2.5 - Illustration of the convection mechanism [4] ................................................ 9

Figure 2.6 - The electric structure of a thundercloud [6] .................................................... 10

Figure 2.7 - (a) A still-camera image of a three-stroke flash, (b) a streak-camera image showing the luminous features of the lightning flash, (c) channel-base current [4] .............................. 12

Figure 2.8 - A diagram showing how thunderstorms act as batteries to keep the earth charged negatively and the atmosphere charged positively [1] ........................................................ 14

Figure 2.9 - CN Tower lightning trajectory showing upward branching, August 24, 2011 [9]... 16 Figure 3.1 - Lightning detection technologies and the relationship between frequency and

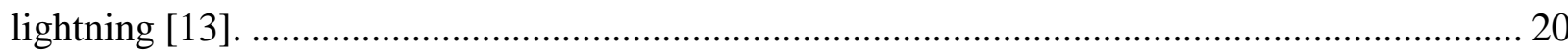

Figure 3.2 - Determination of the location of the lightning stroke using two or three sensors for the magnetic direction finding technique [14] .............................................................. 21

Figure 3.3 - Hyperbolic intersection method using three sensors [14] . .................................. 23

Figure 3.4 - Ambiguous location for a three-sensor hyperbolic intersection [14] ................... 23

Figure 3.5 - Circular intersection approach using four sensors [14] ...................................... 23

Figure 3.6 - IMPACT method on a baseline between two sensors [14] . ................................. 24

Figure 3.7 - Illustration showing the flow of lightning data in the CLDN [22]....................... 26

Figure 3.8 - Map showing the locations of the CN Tower, CLDN and NLDN sensors in the

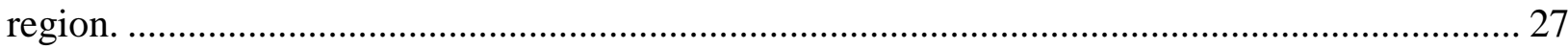

Figure 4.1 - CN Tower and the locations of the current derivative measurement system

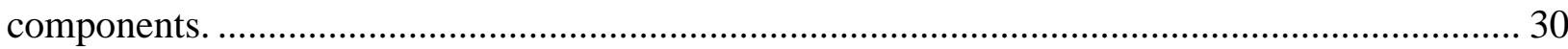

Figure 4.2 - The Old Rogowski coil connection and its location at the CN tower [30]............. 31

Figure 4.3 - The new Rogowski Coil connection and its location at the CN Tower [30]........... 33

Figure 4.4 - LeCroy LT342L digitizer. ….................................................................. 35

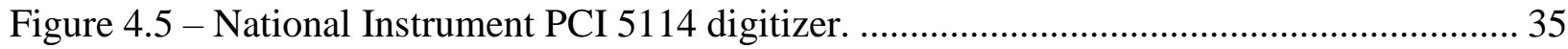

Figure 4.6 - The PXIe 5160 digitizer embedded in an NI PXIe-1082 chassis.......................... 36

Figure 4.7 - Current recording systems located at the $\mathrm{CN}$ tower.......................................... 36

Figure 4.8 - Kodak Zi8 camera record of August 24, 2011 CN Tower lightning flash [9]........ 38

Figure 4.9 - Power Shot Canon S95 record of August 24, 2011 CN Tower lightning flash [9].. 38

Figure 4.10 - Current derivative of the $30^{\text {th }}$ flash, recorded on August 24, 2011 .................... 39

Figure 4.11 - Current derivative of the stroke of Fig. 4.10, expanded................................... 40 
Figure 4.12 - Current waveform of the stroke, shown in Fig. 4.11, obtained by numerical

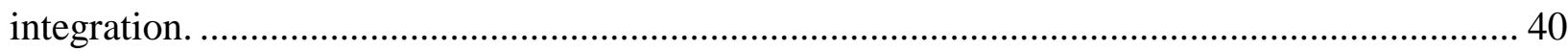

Figure 4.13 - Current derivative signal captured on August 19, 2005 at 14:11:41................ 41

Figure 4.14 - Current waveform (time integral of the current derivative of Fig. 4.13). ............ 41

Figure 5.1 - Daily/monthly distributions of detected strokes within $100 \mathrm{~km}$ from the tower, 2000 .

Figure 5.2 - Daily/monthly distributions of detected strokes within $100 \mathrm{~km}$ from the tower, 2001.

Figure 5.3 - Daily/monthly distributions of detected strokes within $100 \mathrm{~km}$ from the tower, 2002.

Figure 5.4 - Daily/monthly distributions of detected strokes within $100 \mathrm{~km}$ from the tower, 2003.

Figure 5.5 - Daily/monthly distributions of detected strokes within $100 \mathrm{~km}$ from the tower, 2004.

Figure 5.6 - Daily/monthly distributions of detected strokes within $100 \mathrm{~km}$ from the tower, 2005.

Figure 5.7 - Daily/monthly distributions of detected strokes within $100 \mathrm{~km}$ from the tower, 2009.

Figure 5.8 - Daily/monthly distributions of detected strokes within $100 \mathrm{~km}$ from the tower, 2010.

Figure 5.9 - Daily/monthly distributions of detected strokes within $100 \mathrm{~km}$ from the tower, 2011.

Figure 5.10 - Daily/monthly distributions of detected strokes within $100 \mathrm{~km}$ from the tower, 2012.

Figure 5.11 - Daily/monthly distributions of detected strokes within $100 \mathrm{~km}$ from the tower, 2013.

Figure 5.12 - The 11-year combined daily/monthly distribution of detected strokes within 100 $\mathrm{km}$ from the tower. 54

Figure 5.13 - NALDN-detected strokes within $100 \mathrm{~km}$ from the CN Tower in each year......... 55

Figure 5.14 - Number of flashes versus flash multiplicity for different years.......................... 58 Figure 5.15 - Yearly stroke density per year within $100 \mathrm{~km}$ from the tower, including CN tower strokes.

Figure 5.16 - Stroke locations within $100 \mathrm{~km}$ (20-km grid) from the CN Tower during 2005... 61 Figure 5.17 - Stroke locations within $100 \mathrm{~km}$ (20-km grid) from the CN Tower during 2011... 62 Figure 6.1 - Locations of all NALDN-detected strokes on August 19, 2005 within $100 \mathrm{~km}$ from

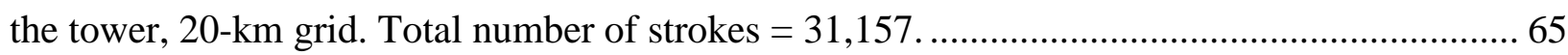
Figure 6.2 - Time distribution of strokes, within $100 \mathrm{~km}$ from the tower, August 19, 2005...... 66 Figure 6.3 - Time distribution of strokes, within $20 \mathrm{~km}$ from the tower, August 19, 2005....... 67 Figure 6.4 - Density of non-CN Tower strokes within $20 \mathrm{~km}$ from the CN Tower, on August 19, 2005. Total number of strokes $=2,718$. 68 
Figure 6.5 - Average flash multiplicity of non-CN Tower flashes within $20 \mathrm{~km}$ from the tower on August 19, 2005.

Figure 6.6 - NALDN-estimated peak current for negative (blue) and positive (red) non-CN

Tower strokes, within $20 \mathrm{~km}$ from the tower during August, 192005 storm............................. 70

Figure 6.7 - Cumulative probability distribution of flash multiplicity for CN Tower flashes (dotted blue line), non-CN Tower negative flashes (blue line) and non-CN Tower bipolar and positive flashes (red line) during August 19, 2005 storm duration.

Figure 6.8 - NALDN estimated locations of lightning strokes detected on August 19, 2005 within $5 \mathrm{~km}$ from the $\mathrm{CN}$ Tower. Blue dots represent non-CN Tower strokes, while red dots

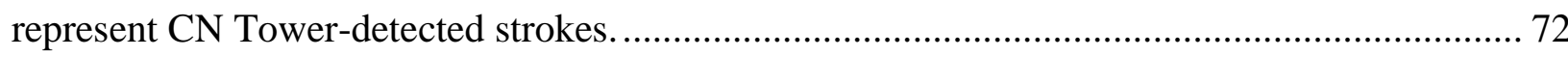

Figure 6.9 - NALDN estimated locations of lightning strokes detected on August 19, 2005 within $5 \mathrm{~km}$ from the $\mathrm{CN}$ Tower, $\mathrm{CN}$ Tower strokes excluded................................................ 73 Figure 6.10 - Location of all strokes within $100 \mathrm{~km}$ from the tower. with $20 \mathrm{~km}$ grid, on August

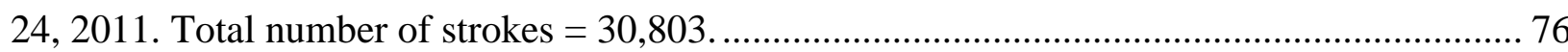
Figure 6.11 - Time distribution of strokes, within $100 \mathrm{~km}$ from the tower, August 24, 2011_... 77 Figure 6.12 - Time distribution of strokes within $20 \mathrm{~km}$ from the tower .................................. 78 Figure 6.13 - Density of non-CN Tower strokes within $20 \mathrm{~km}$ from the CN Tower on August 24, 2011. Total number of strokes $=2,062$. 79

Figure 6.14 - Locations of non-CN Tower strokes detected within $20 \mathrm{~km}$ from the tower $(5-\mathrm{km}$ grid), during the 104-minute time window.

Figure 6.15 - Average flash multiplicity of non-CN Tower flashes within $20 \mathrm{~km}$ from the tower on August 24, 2011. 81

Figure 6.16 - Flash multiplicity of non-CN Tower flashes detected within $20 \mathrm{~km}$ from the tower, during the 104-minute time window. Total number of flashes $=115$. 82 Figure 6.17 - Cumulative probability distribution of multiplicity of CN T flashes (dotted blue line), non-CN Tower negative flashes (blue line) and non-CN Tower bipolar and positive flashes (red line) during the storm duration on August 242011. 83 Figure 6.18 - NALDN estimated peak current for negative (blue, 309) and positive (red, 15) nonCN Tower strokes, within $20 \mathrm{~km}$ from the tower during August 24, 2011 storm. 84 Figure 6.19 - Cumulative probability distributions of NALDN-estimated peak current for CN Tower strokes (dotted blue line) and non-CN Tower strokes (negative, blue line; positive, red line).

Figure 6.20 - NALDN estimated locations of lightning strokes detected on August 24, 2011 within $5 \mathrm{~km}$ from the $\mathrm{CN}$ Tower. Blue dots represent the non-CN Tower strokes, while red dots represent the $\mathrm{CN}$ Tower-matched strokes.

Figure 6.21 - NALDN estimated locations of lightning strokes detected on August 19, 2005

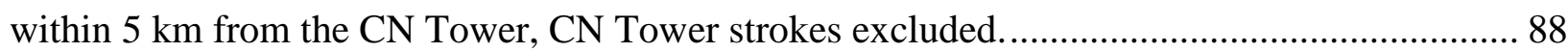

Figure 6.22 - Return-stroke current derivative signals of flash 1............................................... 91

Figure 6.23 - Return-stroke current derivative signals of flash 21............................................ 91 
Figure 6.24 - Cumulative distribution of flash multiplicity for 758 flashes within $20 \mathrm{~km}$ from the tower, August 24, 2011........................................................................................ 92

Figure 6.25 - Cumulative distribution of flash multiplicity for $\mathrm{CN}$ Tower and non-CN Tower flashes, August 24, 2011........................................................................................ 93 Figure 6.26 - Cumulative distribution of flash duration for multi-stroke flashes, August 24, 2011. Figure 6.27 - Cumulative distribution of flash duration for non-CN Tower flashes, August 24, 2011.

Figure 6.28 - Cumulative distribution of non-CN Tower flashes peak current; positive (red), bipolar (black dotted) and negative (blue) flashes. 95 


\section{Chapter 1}

\section{Introduction}

Lightning can be described as an impulse of a very high-current discharge that occurs when a very large amount of charges accumulates in a thundercloud, which is sufficient to breakdown the air between the cloud and the point of contact; whether it be the ground or any other object. The lightning path is measured in kilometers and its current is measured in tens of kilo amperes [1].

Scientists have been closely monitoring and studying lightning ever since Benjamin Franklin proved, through his experiment, that lightning is an electrical event [1]. For many years, lightning had been the cause for many tragic events in our daily lives, ranging from: human fatalities or injuries, forest fires, damaged transmission lines, disrupted aviation systems and destructions of ground installations. Because of these troubles that lightning may cause to our day-to-day life, the main purpose of studying lightning and analyzing its characteristics is protection. And in order to design lightning protection systems, it's necessary to study the lightning flash and its characteristics.

There are many applications that use the lightning data and studies, typical users are as follows:

1. Weather forecasting: predicting severe weather in order to warn the public for their safety. (It is estimated that there are about 10 lightning-related deaths and 164 lightning-related injuries in Canada per year [2].) 
2. Aviation and air traffic authority: rescheduling or rerouting flights when hazardous thunderstorms are expected.

3. Forestry: Help investigate fire start location for better control of the fire. Since forest fires in Canada caused by lightning represent 45 per cent of all fires and usually 81 per cent of the total area is burnt [3].

4. Insurance applications: Claims investigation when lightning is the cause of property damage.

5. Public utilities: Improve lightning protection systems in lightning-prone areas, schedule maintenance and repairs for electric power lines.

6. Recreation: Early warning for outdoor activities.

With all its destructive power, lightning is a great source of energy and having the ability to make use of this energy would be very beneficial. However, it is very challenging to use or store this energy. Mainly because of two reasons: firstly, most of the lightning energy is lost in the lightning channel into thunder, light, heat and radio waves; and secondly, the location of lightning is generally unpredictable [4].

The existence of the $\mathrm{CN}$ Tower in Toronto is pivotal to many lightning research studies, including this thesis. The work presented in this thesis includes a macroscopic overview of lightning return-stroke characteristics detected within $100 \mathrm{~km}$ from the CN Tower for 11 years (2000-2005 and 2009-2013). Also, an extensive analysis of the characteristics of lightning occurring in the vicinity of the $\mathrm{CN}$ Tower while the tower was heavily struck by lightning during two severe storms that took place on August 19, 2005 and August 24, 2011 is presented and discussed. These analyses are done using the data acquired from both; the North American Lightning Detection Network (NALDN) and the current derivative measurement system located at the $\mathrm{CN}$ Tower.

In Chapter 2, the lightning phenomenon is discussed. Starting with a history review of lightning studies and how it was confirmed being an electrical phenomenon by Benjamin Franklin. Followed by displaying different types of lightning according to Berger, and explaining the 
concepts of cloud electrification. Some of the most commonly used lightning terminologies; such as, stepped leader, return stroke and dart leader, are also introduced.

Chapter 3 discusses the methods and techniques of detecting lightning activities and the main instruments used in the process. It also focuses on the North American Lightning Detection Network (NALDN) which is responsible for capturing and recording lightning activity in the vicinity of the $\mathrm{CN}$ Tower.

Chapter 4 provides an insight into the current derivative measurement systems located at the CN Tower. History, technology upgrades and current operational status are presented. Also, the system used for the visual observation of lightning strikes to the $\mathrm{CN}$ Tower, along with a sample of records obtained by the different systems, are presented in this chapter.

Next, a comprehensive analysis of the NALDN detected data for the $100-\mathrm{km}$ area around the $\mathrm{CN}$ Tower for 11 years is presented in Chapter 5. A macroscopic overview of the analysis is displayed in thought-provocative charts and tables, making the data easily read and understood. The lightning characteristics discussed in this chapter are: daily and monthly distribution of strokes, estimated peak currents and their polarity, flash multiplicity, and flash and stroke densities.

Moreover, in Chapter 6, a more focused analysis of the lightning environment in the vicinity of the CN Tower during two major storms, that took place on August 19, 2005 and August 24, 2011, is presented and discussed. This focused analysis is based on the NALDN strokes data, which is then matched with the data acquired by the current derivative measurement system located at the CN Tower.

Lastly, in Chapter 7, conclusions related to the research work presented in this thesis are given and a discussion entailing suggestions for future work is outlined. 


\section{Chapter 2}

\section{Lightning Phenomenon}

\subsection{History of Lightning Studies}

Lightning is an amazing and interesting natural phenomenon that the world has witnessed since the beginning of human life. Lightning, although displaying a spectacular show of beauty, has distressed humans for its destructive powers; ranging from damage of structures and installations, forest fires, blackouts, communication interruptions and most significantly loss of lives. As a result, it has been extremely important to understand what lightning is and how to protect our lives from its damaging forces.

Very early, many scientists became curious about the physical nature of lightning. Modern lightning research started in the second half of the nineteenth century, long before Benjamin Franklin proved his theory about lightning being an electric phenomenon. In fact, many scientists contemplated the same thought, but their concerns didn't go beyond suggestions [1].

Franklin was the first to design an experiment to prove that clouds are electrified and thus lightning is electrical, in late eighteenth century. He first suggested an experiment in which a man stands on an insulated electrical structure and holds a thirty feet pointy iron rod pointing towards the sky, Fig. 2.1 (a). The man would be able to see electric sparks from his other hand to the ground when electrified clouds pass by. He also suggested another position for the experimenter, as shown in Fig. 2.1 (b), should he felt any danger. 
Many scientists around the world carried out Franklin's experiment successfully. However, before Franklin got the chance to do it himself, he suggested another way to prove his theory due to the danger involved with the first experiment. Because if the iron rod was to be directly hit by lightning, the experimenter could be killed. During a thunderstorm in 1752, Franklin performed his second experiment where he flew a kite, in lieu of the electric rod, which caused electric sparks to jump to the key that was tied to the kite's string to his hand's knuckles proving his theory. Benjamin's Electric Kite experiment is shown in Figure 2.2.

After Benjamin Franklin proved his theory about lightning, no significant lightning research materialized until late nineteenth century when photography and spectroscopy became available as diagnostic tools in lightning research [5].

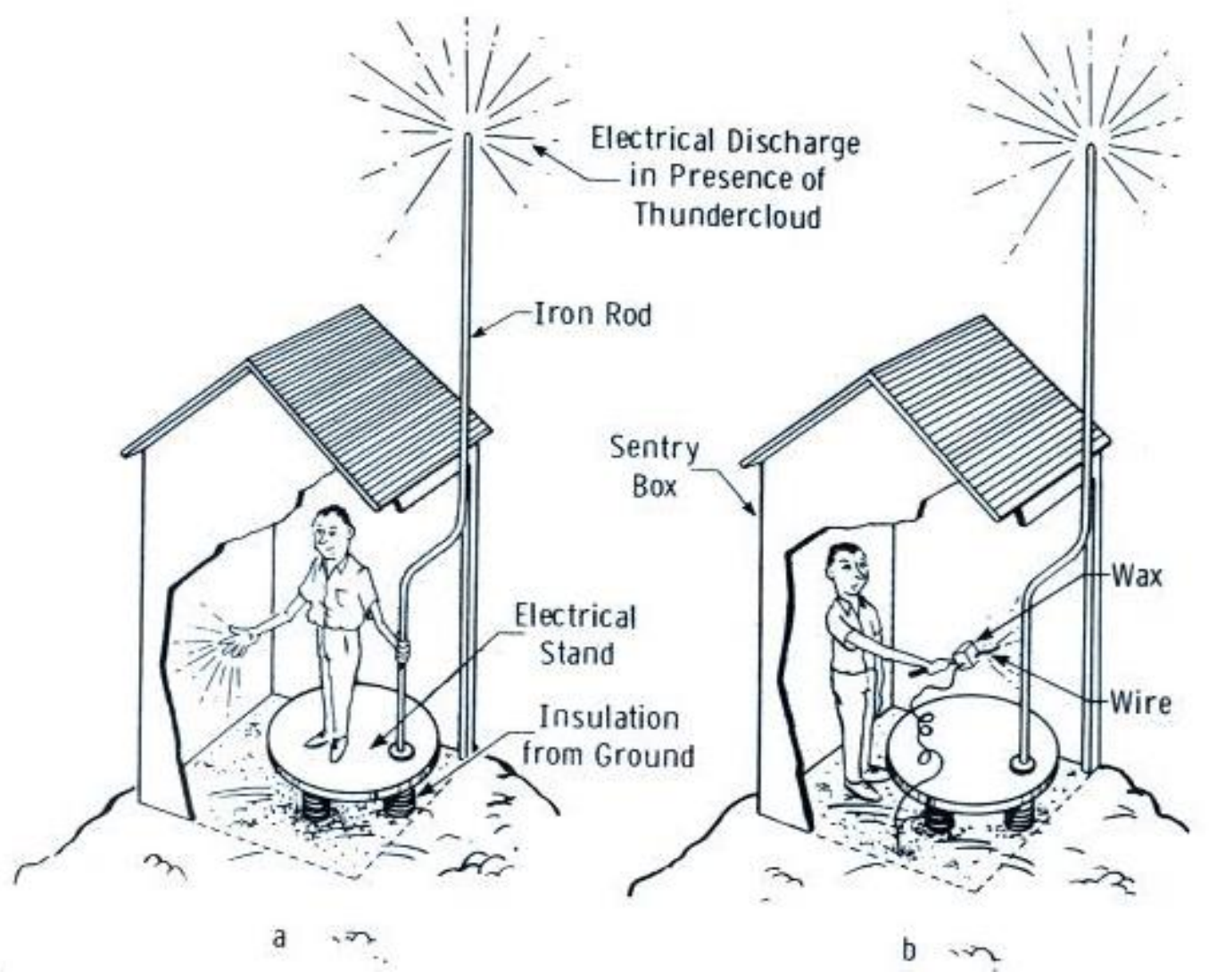

Figure 2.1 - Franklin's experiment to prove that lightning is electrical [1]. 


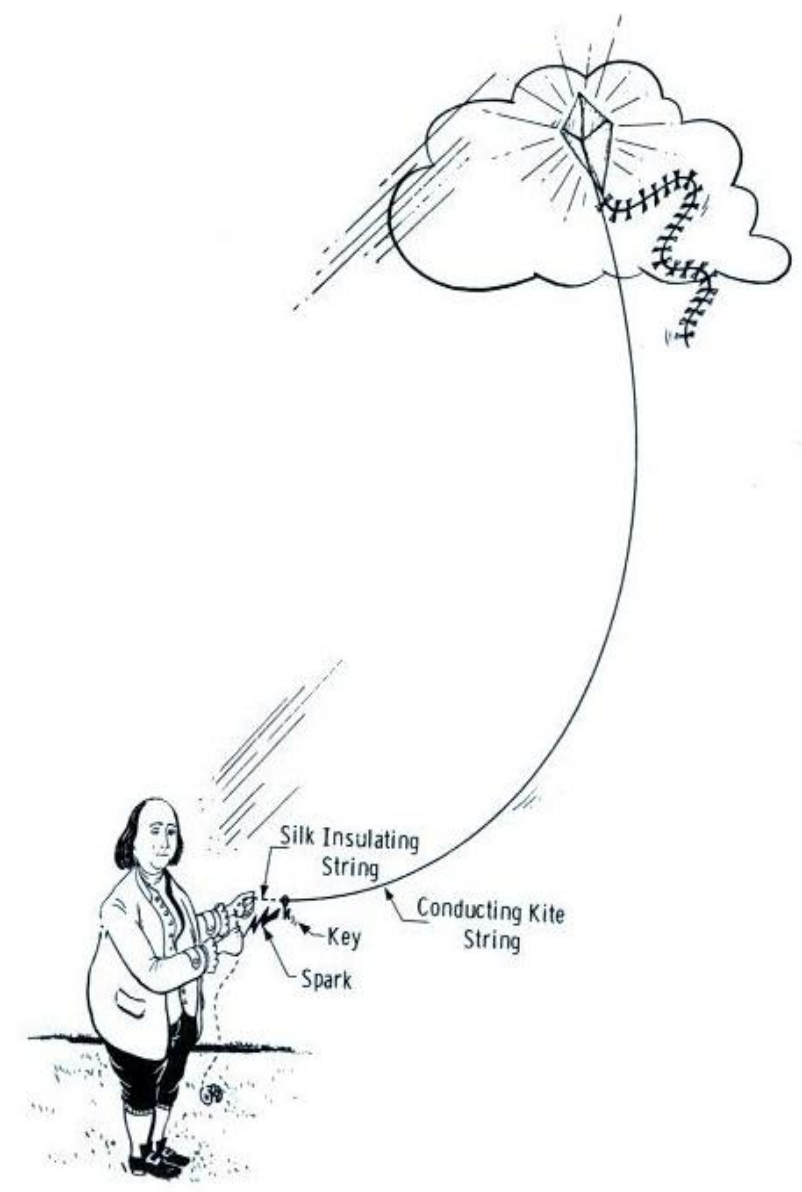

Figure 2.2 - Franklin's electrical kite experiment [1].

\subsection{Different Categories of Lightning.}

Lightning is a transient high-current electrical discharge that travels between a charged cloud and the ground, or any object on it. In general, lightning can be grouped into two main categories; those that strike the ground, referred to as cloud-to-ground, and those that do not, referred to as cloud lightning. Cloud-to-ground lightning can be categorized into four main types by means of the observed polarity of the charge lowered to ground and the direction of propagation, according to Berger (1978) [4]. Figure 2.3 shows the four different types of lightning, namely:

1. Downward negative lightning.

2. Upward negative lightning.

3. Downward positive lightning

4. Upward positive lightning. 

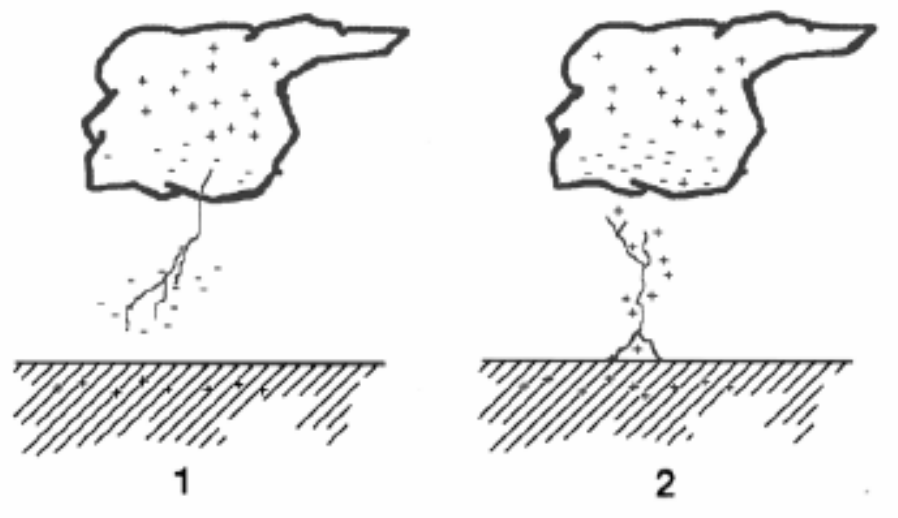

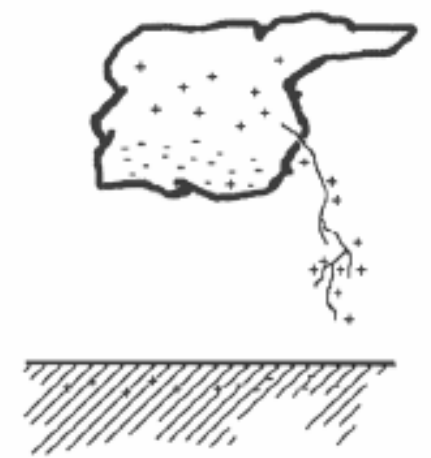

3

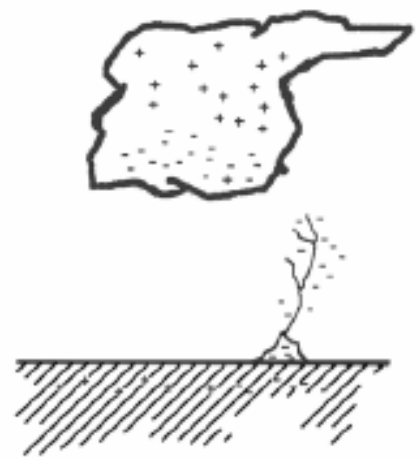

4

Figure 2.3 - The four lightning categories [5].

Category 1 is the most common lightning discharge and it accounts for almost $90 \%$ of all lightning strikes worldwide. Category 3 comes next with less than $10 \%$ of worldwide lightning events, and the remaining 2 categories are less frequent. There are other less common types that are called cloud discharges. They take place between adjacent clouds, or cloud to air.

Most lightning studies focus on cloud-to-ground lightning flashes because they are very visual and they do affect our daily life, even though cloud lightning (within the thundercloud) is much more frequent. There are other types of lightning discharges; such as, cloud-to-cloud and cloudto-air, which are not as common. Lightning also occurs in sandstorms, snowstorm, above volcanic eruptions, and even out of the clear sky. The main cause for lightning to occur in a region is to have large electrical charge enough to breakdown the air [1]. 


\subsection{Cloud Electrification}

Lightning is defined as an electric discharge, but in order for it to materialize, a separation of charge process must take place inside the thundercloud, but how does the separation of charge occur?

\subsubsection{Precipitation Method}

In 1885, two German physicists, Julius Elster and Hans F. Geitel, proposed the precipitation hypothesis. This hypothesis assumes that the separation of charge happens as a result of collisions between the large precipitation particles in the thundercloud such as; raindrops, hailstones and graupel particles (mushy ice pellets, millimeters to centimeter in size), and the much smaller ice crystals and mist of water droplets [6]. The collision is anticipated to transfer negative charge to the precipitation particles and positive charge to the mist, and as a result of the weight difference, the precipitation particles accumulate at the lower part of the cloud making it negatively charged, while the positively lighter mist is left at the upper part of the cloud. Figure 2.4 shows an illustration of the electrical structure of a thundercloud based on the precipitation hypothesis [6].

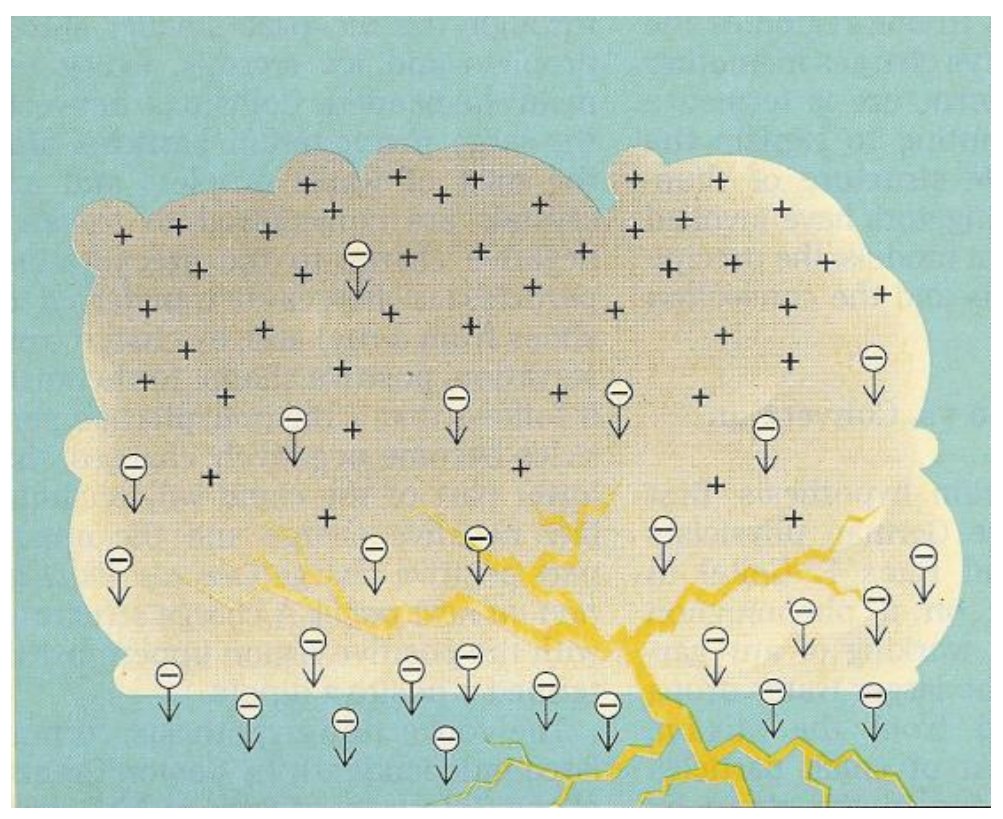

Figure 2.4 - The Precipitation method explaining the electrical structure of a thundercloud [6]. 


\subsubsection{Convection Mechanism}

In this mechanism, charges are thought to be initially introduced to the thundercloud by means of two main external sources; corona discharge near the surface of the earth and cosmic rays near the top of the cloud [6], [4].

The positive ions resulting from the corona discharge at the surface of the earth are carried upward by warm air, by convection, until reaching the upper region of the cloud, then they start attracting the negative ions, which formed by cosmic rays, at the top of the cloud. Once the negative ions enter the cloud they quickly attach themselves to the water droplets and ice crystals forming a negative screening layer that is carried downwards by the downdrafts towards the base of the cloud. Figure 2.5 shows the separation of charge process as explained by the convection mechanism.
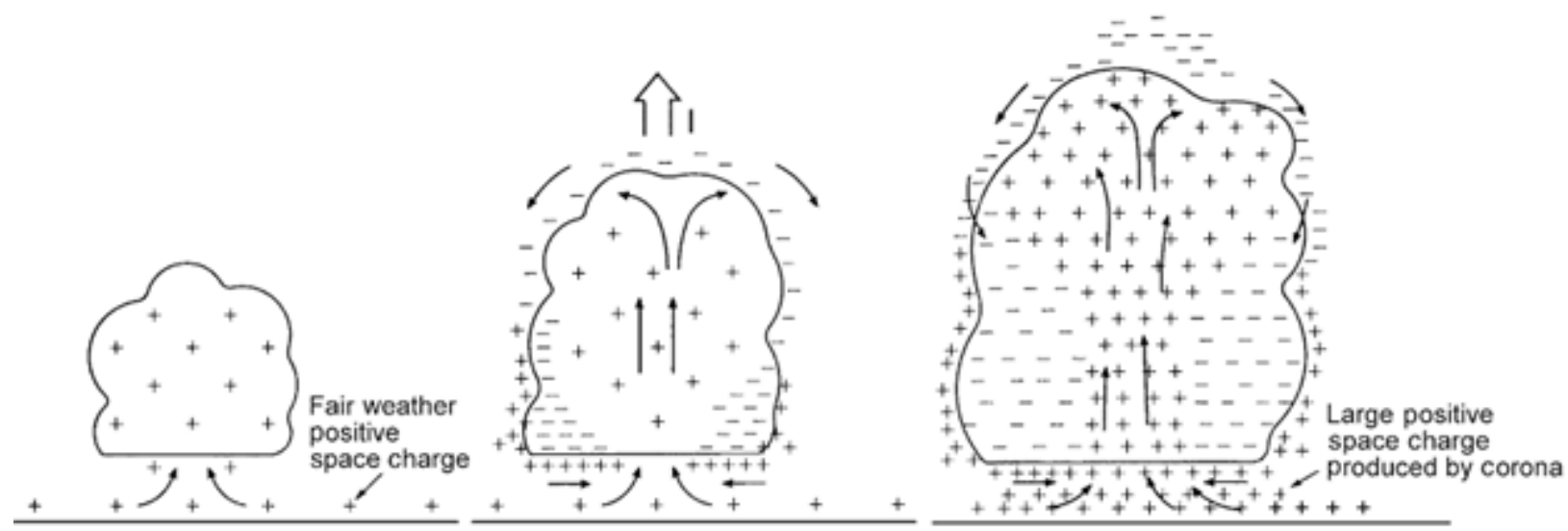

Figure 2.5 - Illustration of the convection mechanism [4].

\subsubsection{Graupel-Ice Mechanism}

In the past, some scientists suggested that the electrical structure of the thundercloud formed a positive dipole, with the positive region uppermost, as explained by the precipitation and convection models, while others suggested that it was negative dipole, with the negative region uppermost. However, 50 years of thundercloud observations and several modifications of the precipitation method led to the conclusion that the electric structure of the thundercloud is, as a 
matter of fact, tripolar [6]. Where the region of negative charges is in the middle between the uppermost positive charges and a smaller region of positive charges at the base of the cloud [6].

The tripolar structure of the thundercloud couldn't be explained based on either the precipitation or the convection hypotheses. However, laboratory experiments showed that the precipitation (graupel) particles acquire positive charges while colliding with ice crystals at temperatures exceeding the charge-reversal temperature $T_{R}$, forming a smaller region of positive charges at the base of the cloud [6]. Figure 2.6 shows the tripolar structure of a thundercloud along with the height and temperature of each region.

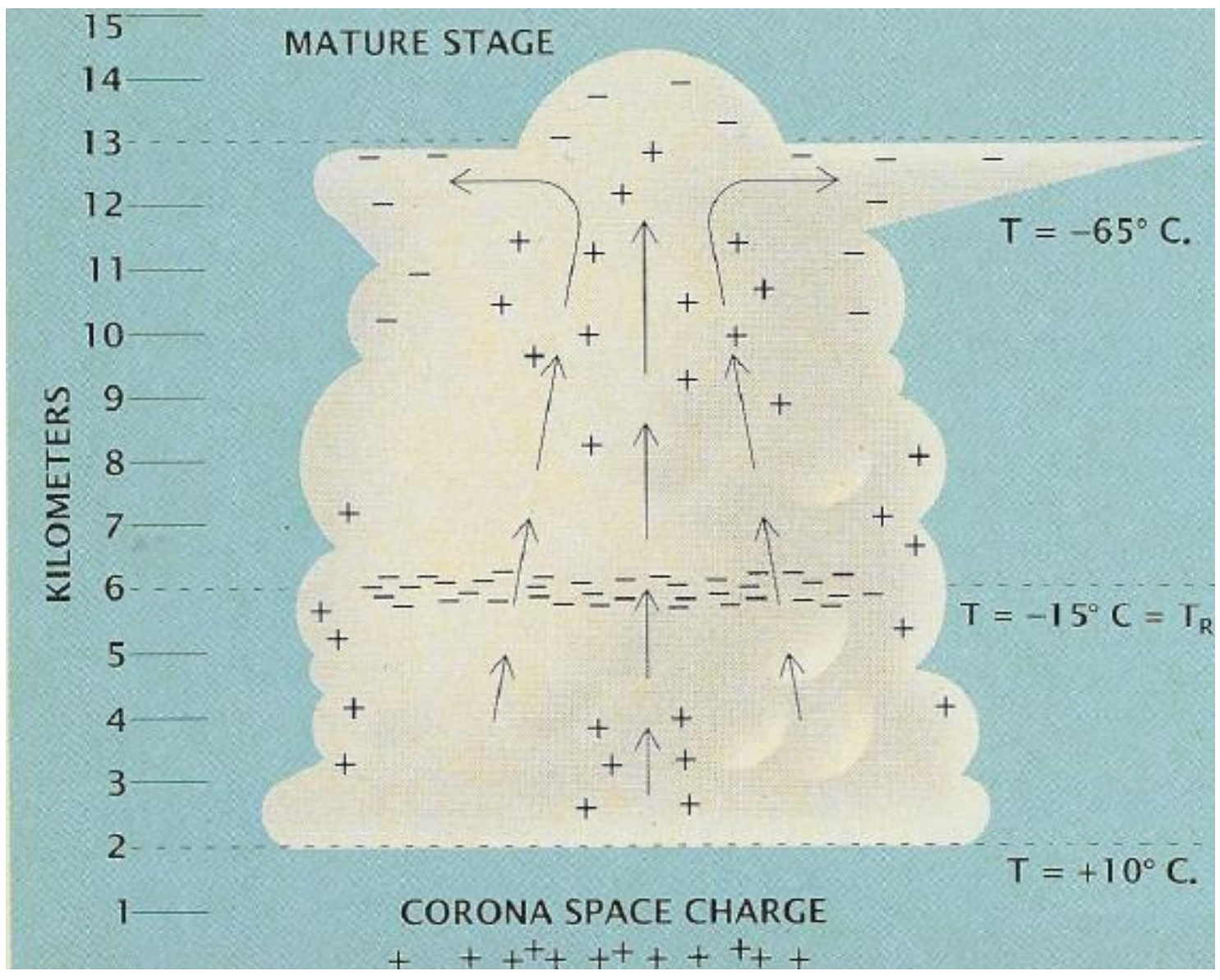

Figure 2.6 - The electric structure of a thundercloud [6]. 
The thundercloud continues to build up positive and negative charges as a result of the charge separation process until it becomes charged to the point where the electric field at the bottom of the cloud exceeds the dielectric strength of the atmosphere, resulting in the initiation of ground lightning flash. In a typical cloud-to-ground lightning flash, the cloud is considered to be the source of charge for the lightning channel, hence the charge in the cloud must be greater than the charge that flows in the channel [6].

\subsection{Lightning Terminology}

As discussed before, downward-initiated negative lightning flashes account for $90 \%$ of all cloud-to-ground discharges. A lightning flash includes a number of processes that are to be discussed in their chronological order, all of which involve charge motion. Typically, a downwardinitiated lightning flash contains three to five strokes. Each stroke comprises a downward-moving stepped leader (SL), or a dart leader (DL) for subsequent strokes, which is followed by an upwardmoving return stroke (RS) [4].

\subsubsection{Stepped Leader}

A stepped leader is defined as a weakly luminous predischarge, which propagates downwards in discrete steps forming a zig zag path until it becomes close enough from an object, then it triggers streamer/streamers. As soon as a streamer connects with the stepped leader a very luminous return stroke is initiated. The stepped leader is believed by many scientists to start with an in-cloud electrical breakdown between the middle negatively charged region and the small lowermost positively charged. This breakdown is enough to free some charges attached to ice and/or water particles, resulting in a strong negative charge concentration at the base of the cloud, which produces electric fields causing a negatively-charged column to breakdown the air, eventually finding its way downward towards ground [1]. 
According to Schonland (1956), the individual steps of stepped leaders move in luminous steps of 10 to $200 \mathrm{~m}$ in length with a time interval between steps of about 40 to $100 \mu \mathrm{s}$. The average duration of stepped leader is some tens of milliseconds, while its average velocity is estimated to be $2 \times 10^{5} \mathrm{~m} / \mathrm{s}$; both the step length and its luminosity are directly proportional to the leader speed. Channel length is also estimated to be $7 \mathrm{~km}$ in length based on the above-mentioned duration and speed. When the leader is carrying a total of 5 coulombs of negative charge distributed over its channel length (i.e. $7 \mathrm{~km}$ ) then the average charge per unit length is about $7 \times 10^{-4} \mathrm{C} / \mathrm{m}[4]$. The first return stroke peak currents are typically around $30 \mathrm{kA}[7]$.

Figure 2.7 (b) shows a diagram of a streak-camera photograph of a three-stroke lightning flash, illustrating the movement of the stepped leader and its successive dart leaders. Such a camera is composed of a fixed lens and a strip of horizontally moving films, operating at a constant velocity across the image plane.

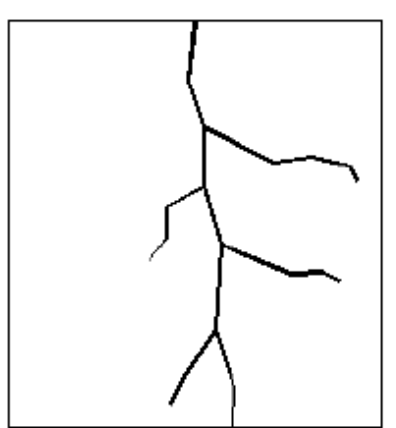

(a)

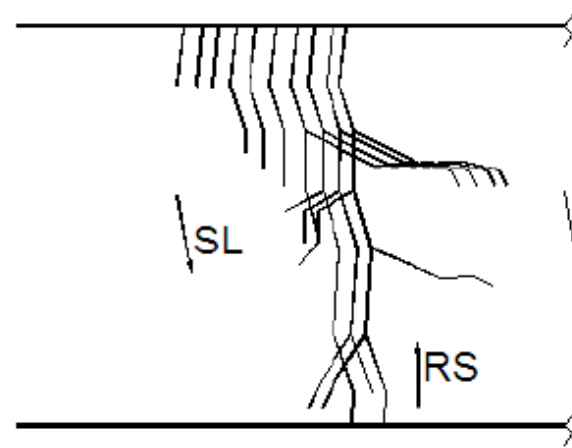

1

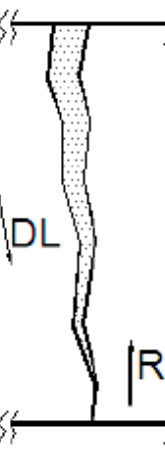

2

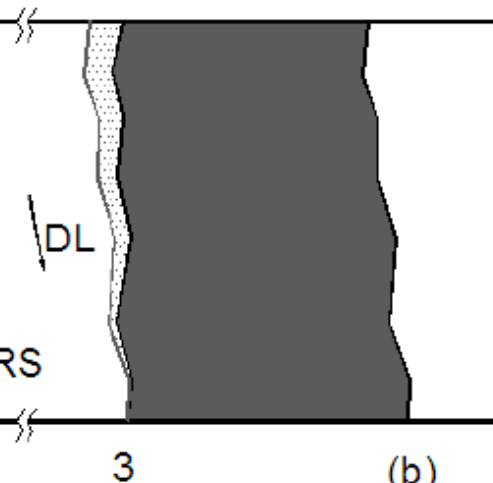

(b)

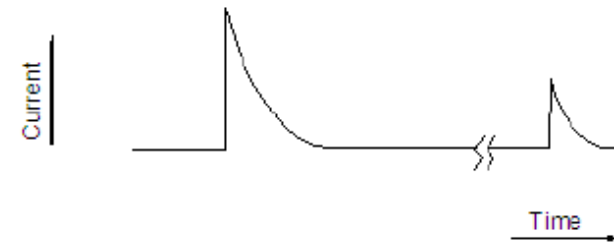

Figure 2.7 - (a) A still-camera image of a three-stroke flash, (b) a streak-camera image showing the luminous features of the lightning flash, (c) channel-base current [4]. 


\subsubsection{Return Stroke}

The return stroke is the most luminous component of the lightning flash that is seen, even by the human eye, outside of the thundercloud. As a result of the data reported by Berger (1975), the median return-stroke current peak for first strokes is two to three times higher than that for subsequent strokes. However, the median current maximum rate-of-rise of subsequent return strokes is three to four times higher than that of first strokes [4].

By using streak photography of lightning flashes, the speed of propagation and luminosity of the return-stroke channel can be studied, which is believed to reflect the current variation [4]. As expected, research studies concluded that subsequent return strokes are faster than first return stroke with the mean values being $1.2 \times 10^{8} \mathrm{~m} / \mathrm{s}$ and $9.6 \times 10^{7} \mathrm{~m} / \mathrm{s}$, respectively [4].

\subsubsection{Dart Leader}

After the first return stroke deposits its charge, the lightning flash may end. However, if additional charge is made available, a subsequent stroke or more may materialize. In this case a dart leader travels, at a higher speed than that of the stepped leader, through the same channel initiating a subsequent return stroke. The dart leader-stroke process may continue producing more subsequent strokes, as shown in figure 2.7 (b).

A dart leader has the same channel length as the stepped leader. However, the dart leader travels at a speed in the range of $10^{7}$ to $2 \times 10^{7} \mathrm{~m} / \mathrm{sec}$, substantially higher than that of the stepped leader, since the channel is already ionized by the stepped leader. The dart leader's trip to earth usually takes a few milliseconds. The dart leader deposits less charge along its path and generally not as branched as the stepped leader. Thus, dart leaders have smaller peak current values, between 10 and $15 \mathrm{kA}$, than that of the stepped leader [4], [7]. 


\subsection{Importance of Lightning}

Even though in many cases, lightning is looked upon as the cause of destruction and damage, it is very much needed in nature as it keeps the earth's electrical equilibrium. It plays an essential role in earth's ecosystem by helping to maintain the earth's fine weather field of about $100 \mathrm{~V} / \mathrm{m}$ [5]. The process of thunderstorms and lightning preserves the global battery, which keeps the upper atmosphere and the earth positively and negatively charged, respectively. During fine weather, atmospheric electrical currents flow downward, while during thunderstorms they flow upward. Charges are then transferred from thunderstorms to earth by means of rain, lightning and corona discharge [5]. This complete process is shown in Figure 2.8.

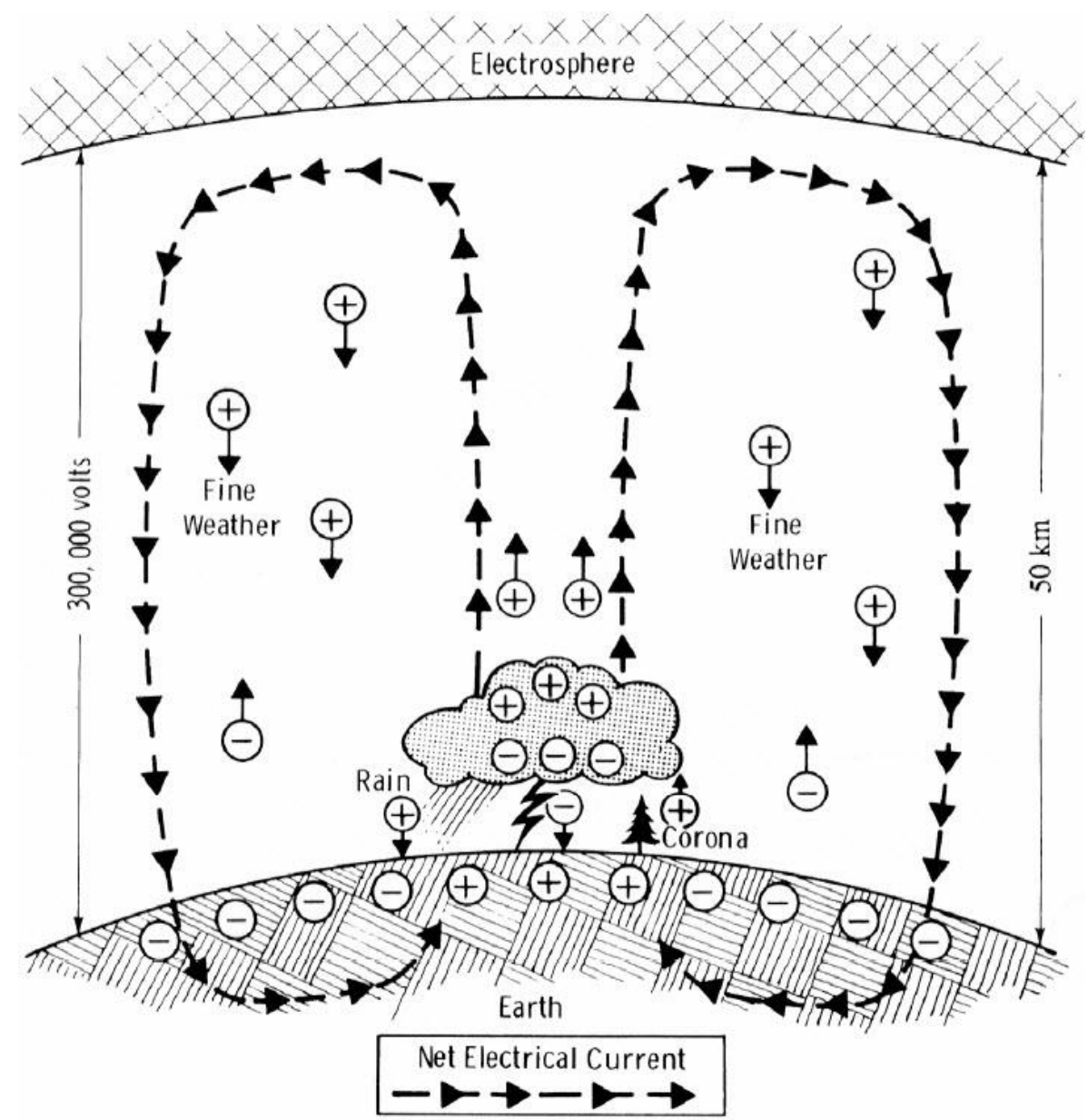

Figure 2.8 - A diagram showing how thunderstorms act as batteries to keep the earth charged negatively and the atmosphere charged positively [1]. 
Another advantage of lightning is that during lightning discharge fixed nitrogen is produced, and during the nitrogen fixation process, nitrogen is converted to ammonium $\left(\mathrm{N}_{2} \rightarrow \mathrm{NH}_{4}{ }^{+}\right)$, which is a necessary process for living organisms to gain nitrogen directly from the atmosphere, while the fixed nitrogen is essential in the food making process by plants [5].

Cloud-to-ground lightning is seen as the major cause of faults, transients and outages in electric power transmission and distribution systems. In Canada, lightning strikes kill up to 10 people, seriously injure up to 164 others, and ignite some 4,000 forest fires [8]. Accordingly, the main reason for studying lightning characteristics is protection against lightning destructive powers. Ultimately to equip man-made structures and buildings with good lightning protection systems. Lightning studies are essential in many areas, including, but not limited to, electric power industries, where engineers need to be aware of return-stroke current peaks and the associated electromagnetic fields in order to be able to design proper lightning protection systems for power lines and power stations, aviation, forests, weather services, insurance industry and public utilities.

\subsection{Usage of lightning Energy}

A single lightning flash has enough energy to operate five $100 \mathrm{~W}$ light bulbs continuously for one month ( 360 kilowatt hours) [4]. Considering this amount of energy, one would think that it is useful to utilize lightning energy. However, it is impractical to do so because of the fact that a single lightning flash strikes different points on the ground and then requiring many lightningcapturing towers [4]. Also, this large amount of energy is not totally delivered at the striking point, but rather lost to heating the air, light, thunder and radio waves [4].

\subsection{Tall-Structure Lightning}

Upward lightning is defined as a discharge that is initiated by an upward moving stepped leader, it could be generated from a man-made tall structure or from mountain tops. A fair amount of studies and research have been done towards characterizing and understanding tall-structure 
lightning [5]. Structures of 500m height or more tend to experience upward-initiated flashes, while objects with heights in the range of 100-500m experience both upward- and downward-initiated flashes [4]. Examples of famous tall structures that were used to study lightning are: The Empire State Building (410 m), New York City, USA, Ostankino Tower (540 m), Moscow, Russia, and the CN Tower (553 m), Toronto, Canada. Figure 2.9 shows an upward-initiated lightning flash striking the CN Tower on August 24, 2011.

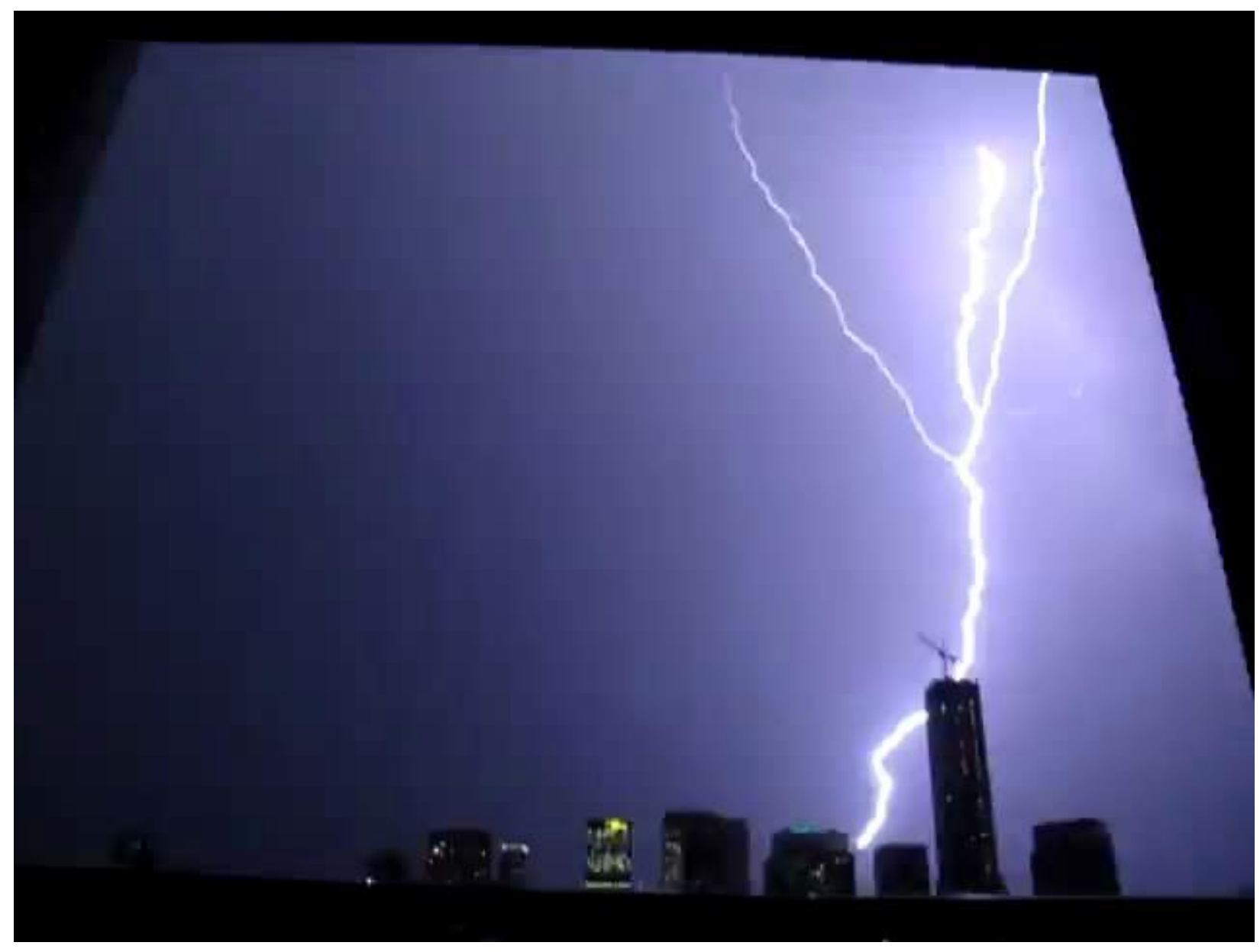

Figure 2.9-CN Tower lightning trajectory showing upward branching, August 24, 2011 [9]. 
It is worth mentioning that the most important component in a lightning flash is the lightning return-stroke current, which is practically very hard to measure directly because one must know the exact location of the lightning strike. This could be achieved by means of rockets to trigger lightning, tall structures or towers placed on mountain tops. The CN Tower, standing at a height of $553 \mathrm{~m}$, presents an excellent opportunity for studying lightning characteristics and for the measurement of the lightning return-stroke current derivative. Lightning studies carried out at the CN Tower in 1991 showed that only $2.8 \%$ of flashes hitting the tower were downward-initiated during that year [10].

In upward-initiated lightning, momentarily before the initiation of an upward ground-tocloud flash, charged clouds provide high electric fields at the top of a tall structure, resulting in the initiation of an upward-moving stepped leader. Then, it is more likely to be followed by a downward-moving dart leader, initiating an upward-moving, subsequent-like, return-stroke. And like the common cloud-to-ground lightning, the upward-initiated lightning flash can have one or multiple lightning return-strokes [4], [5]. 


\section{Chapter 3}

\section{Lightning Detection}

"Lightning detection and mapping systems can be used to minimize the harmful effects of lightning by providing early warnings of such hazards. These systems can also be used to determine how much lightning actually occurs within a given region and the statistics of discharge parameters that are important in research and in the design of lightning protection systems." - E. P. Krider (1994).

In this chapter, the science of lightning location and detection is discussed along with the various techniques used in detecting the electromagnetic radiations produced by the different processes within a lightning flash. Furthermore, The North American Lightning Detection Network is discussed with emphasis on its history and detection techniques used. And finally, the location of the CN Tower in respect to the network will be highlighted.

\subsection{Lightning Locating Systems (LLS)}

Lightning emits an enormous amount of electromagnetic energy in the frequency range from $1 \mathrm{~Hz}$ to near $300 \mathrm{MHz}$. In addition to the electromagnetic radiation, lightning also produces acoustic radiation. It should be noted that lightning electromagnetic radiations can be detected at higher frequencies of microwaves $(300 \mathrm{MHz}-300 \mathrm{GHz})$ and even in visible light $\left(10^{14}-10^{15} \mathrm{~Hz}\right)$ [4]. Generally, any radiations caused by lightning can be used to detect and locate the lightning 
source that caused these radiations [4]. The lightning locating system (LLS) is the most common way used to geolocate lightning, which may be a ground-based or satellite-based electromagnetic sensor or a network of sensors. A ground-based LLS consists of a network with a minimum of four to five sensors and a central processor. The electromagnetic signal produced by a lightning discharge is measured by the sensors and then information about the associated waveform characteristics is sent to the central processor. After a lightning event is detected by multiple sensors in a network and reported to the central processor, one or more techniques can be used at the central processor to geolocate the lightning event. Ground-based LLSs have been operating since the 1920's and modern LLSs are able to determine the location, intensity, and the type of the lightning event, as well as tracking the movement of thunderstorm cells and the evolution of their charge structure in real time [11].

The Lightning flash contains several individual processes; each process has a duration range of a few hundred milliseconds to a few microseconds or less. These processes produce electromagnetic signatures in the range from a few hertz (long continuing currents) to $1020 \mathrm{~Hz}$ (hard X-rays) [12]. Various techniques are being used to detect the different processes within the lightning flash based on the frequency of the electromagnetic radiations from each process. Figure 3.1 shows the relationship between frequency and lightning power spectrum along with lightning detection technologies used in different frequency ranges. For example, sensors that operate in the LF and VLF range can be used to detect and locate transient pulses that propagate along the surface of the earth produced by return strokes in CG flashes, and also the larger pulses that can propagate thousands of kilometers as they reflect between the ionosphere and the ground produced by cloud flashes [13].

Even though there are various techniques used in locating lightning events, such as: magnetic direction finding (MDF), time of arrival (TOA), and interferometry, the two most commonly used locating techniques are the first mentioned two techniques [4], [11]. A combination of the above mentioned two techniques, referred to as Improved Accuracy from Combined Technology (IMPACT), is also used in locating lightning. The basics of these three methods will be discussed in the following subsections. 


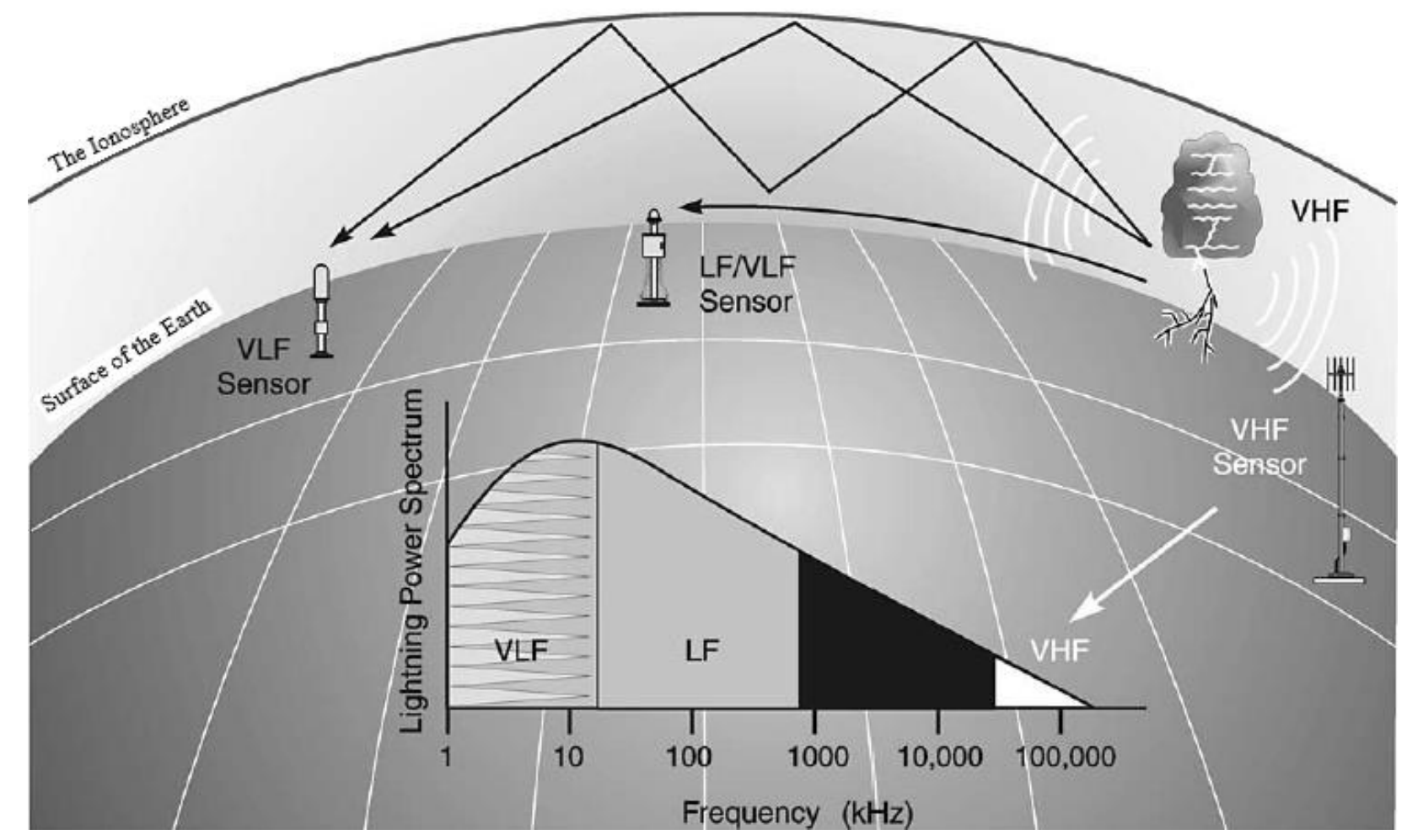

Figure 3.1 - Lightning detection technologies and the relationship between frequency and lightning [13].

\subsubsection{Basic Magnetic Direction Finding Technique (MDF)}

The main principle of the magnetic direction finding technique is measuring the magnetic field of lightning flash by employing two or more sensors in order to measure the azimuth (angle from true north) between the sensor and the lightning stroke. This is achieved by using a crossedloop antenna with two vertical and orthogonal magnetic loops, since the azimuth angle is typically determined using two antennas according to Faraday's law. The more sensors reporting a discharge the less the error in measuring the angle, typically three or more sensors are employed [4], [14]. Figure 3.2 shows the estimated location of the stroke if reported by only 2 sensors $\left(\mathrm{L}_{12}, \mathrm{~L}_{23}\right.$ and $\left.\mathrm{L}_{13}\right)$, while the dark dot shows the optimal location estimate using the three sensors $\left(\mathrm{S}_{1}, \mathrm{~S}_{2}\right.$ and $\left.\mathrm{S}_{3}\right)$ and the mark ' $\mathrm{X}$ ' indicates the actual stroke location. 
Furthermore, poor results may occur if the discharge occurs along a line between two sensors and these sensors are the only ones to see the discharge, estimating the azimuth measurement can result in significant errors in location. In some cases, the measurements may not produce an intersection at all. Because of this problem, practical networks have at least three sensors [14].

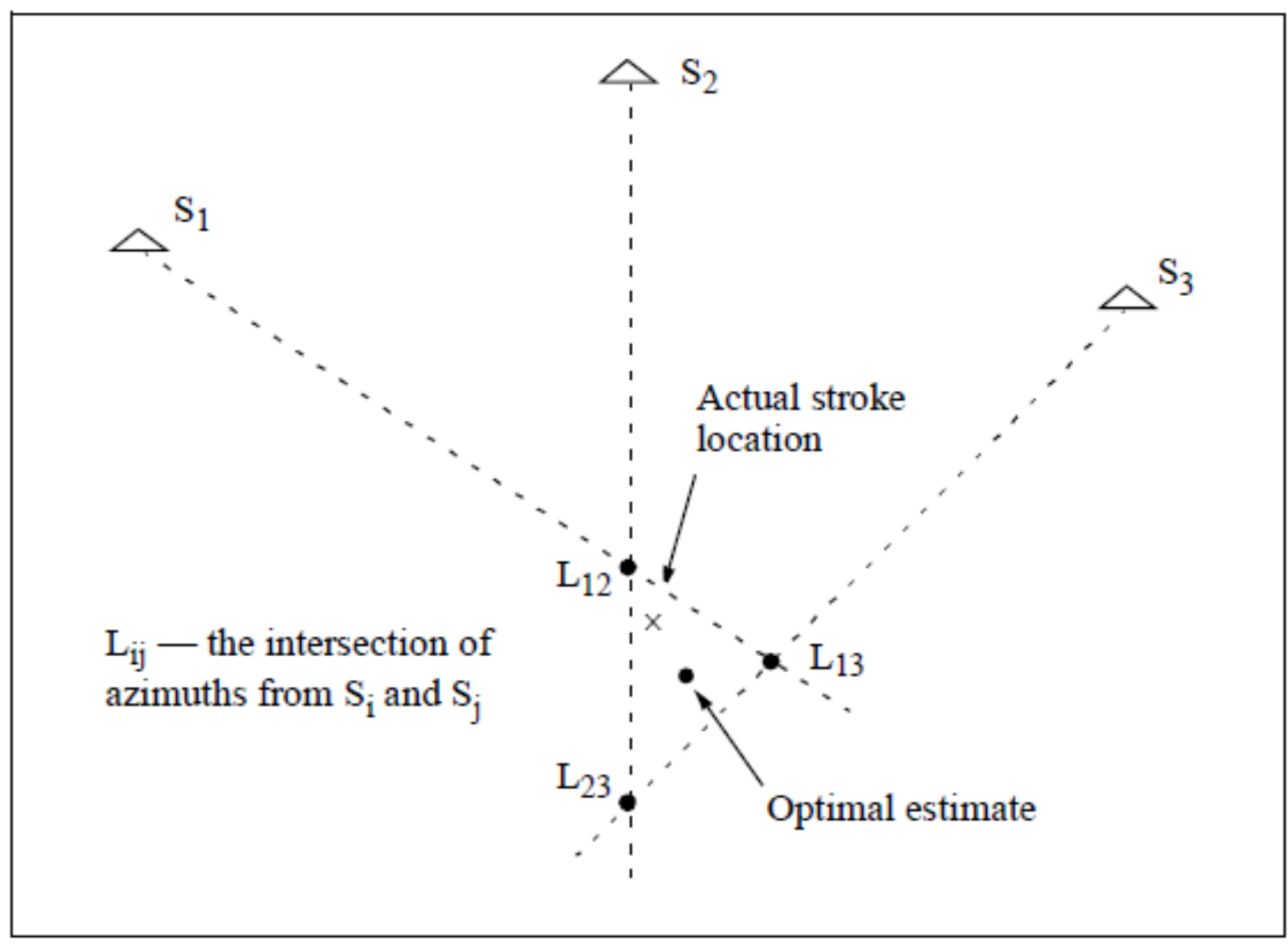

Figure 3.2 - Determination of the location of the lightning stroke using two or three sensors for the magnetic direction finding technique [14].

\subsubsection{Basic Time-of-Arrival Technique (TOA)}

Time-of-arrival systems employ sensors which measure the arrival time of the lightning discharge. There are three types for locating lightning by Time-of-arrival systems [4]:

1. Very-short-baseline (tens to hundreds of meters) Systems.

2. Short-baseline (tens of kilometers) Systems: used to study the development of discharge and provide images of lightning channels. 
3. Long-baseline (hundreds to thousands of kilometers) Systems: usually used to find the strike point on the ground.

The first two systems (very-short and short-baseline) operates at frequencies in the range of 30 to $300 \mathrm{MHz}$ (VHF), while the long-baseline system operates at frequencies in the range of 3 to $300 \mathrm{kHz}$ (VLF and LF) [4].

The lightning positioning and tracking systems (LPATS) is a commercial long-baseline TOA system that was originally developed by Atlantic Scientific Corporation, which later became Atmospheric Research Systems, Inc. (ARSI). [4] The LPATS uses sensor stations placed 200 to $400 \mathrm{~km}$ apart to measure the relative time difference between signal arrival times at multiple sensors. As shown in Fig. 3.3, the source location is defined by the intersections of hyperbolas provided by the multiple stations, a hyperbola is defined as the constant difference in the arrival time at two stations [15]. Under some geometrical conditions, hyperbolas produced from only three sensors may intersect at two points, leading to a false stroke location, as shown in Fig. 3.4. This problematic condition can be avoided if four sensors detect the discharge [15].

Figure 3.5 shows another approach used to estimate the location and time of the lightning discharge, referred to as circular intersection. In this approach, each sensor produces a circle of possible locations whose radius is based on the difference between the estimated time of the discharge and the measured time of its arrival at the sensor site. The stroke location is the intersections of all circles that are produced by all the sensors. This approach of circular intersections can produce an optimized solution when more than three sensors are used, while when only three sensors are used, both the hyperbolas and circular intersection methods produce the same location [14]. 


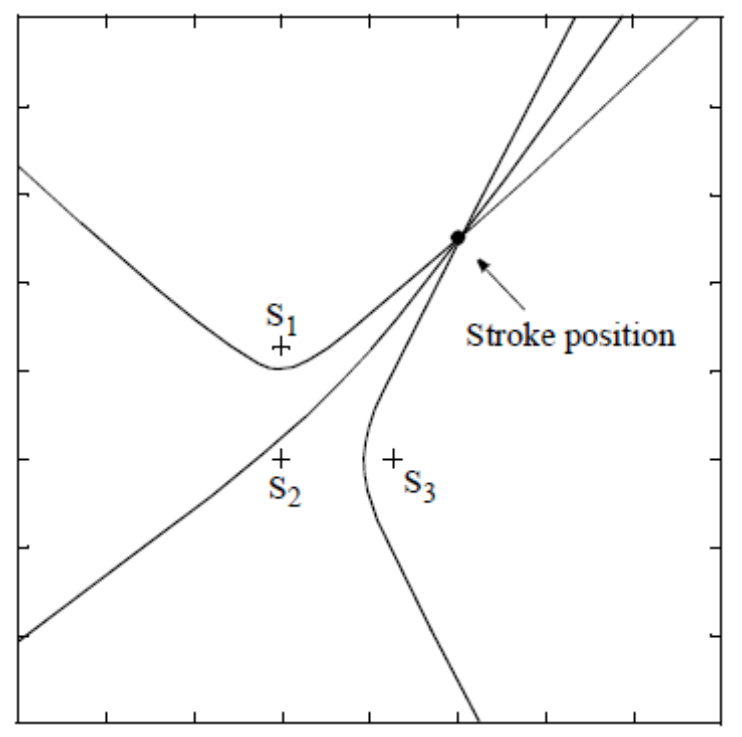

Figure 3.3 - Hyperbolic intersection method using three sensors [14].

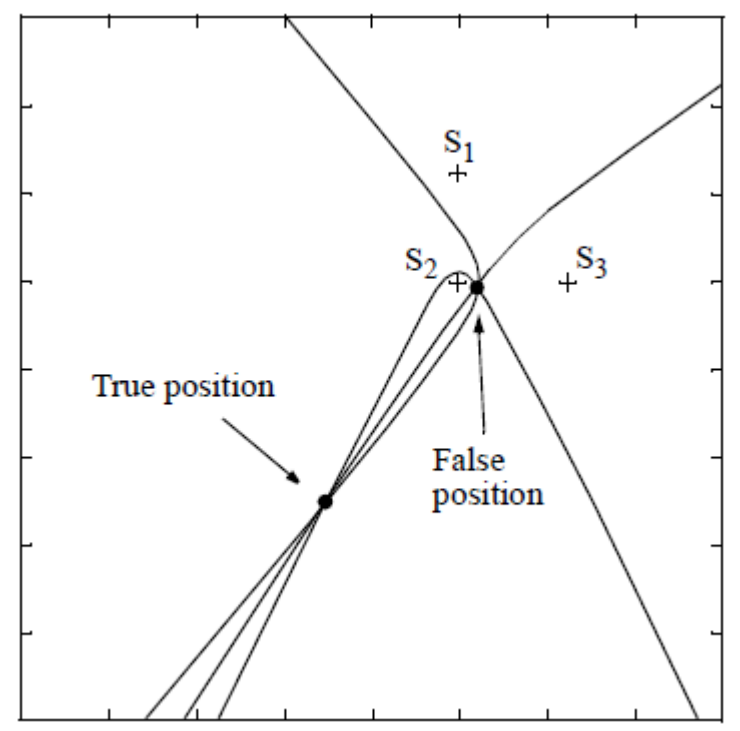

Figure 3.4 - Ambiguous location for a threesensor hyperbolic intersection [14].

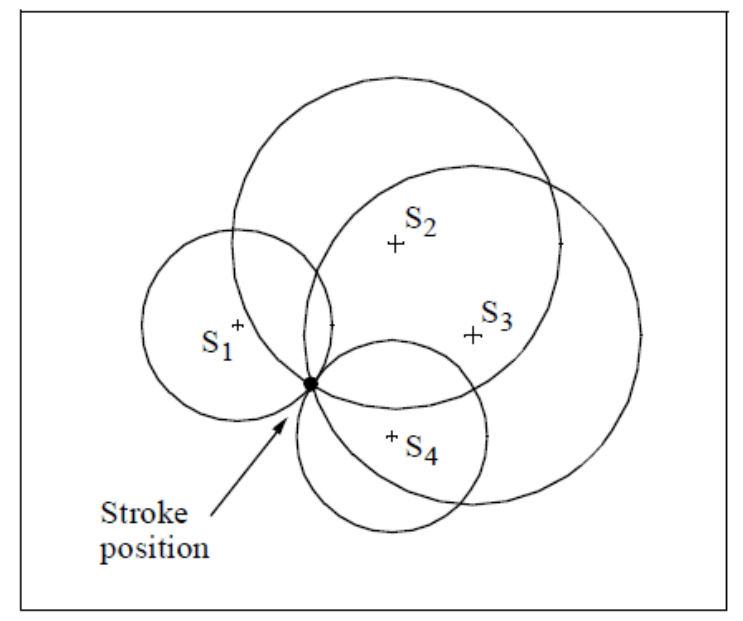

Figure 3.5 - Circular intersection approach using four sensors [14].

\subsubsection{Improved Accuracy from Combined Technology (IMPACT)}

This technology, as noticed from what it is called, combines the above-mentioned two technologies; the direction finding and time-of-arrival, for an improved lightning location method. This method can measure the arrival times and directions of all strokes by employing the azimuth information provided by the direction finding, and the range information provided by the absolute arrival time and then producing three estimated parameters; latitude, longitude, and discharge time. 
Therefore, the IMPACT method has redundant information allowing for an optimized estimate of the lightning strike location even if the timing and angle information were provided by only two sensors [15]. This approach outperforms either method by itself, and also eliminates the problems faced while using each of the methods separately as discussed before. For example, a strike occurring along the baseline between two sensors is located precisely by the intersection of the azimuth vectors and range circle, as shown in Fig. 3.6. In this figure, $\theta_{1}$ and $\theta_{2}$ are the azimuth information, while $r_{1}$ and $r_{2}$ are the range values for sensors $S 1$ and $S 2$, respectively. These four measured parameters produce the estimated latitude, longitude and discharge time [14], [15].

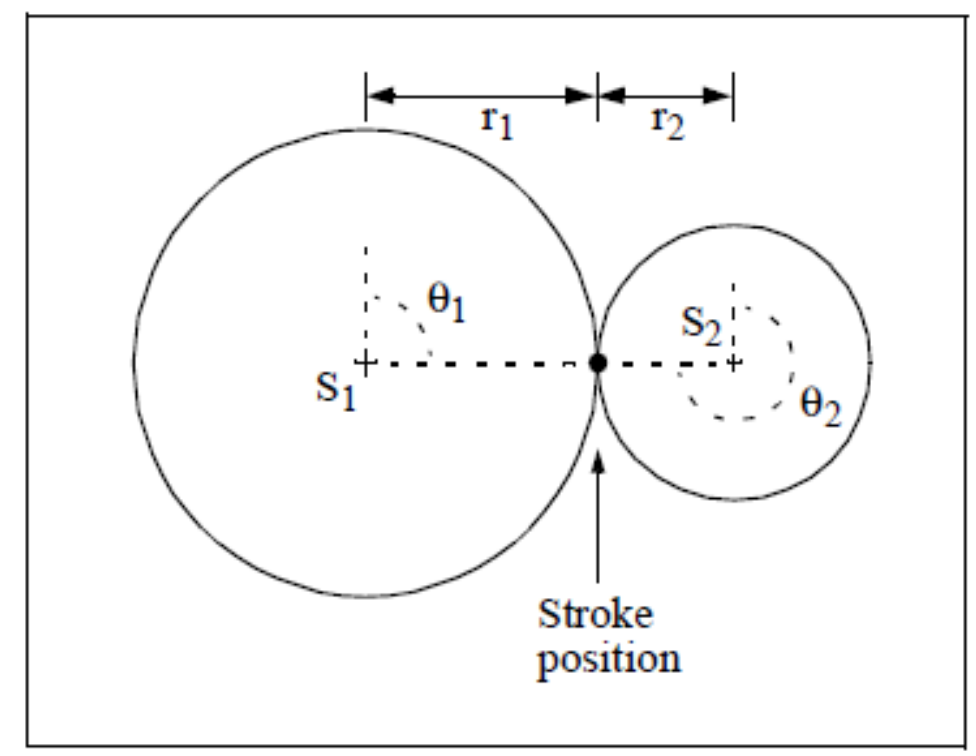

Figure 3.6 - IMPACT method on a baseline between two sensors [14].

\subsection{North American Lightning Detection Network (NALDN)}

The North American Lightning Detection Network (NALDN) is a commercial lightning detection network consisting of the U.S. National Lightning Detection Network (NLDN) and the Canadian Lightning Detection Network (CLDN). The main purpose that the NALDN was developed is to provide lightning information by accurately detecting and locating most cloud-toground (CG) lightning strokes and a small percentage of cloud-to-cloud lightning. The NALDN allows lightning activity to be monitored in real-time for use in the protection of North American forests, for forensic applications such as in the electric power and insurance industries, and for a 
broad range of applications in weather forecasting and climatology. The U.S. NLDN is owned by Vaisala Inc., while CLDN is owned by Environment Canada. The CLDN and NLDN are completely interconnected, with all data processing performed by Vaisala Inc. at the Network Control Centre in Tucson, Arizona [16].

The NLDN has been operational and providing lightning data in real-time since 1989. The North American Lightning Detection network (NALDN) was created when the Canadian Lightning Detection Network (CLDN) was combined with the U.S. National Lightning Detection Network (NLDN) in 1998 [17]. The NALDN is the largest lightning detection network in the world [8]. The history of how exactly the NALDN started from the very beginning is laid out in details in [18]. Since then, the network has undergone several upgrades along the years. The first upgrade was done in 1995 when the 130 network-wide sensors were reduced to 106; 59 LPATS-III sensors and 47 IMPACT sensors, due to the increase in the effective range of the sensors [19]. The next upgrade was completed in 2003-2004 with the replacement of the TOA-only LPATS III sensors with IMPACT sensors [13]. Another network update took place in 2010-2012 where the older generation IMPACT sensors were replaced with Vaisala's LS7001 sensors [20]. And finally, the most recent network-wide upgrade was completed in August 2013 deploying the LS7002 sensors in replacement of the older generation LS7001 and IMPACT sensors. The new LS7002 improves the sensitivity of the sensors leading to an enhanced detection of cloud and cloud-to-ground lightning [21].

Figure 3.7 shows an illustration of the CLDN telecommunication topology that displays how the lightning data is collected and processed, in the following sequence:

1. Sensors detect lightning strokes and transmit the data via a digital subscriber line (DSL), cellular modem (EVDO, or Evolution Data Optimized) or communications satellite

2. Lightning data from the DSL and cellular modem sites are captured via a Virtual Private Network (VPN) tunnel established by the Vaisala Control Centre (VCC) in Tucson for processing. (2) Lightning data using satellite communications (2a) is transmitted to the Telesat hub in Montreal (2b) and backhauled to Vaisala for processing $(2 \mathrm{c})$ 
3. Lightning solutions are sent from VCC via land line to the Canadian Meteorological Centre (CMC), and other Canadian clients (3)

4. Lightning solutions sent from CMC to various sensor units (4)

5. Display within 60 seconds of lightning occurrence



Figure 3.7 - Illustration showing the flow of lightning data in the CLDN [22].

In a nutshell, The NALDN runs 24 hours a day, 7 days a week, 365 days a year and detects cloud-to-ground lightning strikes and a small percentage of cloud-to-cloud lightning. The CLDN by itself can detect up to 45,000 lightning strikes an hour, even though the maximum number of strikes per hour in Canada is less than 25,000 [8].he lightning sensors are capable of determining information such as; the strength, polarity (positive or negative charge) and time of lightning strikes. These information is then combined to determine the location of the lightning strikes and then distributed among various clients and Environment Canada's Storm Prediction Centres [8]. 


\subsection{CN Tower Lightning}

The Toronto Canadian National (CN) Tower stands at a height of $553 \mathrm{~m}$, above ground level (AGL), was the tallest free-standing structure in the world for 34 years, since it was built in 1976 until 2010 [23]. Lightning strikes to the CN Tower started to be observed in 1978, 2 years after its completion. Besides serving as a telecommunications hub, it is considered as one of the most important sites in the world to study tall-structure lightning and to collect important lightning data such as; magnetic and electric fields, electric currents and visual parameters. Its location on the borders of CLDN and NLDN, as shown in Fig. 3.8, also provides an excellent opportunity to evaluate the performance characteristics of NALDN in the Toronto area and beyond. Because of the proximity of the CN Tower to the U.S. border, two out of the three closest lightning detection sensors to the tower are, in fact, NLDN sensors [16].

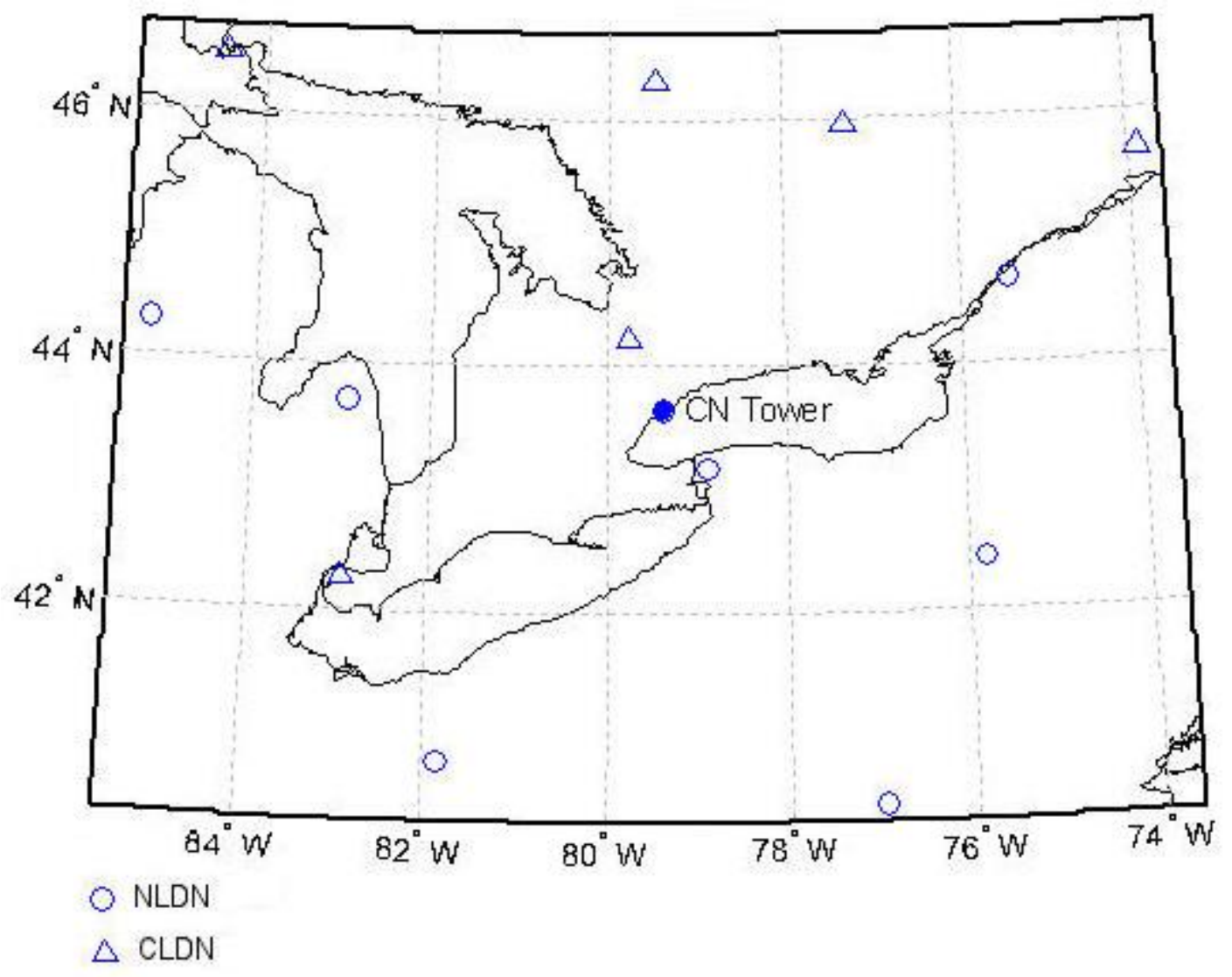

Figure 3.8 - Map showing the locations of the CN Tower, CLDN and NLDN sensors in the region. 


\section{Chapter 4}

\section{CN Tower Lightning Current Measurement Systems}

A summary of the lightning instruments used to measure and record lightning parameters at and around the $\mathrm{CN}$ Tower is presented in this chapter. Firstly, the current derivative measuring systems' locations and configurations are discussed. Afterwards, the video recording systems are introduced, as well as the technical specifications and a sample of the data captured by each system.

\subsection{Introduction}

Shortly after its construction in 1976, the 553-m CN Tower has offered an ideal structure for studying tall-structure lightning. Besides attracting a lot of tourism to the area, could it have an effect on the lightning activity in its vicinity [24], [25]? Lightning strikes to the CN Tower have been optically observed since 1978, two years after its construction. Although the lightning flash density (number of flashes per square kilometer per year) in the Toronto area is about 2 [24], the 553-m Tower usually receives several dozes of lightning flashes every year [26]. Thus, the CN Tower is one of the best sites in the world to study tall-structure lightning and to obtain definitive lightning data such as currents, generated fields and channel optical parameters [26]. 
In order to capture and record the different lightning parameters, various measuring and monitoring systems are being used at and around the CN Tower. In 1991, five independent measuring systems started to simultaneously operate to record different lightning parameters [25], namely the current derivative at the $\mathrm{CN}$ tower, channel trajectories at $11.8 \mathrm{~km}$ west of the tower and $2 \mathrm{~km}$ north of it, the electric and magnetic fields, as well as the return-stroke velocity at station located $2 \mathrm{~km}$ north of the tower.

\subsection{Current Derivative Measurement Systems}

Figure 4.1 displays the $\mathrm{CN}$ Tower, along with the locations of the current derivative measurement system components [27]. Since 2011, the tower has been equipped with two independent current derivative measurement systems that include two current-sensing Rogowski coils. The first is a 3-m-long, 40-MHz Rogowski coil, which was installed at the tower in 1990 [28]. It is placed at the 474-m above ground level (AGL), encircling one fifth of the tower's pentagonal steel structure [28], and connected via a tri-axial cable to a current derivative recording digitizer, placed at 410-AGL. A newer 6-m-long 20-MHz Rogowski coil, encircling the whole steel structure of the tower at the 509-m AGL, is connected to another current derivative recording digitizer via an optical fiber link [26]. The current derivative recording systems, placed at the 410m AGL, contain a double-channel 8-bit LeCroy LT342L digitizer, featuring 2-ns time resolution, and a double-channel NI PCI-5114 digitizer with large memory that allowed, for the first time at the tower, the continuous recording of each $\mathrm{CN}$ Tower flash. For the first time, this experimental configuration enabled two seconds of continuous recording of the current derivative of each $\mathrm{CN}$ Tower's flash that contains at least one return stroke [28], [29]. 


\section{Tip of the Tower 553-m}

New Coil 509-m

Old Coil 474-m
Recording Instrumentation 410-m

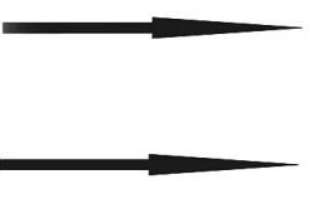

Old Coil 474-m
Recording Instrumentation 410-m

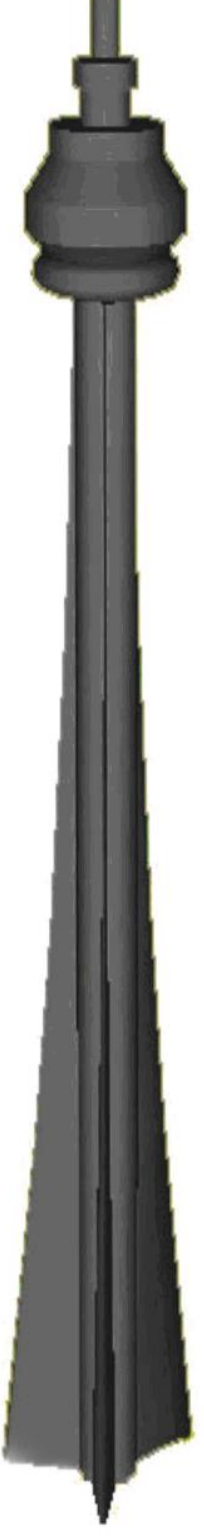

Figure $4.1-\mathrm{CN}$ Tower and the locations of the current derivative measurement system components. 


\subsubsection{Old and New Rogowski Coils}

The old Rogowski coil was installed at the CN tower in 1990 at a height of 474-m above ground level (AGL), it is a 3-m long, toroidal and non-ferrous coil with many turns consisting of 2 sections of $1.5-\mathrm{m}$ each. The coil encircles one fifth of the tower's steel structure, as shown in Fig. 4.2, and hence the measured current represents only $20 \%$ of the total current, assuming a uniform current distribution along the tower's symmetrical structure. It is connected at one end to an impedance matching box and to resistors at the other end, resistors are used to damp oscillations in the coil and absorb any reflections. The impedance matching box is then connected to the LeCroy LT342L digitizer through a 165-m, $50 \Omega$ tri-axial cable.
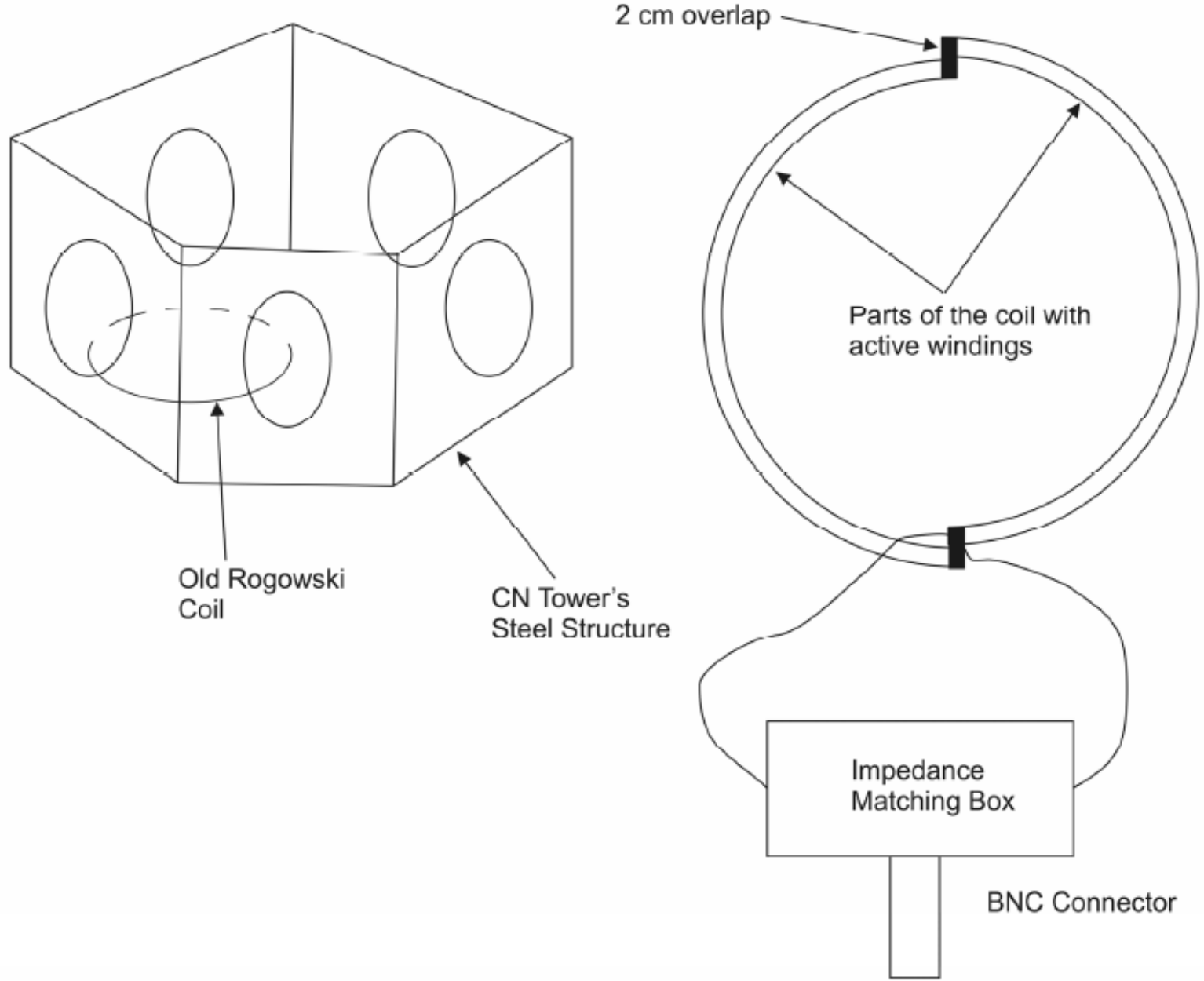

Figure 4.2 - The Old Rogowski coil connection and its location at the CN tower [30]. 
The lightning current signal picked up by the old Rogowski coil had high level of noises accompanied with it. This is due to many factors such as:

1. The old Rogowski coil encircles one fifth of the tower's steel structure, capturing only $20 \%$ of the lightning current derivative.

2. The tri-axial cable of $165-\mathrm{m}$ in length used to connect the coil to the digitizer.

3. LORAN-C signals that are used by radio navigations in ships as well as noise signals from other communication antennas are picked up by the coil.

These problems led to the need of deploying a new Rogowski coil and alleviate the signal noises.

The technical specifications of the old and new Rogowski coils are displayed in Table 4.1, and the old and new coil connections and their location on the CN Tower are shown in Figures 4.2 and 4.3 , respectively.

Table 4.1 - Technical specifications of the old and new Rogowski coils

\begin{tabular}{|l|l|l|}
\hline & Old Rogowski Coil & New Rogowski Coil \\
\hline Frequency bandwidth & $40-\mathrm{MHz}$ & $20-\mathrm{MHz}$ \\
\hline Rise time & $8.7 \mathrm{~ns}$ & $17.4 \mathrm{~ns}$ \\
\hline Sensitivity & $0.32 \mathrm{~V} /(\mathrm{A} / \mathrm{ns})$ & $1.2862 \mathrm{~V} /(\mathrm{A} / \mathrm{ns})$ \\
\hline Accuracy & $\pm 6 \%$ & $\pm 6 \%$ \\
\hline Impedance & $50 \Omega$ & $50 \Omega$ \\
\hline Length & $3 \mathrm{~m}$ (two $1.5 \mathrm{~m}$ long & $\begin{array}{l}6 \mathrm{~m} \text { (four } 1.5 \mathrm{~m} \text { long } \\
\text { sections) }\end{array}$ \\
\hline
\end{tabular}

Even though the new Rogowski coil was purchased in 1997, the first successful results were obtained during the lightning season of 1999. Placed at 509-m AGL and encircling the whole steel structure of the tower, in four connected sections, the new Rogowski coil is capable of measuring $100 \%$ of the total lightning current derivative. The coil is then connected to the recording station via an optical fiber link, as shown in Fig. 4.3. The matching boxes are placed to ensure the output of Matching Box 3 is $50 \Omega$, and the attenuator is used to prevent the saturation of the optical fiver link [30]. 


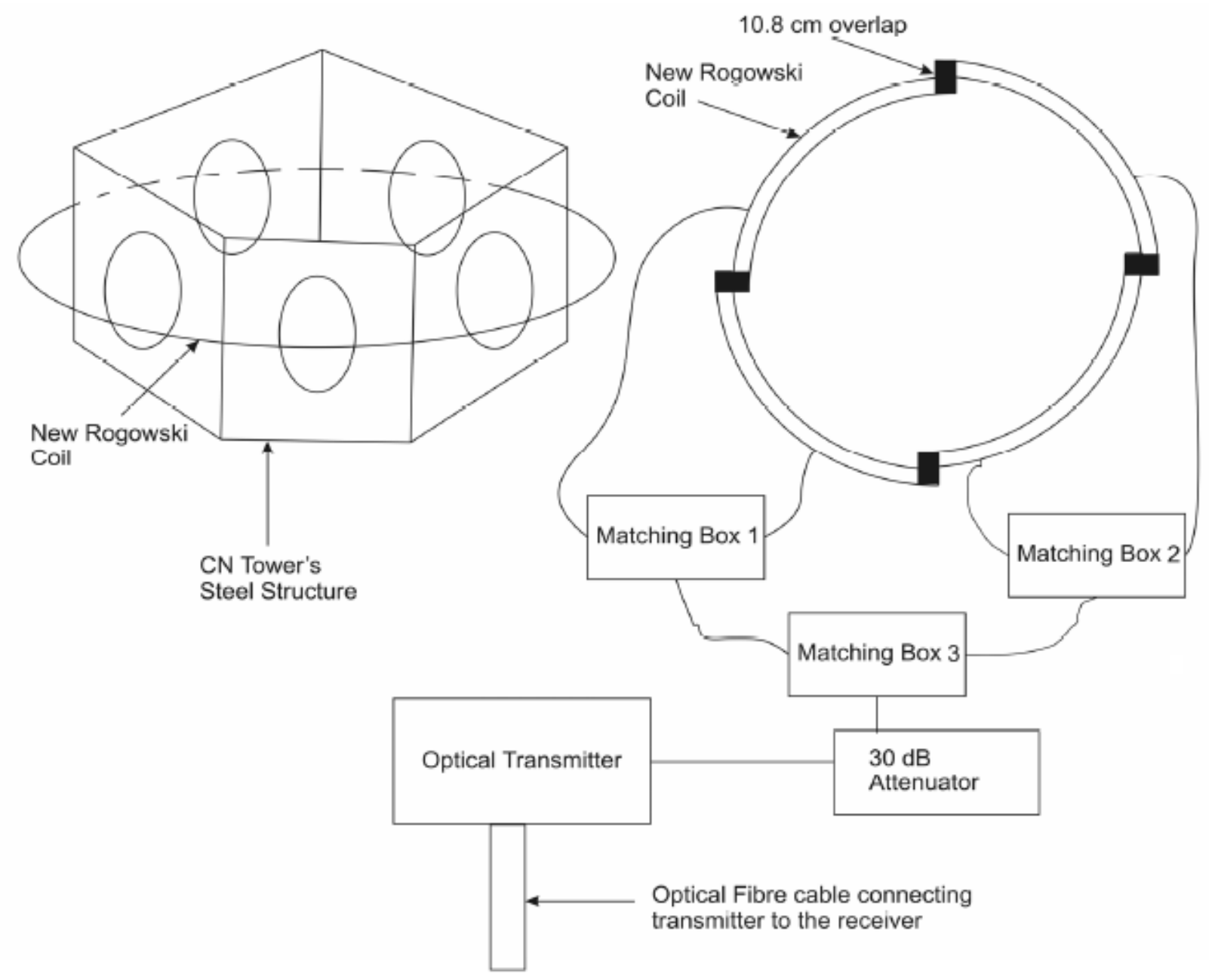

Figure 4.3 - The new Rogowski Coil connection and its location at the CN Tower [30].

The main enhancement that the new Rogowski coil provided to the lightning current derivative measurement system was the reduction of the noises. A better signal-to-noise ratio (SNR) was achieved because of the advanced design of the new coil as well as the employment of the optical fiber link between the coil and the digitizer.

\subsubsection{Real-Time Digitizers}

The real-time digitizers are used in the acquisition of the lightning current derivative and their associated electromagnetic fields. Over the years, multiple digitizers have been used as part of the measurement systems at and in the vicinity of the CN Tower. 
Two Sony-Tektronix RTD-710A 10-ns 10-bit double-channel real-time digitizers were used in the acquisition of the data till up to the summer of 2002 when they were replaced by two 2-ns LeCroy LT342L double-channel digitizers, Fig. 4.4. The Sony digitizers had memory limitations that allowed for recording of up to 8 strokes per flash, the upgraded LeCroy digitizers, however, allowed for recording of up to 20 strokes per flash with minimum time resolution of $2 \mathrm{~ns}$.

Since 2011, two independent current derivative measurement systems have been operational at the $\mathrm{CN}$ Tower, each system had its own digitizer. A new double-channel 8-bit National Instrument (NI) PCI 5114 digitizer, shown in Fig. 4.5, connected to the old Rogowski coil via the tri-axial cable, representing one system. The second current derivative measurement system includes the new coil connected to the LeCroy LT342L digitizer via a NanoFast optical fiber link.

Finally, in 2014, a newer and more advanced NI PXIe 5160 digitizer was acquired. Marking the latest addition to the CN Tower current derivative measurement system. The NI PXIe 5160 digitizer along with a timing module and embedded controller are all placed in an NI PXIe- 1082 chassis, as shown in Fig. 4.6. Figure 4.7 shows the current recording systems located at the CN Tower.

Table 4.2 - Technical specifications of the LeCroy LT342L, NI PCI 5114, and NI PXIe 5160 digitizers.

\begin{tabular}{|l|l|l|l|}
\hline & LeCroy LT342L & NI PCI 5114 & NI PXIe 5160 \\
\hline Number of channels & 2 & 2 & 2 \\
\hline Memory & $\begin{array}{l}1 \mathrm{M}: \text { dual channel } \\
2 \mathrm{M}: \text { single channel }\end{array}$ & $64 \mathrm{MB}$ per channel & $2 \mathrm{~GB}$ \\
\hline Bandwidth & $25 \mathrm{~Hz}$ to $500 \mathrm{MHz}$ & $12 \mathrm{~Hz}$ to $125 \mathrm{MHz}$ & $500 \mathrm{MHz}$ \\
\hline Resolution & 8 bits & $8 \mathrm{bits}$ & $10 \mathrm{bits}$ \\
\hline Sampling & Up to $500 \mathrm{MS} / \mathrm{s}$ & Up to $250 \mathrm{MS} / \mathrm{s}$ & Up to $50 \mathrm{GS} / \mathrm{s}$ \\
\hline
\end{tabular}




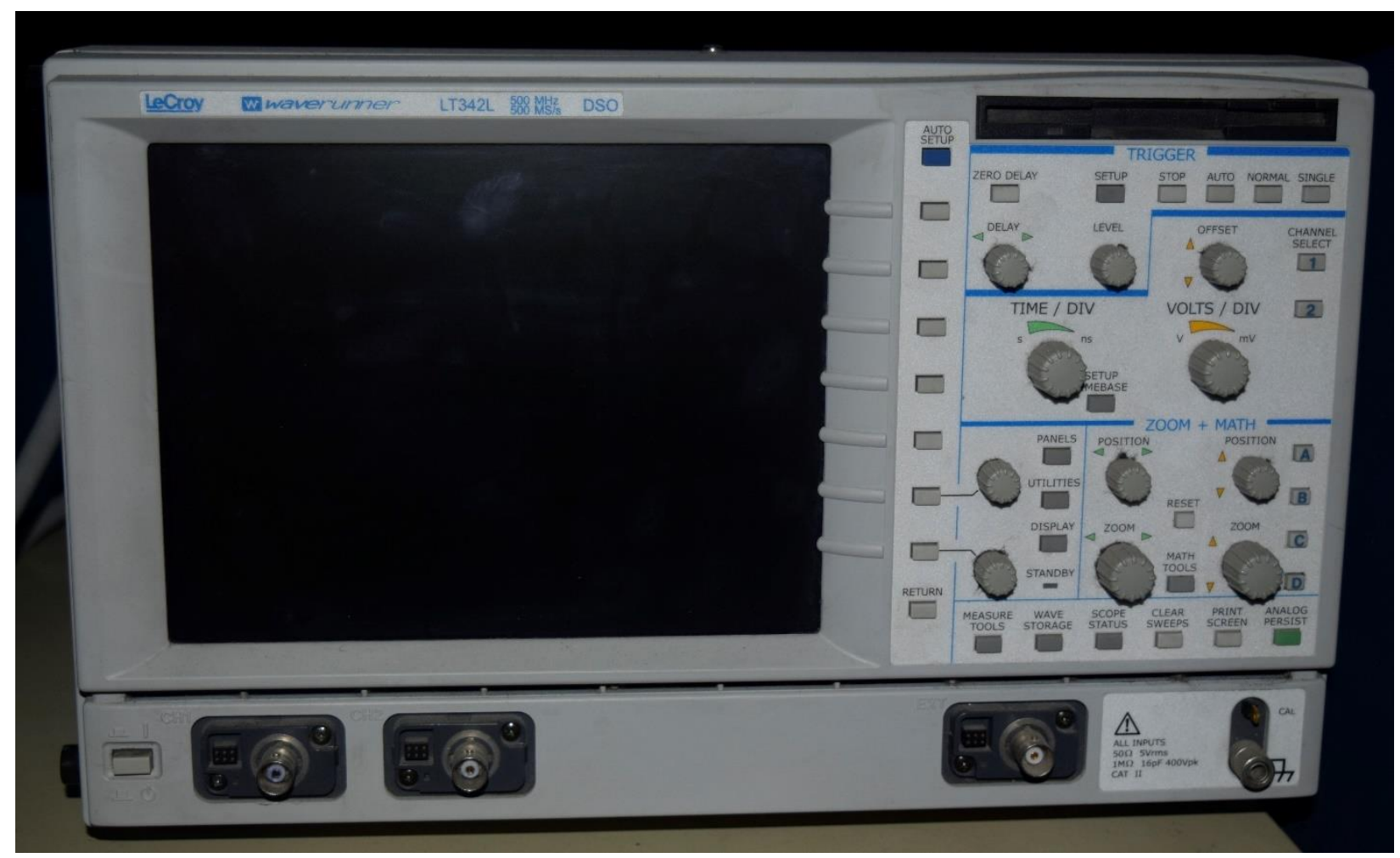

Figure 4.4 - LeCroy LT342L digitizer.

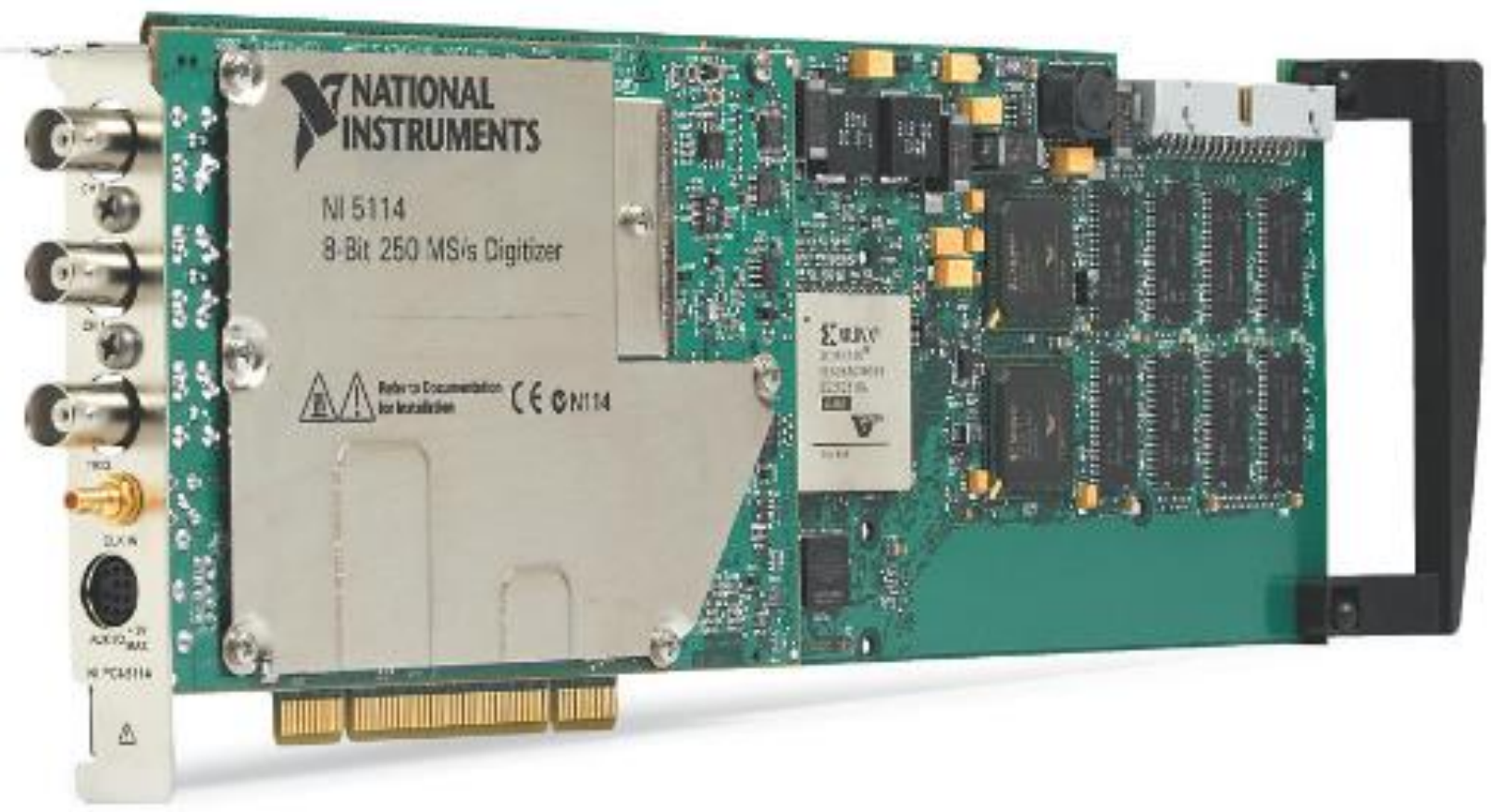

Figure 4.5 - National Instrument PCI 5114 digitizer. 


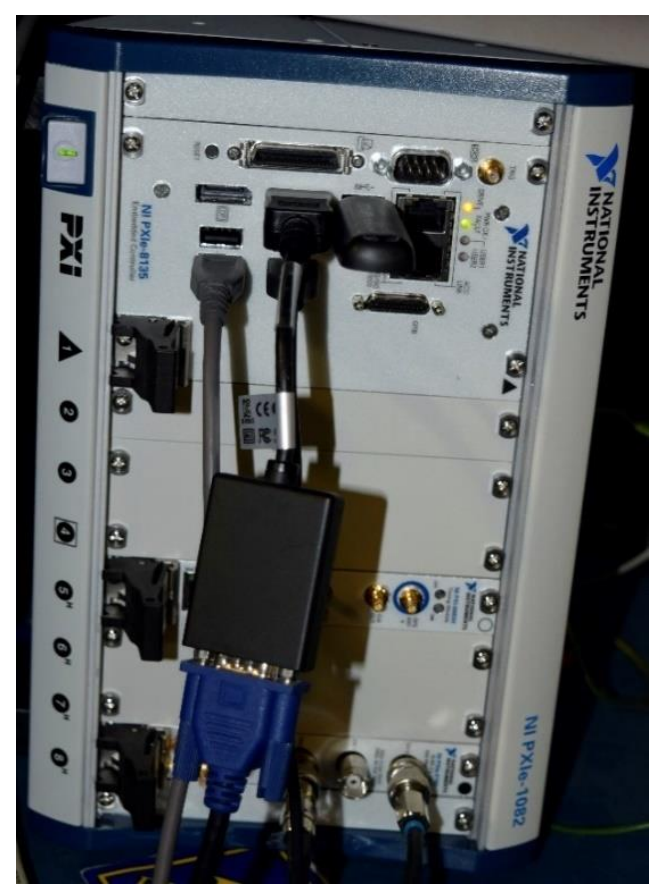

Figure 4.6 - The PXIe 5160 digitizer embedded in an NI PXIe-1082 chassis.

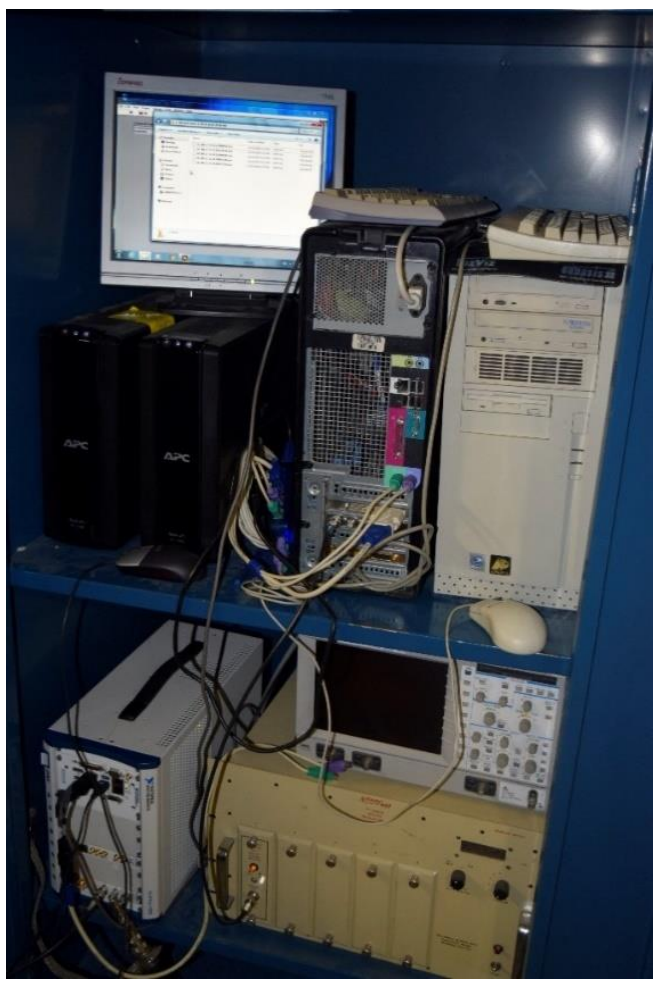

Figure 4.7 - Current recording systems located at the $\mathrm{CN}$ tower. 


\subsection{Video recording system}

Since 1991, lightning strikes to the CN Tower have been visually observed. Currently, the video recording systems at the $\mathrm{CN}$ Tower allow for the recording of the lightning channel trajectory by the means of a Vision Research Phantom v.5.0 high-speed camera, operating at 1000 frames per second and $1 \mathrm{~ms}$ resolution, and a low-speed Sony HDR PJ790VB camera, operating at 60 frames per second and $16.67 \mathrm{~ms}$ resolution [28].

The high-speed camera was acquired in 1996 and is placed at the Pratt Building of University of Toronto (2.0 km north of the CN Tower). Digital records captured by the high-speed camera is saved to PC. While the Sony low speed camera is located at the Kinectrix Inc. building, $11.8 \mathrm{~km}$ west of the $\mathrm{CN}$ Tower. The locations of the two cameras (almost perpendicular) are meant to facilitate the reproduction of the 3-D image trajectory of the lightning flash [30]. The video recording system is essential in confirming the lightning flash direction (upwards or downwards), as well as providing detailed information of lightning flash components, and the number of return stroke.

\subsection{Current Derivative Measurement System Records}

In this section, the typical records obtained by the $\mathrm{CN}$ Tower lightning current derivative measurement systems, mentioned in the above sections, are presented. Video records of lightning return strokes hitting the CN Tower on August 24, 2011 are shown in Figures 4.8 and 4.9. Whereas, Fig. 4.8 represents a video record captured by Kodak Zi8 camera with 8-bit and $1280 \times 720$ image resolution, operates at 30 frames per second and located at $2.47 \mathrm{~km}$ northeast of the CN Tower [31]. While Fig. 4.9 shows a flash trajectory hitting the CN Tower captured by a Power Shot Canon S95 digital camera, with $640 \times 480$ image resolution and operating at $30 \mathrm{frames} / \mathrm{s}$, and is located $3.95 \mathrm{~km}$ north of the tower [31].

Figure 4.10 is showing an example of a lightning flash recorded by the NI PCI 5114 digitizer, the digitizer allowed for a continuous recording of 2 seconds. The figure shows the $30^{\text {th }}$ recorded flash on August 24, 2011 with one return stroke. 


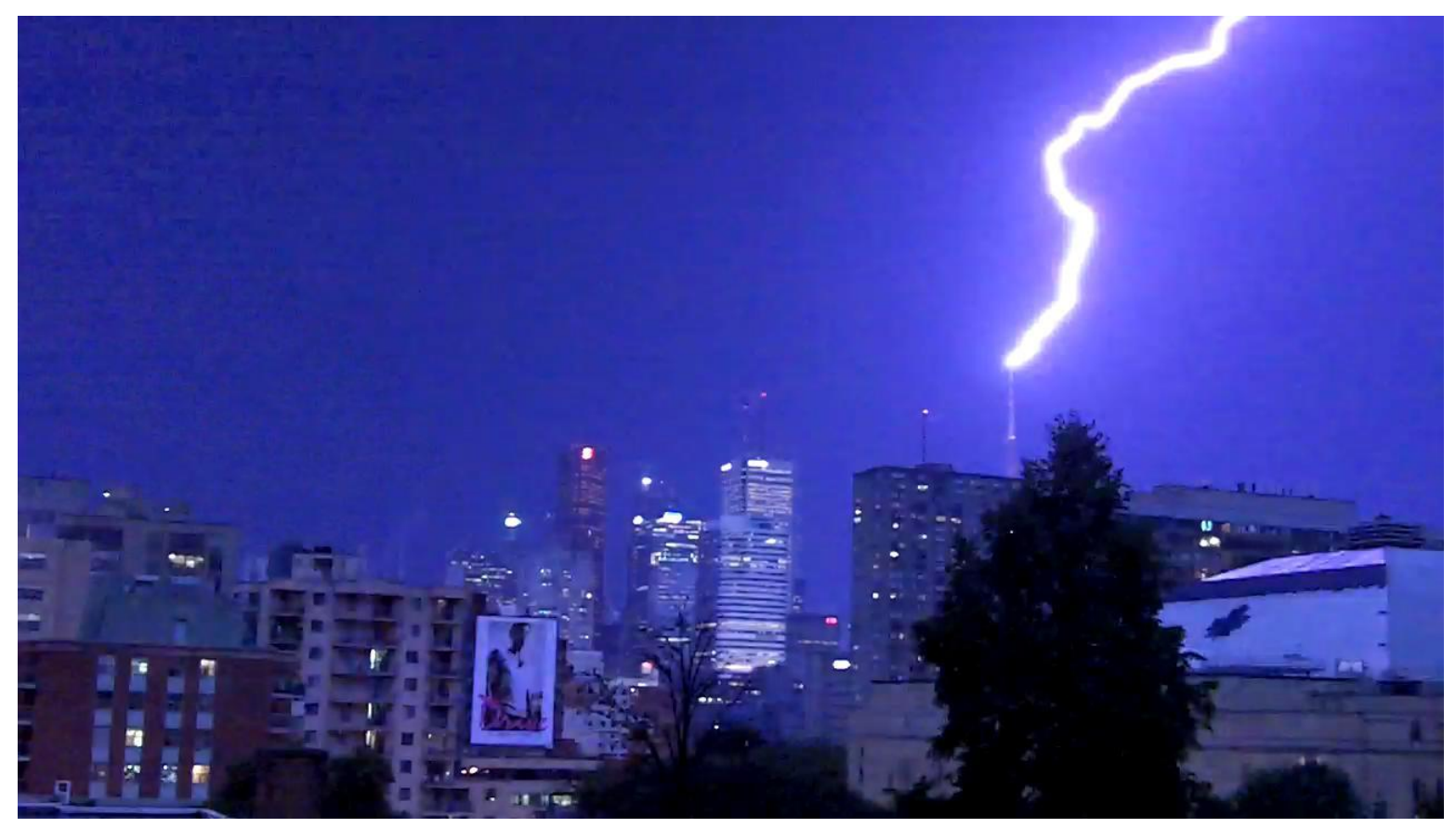

Figure 4.8 - Kodak Zi8 camera record of August 24, 2011 CN Tower lightning flash [9].

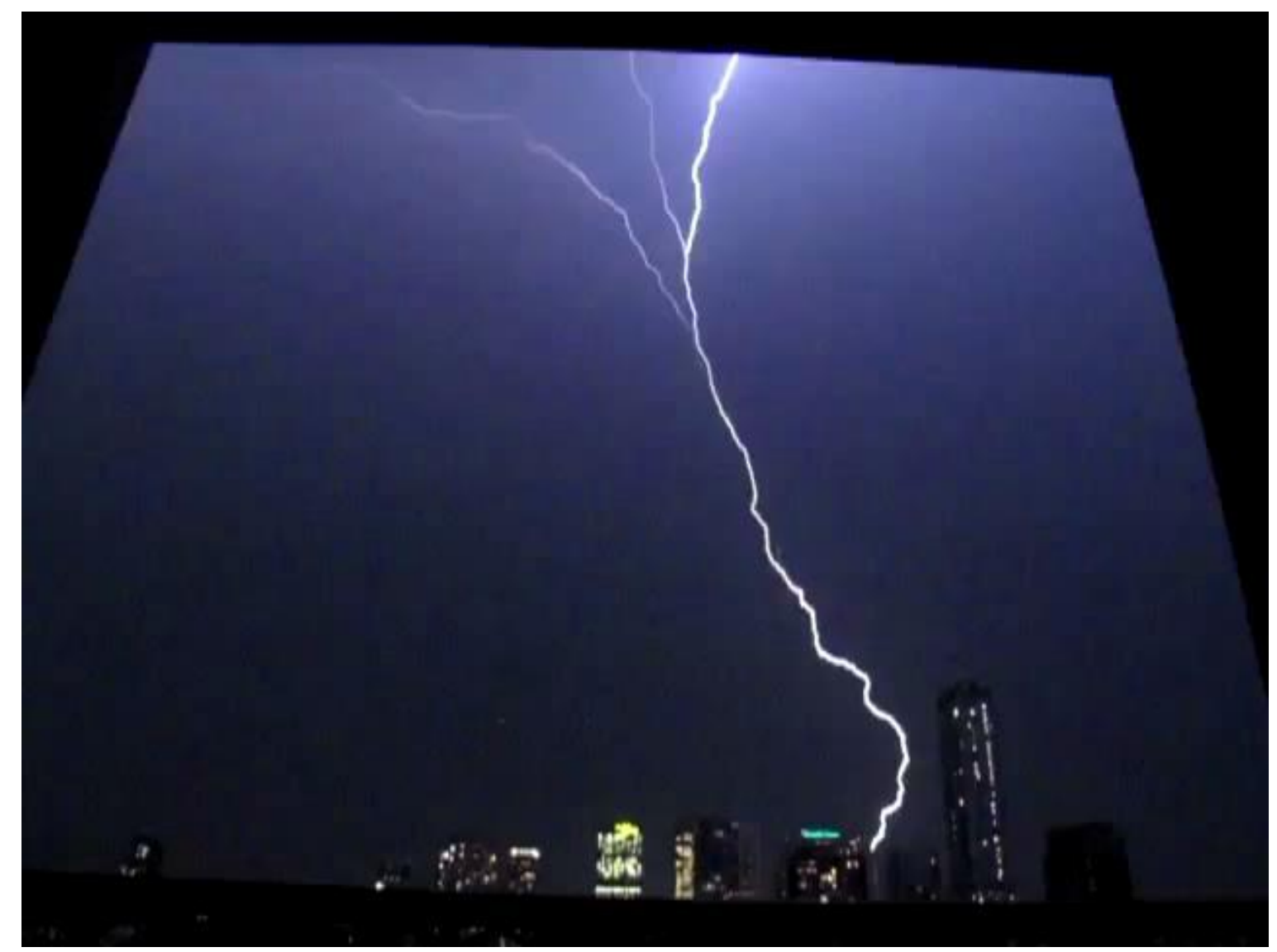

Figure 4.9 - Power Shot Canon S95 record of August 24, 2011 CN Tower lightning flash [9]. 
Figure 4.11 shows the expanded current derivative of the return stroke in Fig. 4.10 and Fig. 4.12 represents its current waveform, which is obtained by numerical integration.

Moreover, Fig. 4.13 shows an expanded current derivative signal captured on August 19, 2005 at 14:11:41 Toronto time. And Fig. 4.14 is showing its current waveform, numerical integration of Fig. 4.13.

It is worth mentioning that both signals shown in Figures 4.11 and 4.13 were captured by the old Rogowski coil, however, on August 24, 2011, it was recorded by the NI PCI 5114 digitizer, and on August 19, 2005, it was recorded by the LeCroy LT342L.

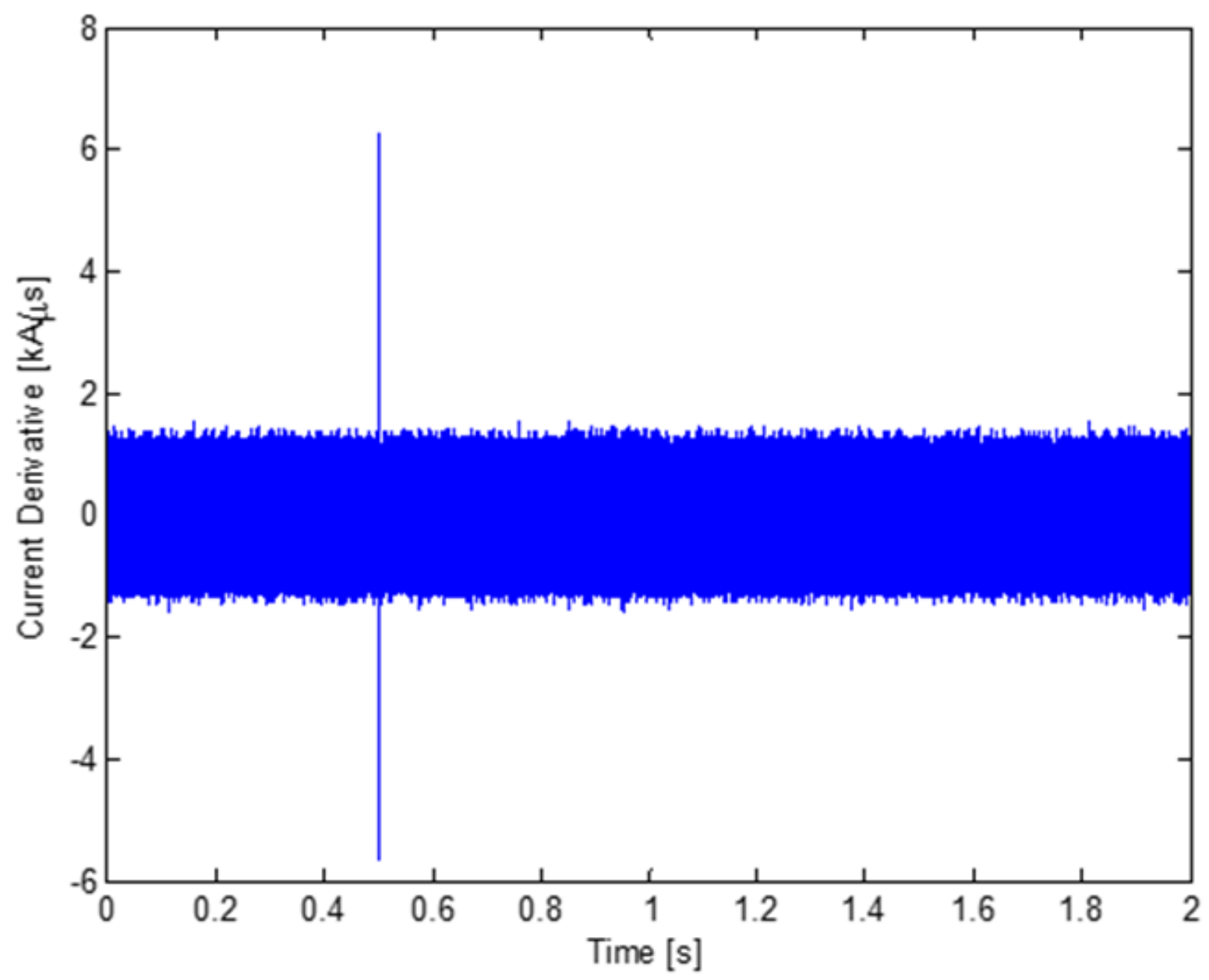

Figure 4.10 - Current derivative of the 30 ${ }^{\text {th }}$ flash, recorded on August 24, 2011. 


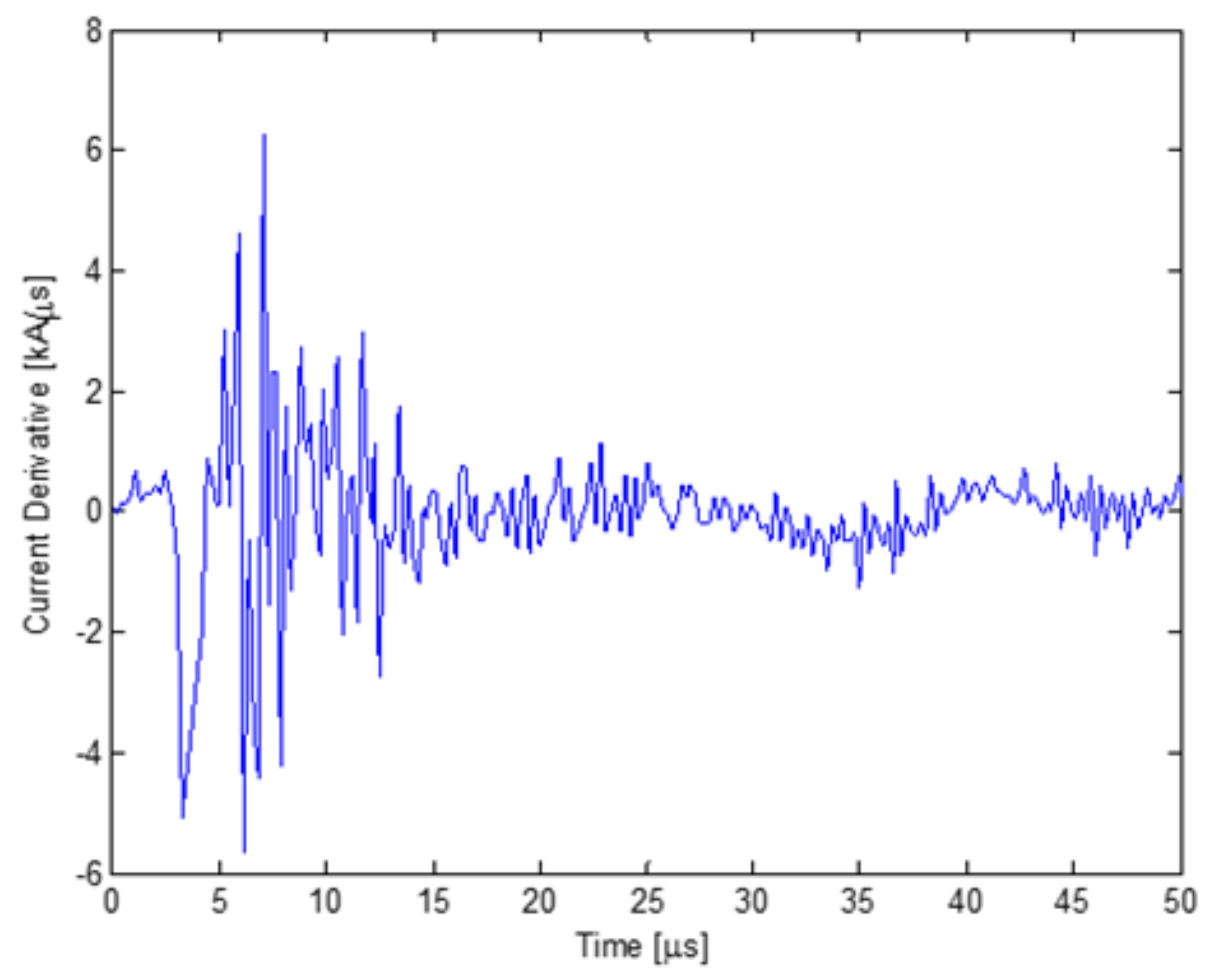

Figure 4.11 - Current derivative of the stroke of Fig. 4.10, expanded.

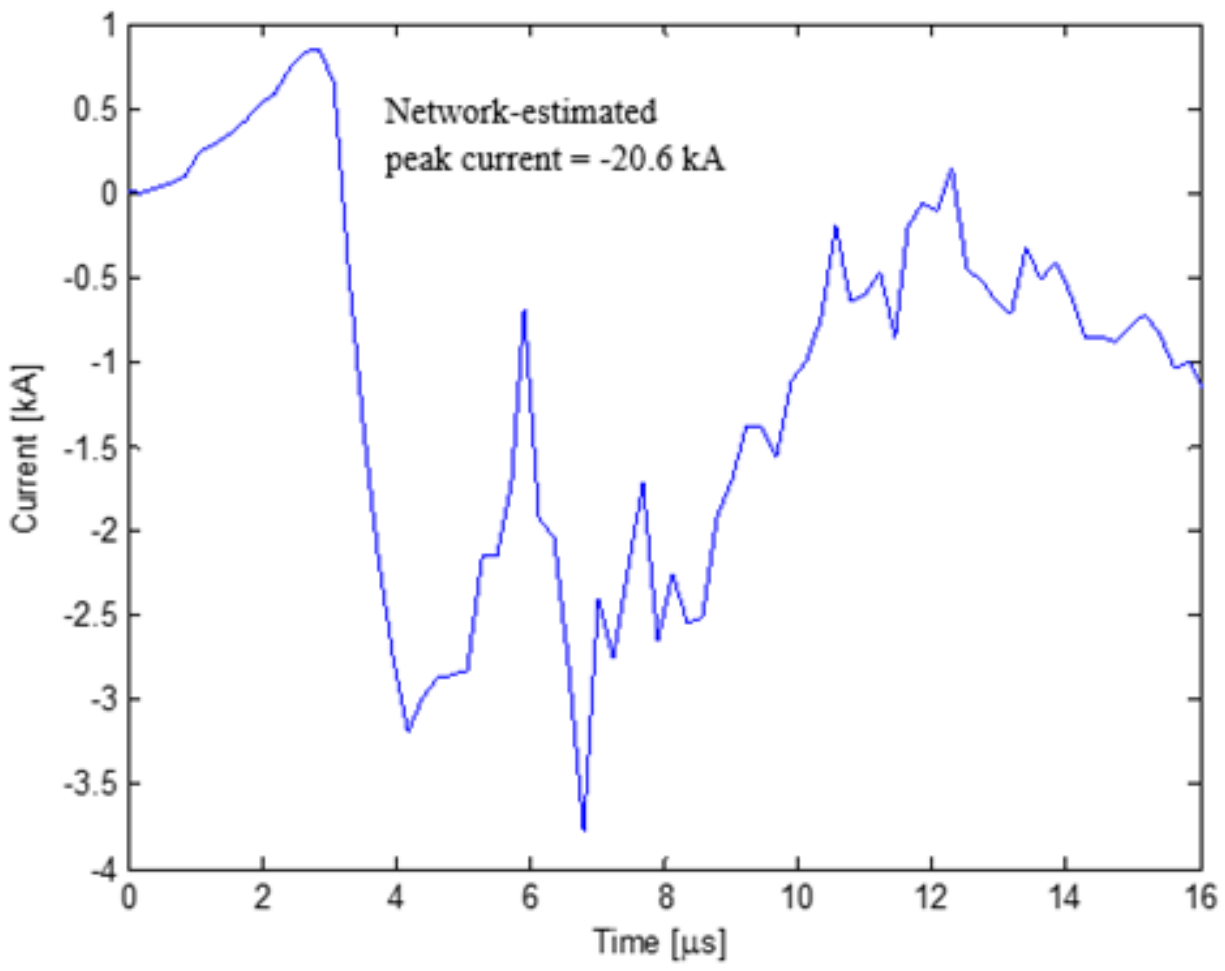

Figure 4.12 - Current waveform of the stroke, shown in Fig. 4.11, obtained by numerical integration. 


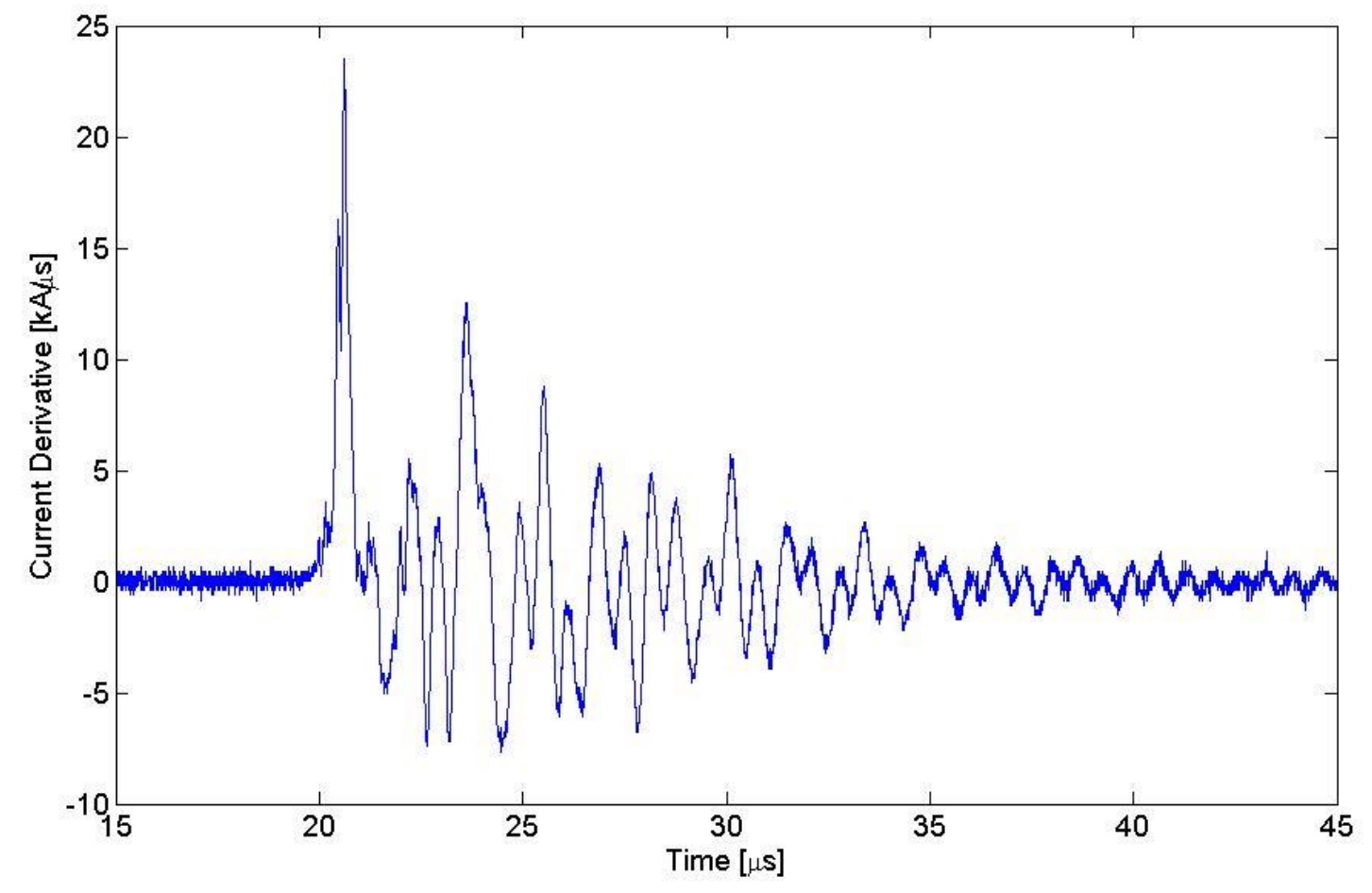

Figure 4.13 - Current derivative signal captured on August 19, 2005 at 14:11:41.

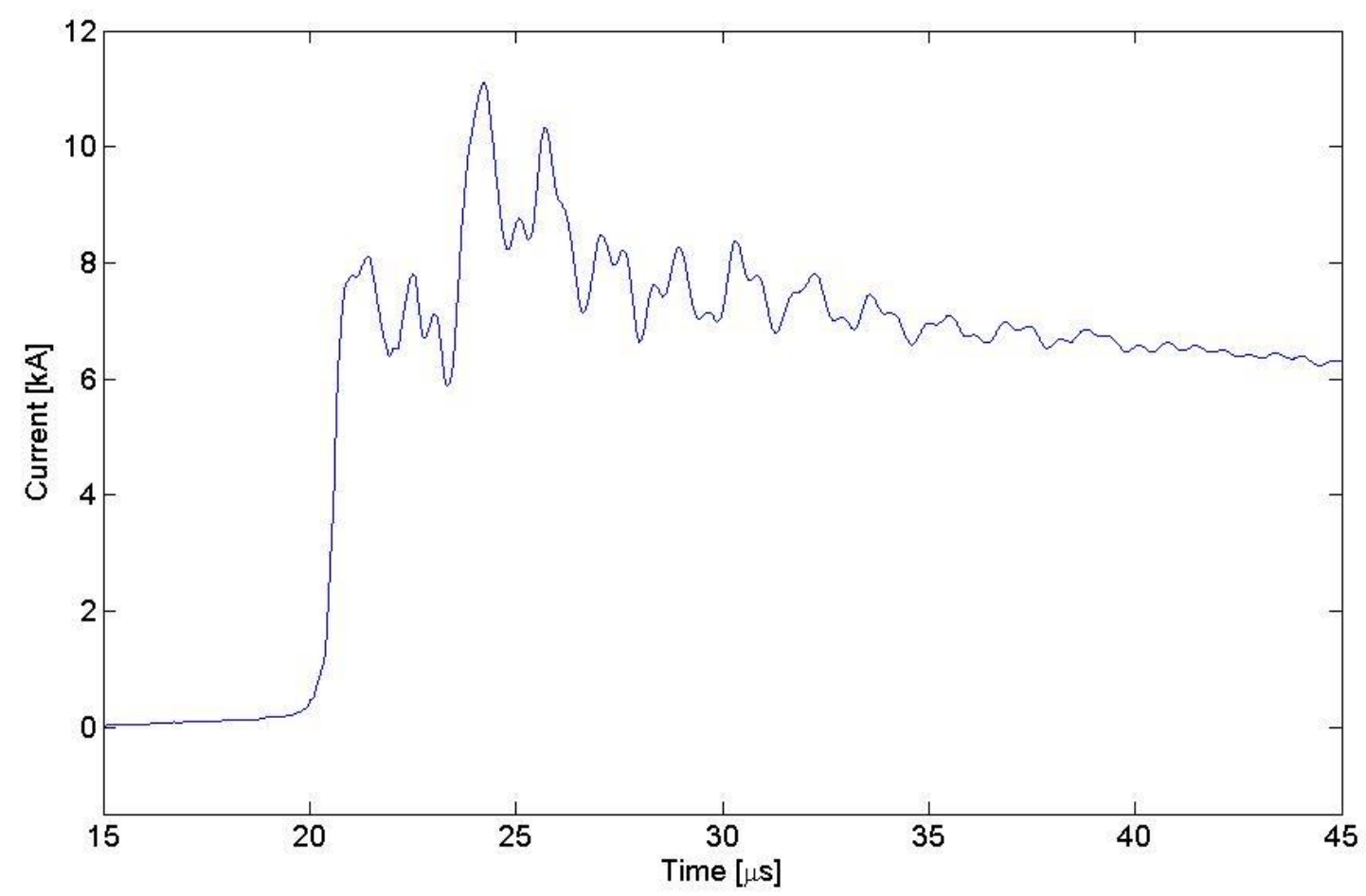

Figure 4.14 - Current waveform (time integral of the current derivative of Fig. 4.13). 


\section{Chapter 5}

\section{Lightning in the Vicinity of the Tower}

In this chapter, the lightning return-stroke data detected by NALDN within $100 \mathrm{~km}$ area around the CN Tower for 11 years (2000-2005 and 2009-2013) are statistically investigated. The North American Lightning Detection Network (NALDN) provides the following lightning information of each return stroke, estimated location and time of occurrence, estimated peak current, and polarity. The Network also provide the multiplicity of each detected flash. The raw data received from the network has been processed, analyzed and presented graphically for each year separately in the following sections.

\subsection{Daily and Monthly Stroke Distribution}

The daily and monthly distribution of strokes within $100 \mathrm{~km}$ from the tower in each of the considered eleven years are presented in Figs. 5.1-5.11. The daily distributions are represented by vertical black lines; each indicates the total number of strokes detected in a single day. The light blue bars denote the total number of detected strokes per month. Also, in each of Tables 5.1-5.11, a summary of the total number of strokes per month, as well as the average, maximum and minimum estimated peak current, is presented. Sorted as per the stroke polarity (whether positive or negative). 


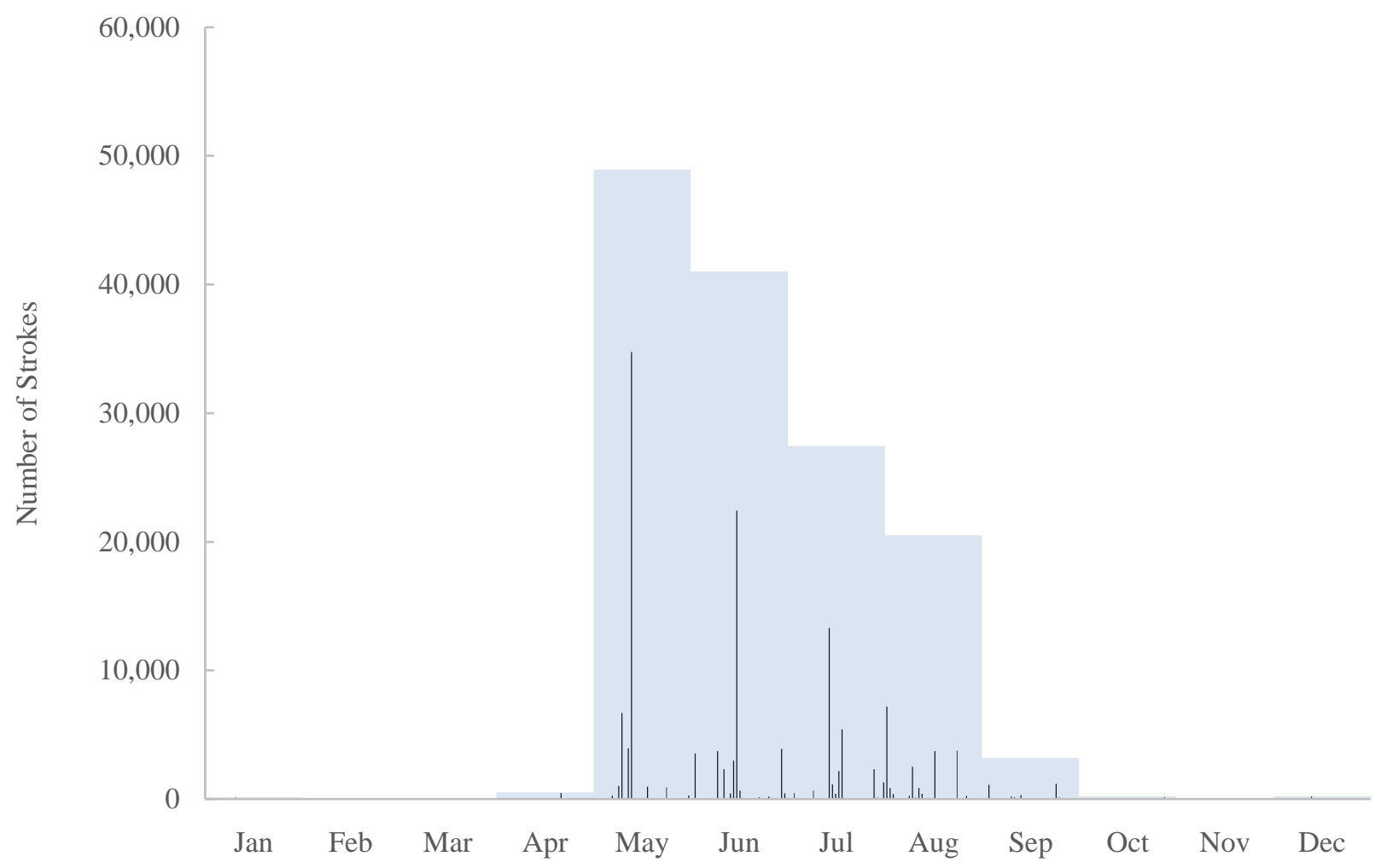

Figure 5.1 - Daily/monthly distributions of detected strokes within $100 \mathrm{~km}$ from the tower, 2000.

Table 5.1 - Monthly number of cloud-to-ground strokes and their peak current values,2000.

\begin{tabular}{|l|l|l|l|l|l|l|l|l|}
\hline \multirow{2}{*}{ Month } & \multicolumn{2}{l}{ Number of strokes } & \multicolumn{2}{l}{ Avg. peak current } & \multicolumn{2}{l|}{ Max. peak current } & \multicolumn{2}{l|}{ Min. peak current } \\
\cline { 2 - 11 } & Positive & Negative & Positive & Negative & Positive & Negative & Positive & Negative \\
\hline Jan & 31 & 111 & 52.08 & -22.10 & 215.00 & -69.40 & 8.90 & -9.90 \\
\hline Feb & 0 & 2 & - & -14.85 & - & -17.00 & - & -12.70 \\
\hline Mar & 26 & 36 & 39.26 & -20.60 & 124.00 & -96.90 & 9.30 & -8.10 \\
\hline Apr & 101 & 437 & 33.56 & -19.29 & 93.90 & -88.10 & 0.80 & -4.10 \\
\hline May & 4,176 & 44,758 & 24.57 & -21.14 & 181.60 & -213.70 & 0.60 & -3.50 \\
\hline Jun & 1,669 & 39,352 & 25.57 & -20.82 & 192.80 & -218.90 & 0.40 & -5.20 \\
\hline Jul & 1,158 & 26,286 & 24.40 & -19.08 & 167.10 & -168.50 & 1.40 & -3.70 \\
\hline Aug & 1,237 & 19,276 & 24.79 & -19.31 & 149.90 & -153.60 & 0.10 & -2.70 \\
\hline Sep & 372 & 2,829 & 32.61 & -22.52 & 129.70 & -130.40 & 1.90 & -2.60 \\
\hline Oct & 80 & 128 & 55.66 & -22.02 & 283.30 & -110.60 & 7.40 & -7.60 \\
\hline Nov & 14 & 36 & 41.29 & -40.03 & 169.30 & -229.80 & 14.20 & -9.50 \\
\hline Dec & $\mathbf{5 7}$ & 150 & 35.77 & -31.16 & 227.40 & -133.20 & 0.40 & -7.80 \\
\hline Totals & $\mathbf{8 , 9 2 1}$ & $\mathbf{1 3 3 , 4 0 1}$ & $\mathbf{2 5 . 7 2}$ & $\mathbf{- 2 0 . 4 2}$ & $\mathbf{2 8 3 . 3 0}$ & $\mathbf{- 2 2 9 . 8 0}$ & $\mathbf{0 . 1 0}$ & $\mathbf{- 2 . 6 0}$ \\
\hline
\end{tabular}




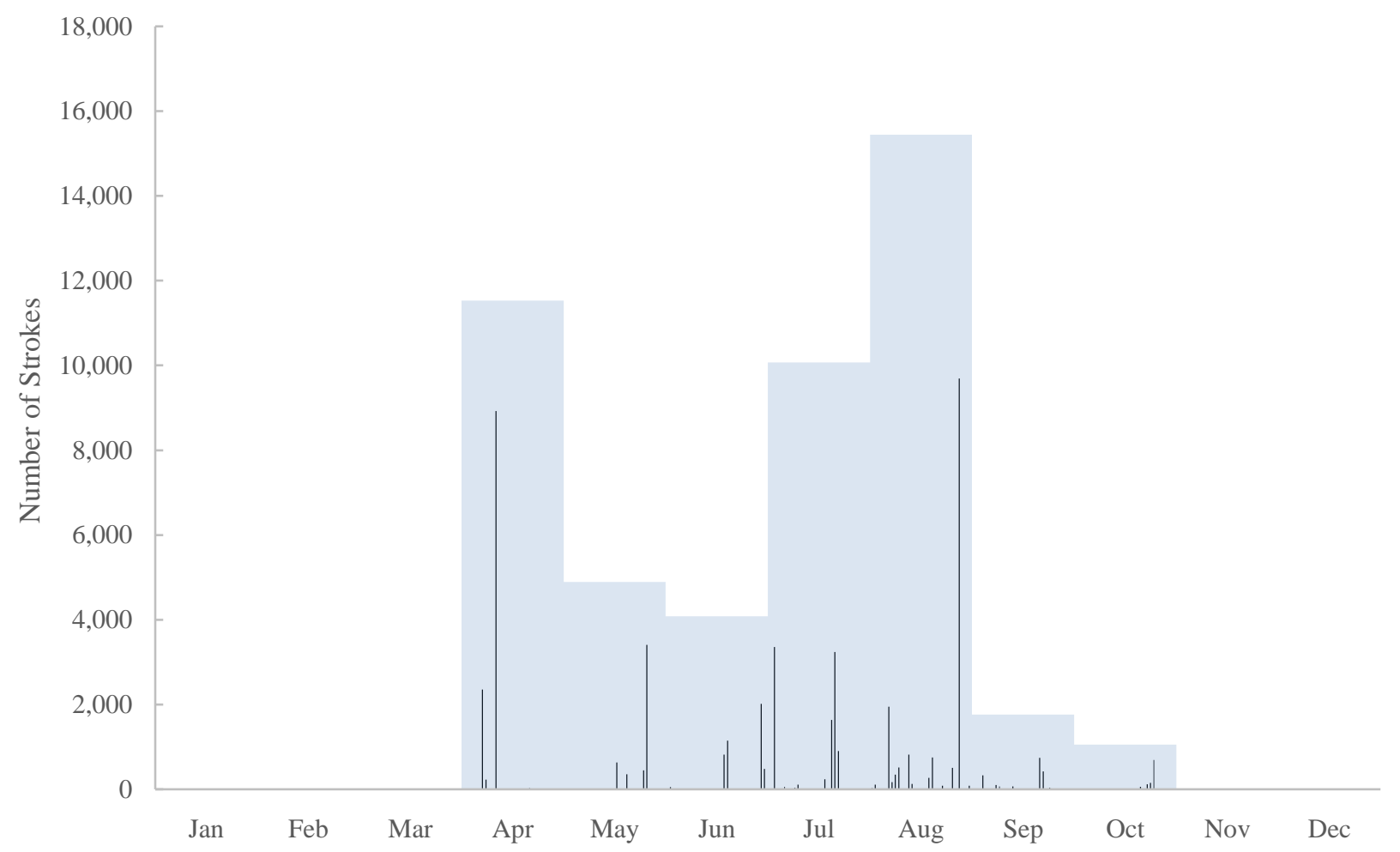

Figure 5.2 - Daily/monthly distributions of detected strokes within $100 \mathrm{~km}$ from the tower, 2001.

Table 5.2 - Monthly number of cloud-to-ground strokes and their peak current values, 2001.

\begin{tabular}{|l|l|l|l|l|l|l|l|l|}
\hline \multirow{2}{*}{ Month } & \multicolumn{2}{|l|}{ Number of strokes } & \multicolumn{2}{l|}{ Avg. peak current } & \multicolumn{2}{l|}{ Max. peak current } & \multicolumn{2}{l|}{ Min. peak current } \\
\cline { 2 - 10 } & Positive & Negative & Positive & Negative & Positive & Negative & Positive & Negative \\
\hline Jan & 0 & 0 & - & - & - & - & - & - \\
\hline Feb & 0 & 1 & - & -34.90 & - & -34.90 & - & -34.90 \\
\hline Mar & 1 & 0 & 95.90 & - & 95.90 & - & 95.90 & - \\
\hline Apr & 480 & 11,050 & 25.89 & -22.94 & 202.50 & -140.90 & 0.10 & -6.30 \\
\hline May & 486 & 4,405 & 38.60 & -18.73 & 328.20 & -106.60 & 5.60 & -5.60 \\
\hline Jun & 187 & 3,898 & 26.42 & -19.32 & 157.30 & -100.90 & 2.90 & -5.50 \\
\hline Jul & 300 & 9,768 & 24.58 & -18.05 & 135.30 & -121.30 & 0.40 & -6.50 \\
\hline Aug & 866 & 14,581 & 24.02 & -22.23 & 161.00 & -179.50 & 0.10 & -4.80 \\
\hline Sep & 306 & 1,460 & 37.43 & -23.62 & 171.50 & -151.90 & 0.90 & -5.30 \\
\hline Oct & 273 & 779 & 41.09 & -18.06 & 189.70 & -85.20 & 6.90 & -7.60 \\
\hline Nov & 1 & 12 & 5.80 & -33.01 & 5.80 & -118.40 & 5.80 & -13.60 \\
\hline Dec & 3 & 16 & 63.63 & -35.14 & 102.00 & -78.60 & 41.80 & -21.40 \\
\hline Totals & $\mathbf{2 , 9 0 3}$ & $\mathbf{4 5 , 9 7 0}$ & $\mathbf{3 0 . 0 6}$ & $\mathbf{- 2 0 . 9 1}$ & $\mathbf{3 2 8 . 2 0}$ & $\mathbf{- 1 7 9 . 5 0}$ & $\mathbf{0 . 1 0}$ & $\mathbf{- 4 . 8 0}$ \\
\hline
\end{tabular}




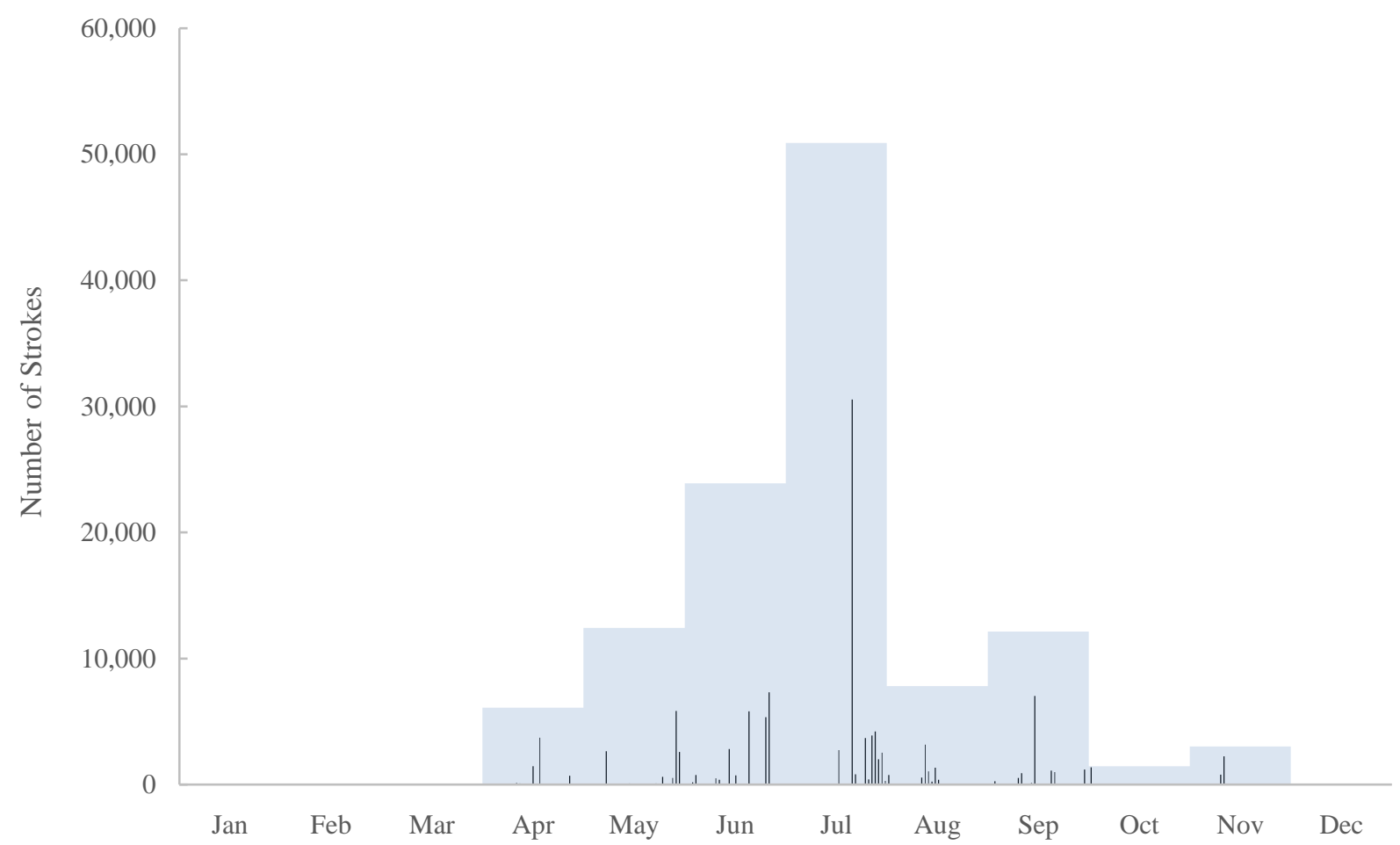

Figure 5.3 - Daily/monthly distributions of detected strokes within $100 \mathrm{~km}$ from the tower, 2002.

Table 5.3 - Monthly number of cloud-to-ground strokes and their peak current values, 2002.

\begin{tabular}{|l|l|l|l|l|l|l|l|l|}
\hline \multirow{2}{*}{ Month } & \multicolumn{2}{|l}{ Number of strokes } & \multicolumn{2}{l|}{ Avg. peak current } & \multicolumn{2}{l|}{ Max. peak current } & \multicolumn{2}{l|}{ Min. peak current } \\
\cline { 2 - 10 } & Positive & Negative & Positive & Negative & Positive & Negative & Positive & Negative \\
\hline Jan & 1 & 0 & 75.20 & - & 75.20 & - & 75.20 & - \\
\hline Feb & 1 & 1 & 20.80 & -42.60 & 20.80 & -42.60 & 20.80 & -42.60 \\
\hline Mar & 0 & 15 & - & -27.29 & - & -60.80 & - & -11.50 \\
\hline Apr & 430 & 5,665 & 33.57 & -18.78 & 212.60 & -131.80 & 0.30 & -5.70 \\
\hline May & 567 & 11,860 & 29.96 & -17.52 & 196.20 & -142.10 & 5.90 & -5.60 \\
\hline Jun & 679 & 23,225 & 27.00 & -18.94 & 285.10 & -155.20 & 6.40 & -5.10 \\
\hline Jul & 1205 & 49,708 & 21.86 & -20.17 & 144.30 & -135.20 & 4.40 & -5.50 \\
\hline Aug & 145 & 7,674 & 22.02 & -20.29 & 124.90 & -119.10 & 7.30 & -6.80 \\
\hline Sep & $\mathbf{3 4 6}$ & 11,784 & 21.30 & -16.90 & 109.90 & -137.60 & 4.00 & -4.10 \\
\hline Oct & 48 & 1413 & 22.30 & -16.04 & 140.30 & -70.90 & 4.30 & -4.30 \\
\hline Nov & 271 & 2745 & 26.85 & -16.76 & 124.80 & -114.00 & 5.10 & -4.30 \\
\hline Dec & 1 & 6 & 35.20 & -13.32 & 35.20 & -25.20 & 35.20 & -7.50 \\
\hline Totals & $\mathbf{3 , 6 9 4}$ & $\mathbf{1 1 4 , 0 9 6}$ & $\mathbf{2 5 . 7 5}$ & $\mathbf{- 1 9 . 1 1}$ & $\mathbf{2 8 5 . 1 0}$ & $\mathbf{- 1 5 5 . 2 0}$ & $\mathbf{0 . 3 0}$ & $\mathbf{- 4 . 1 0}$ \\
\hline
\end{tabular}




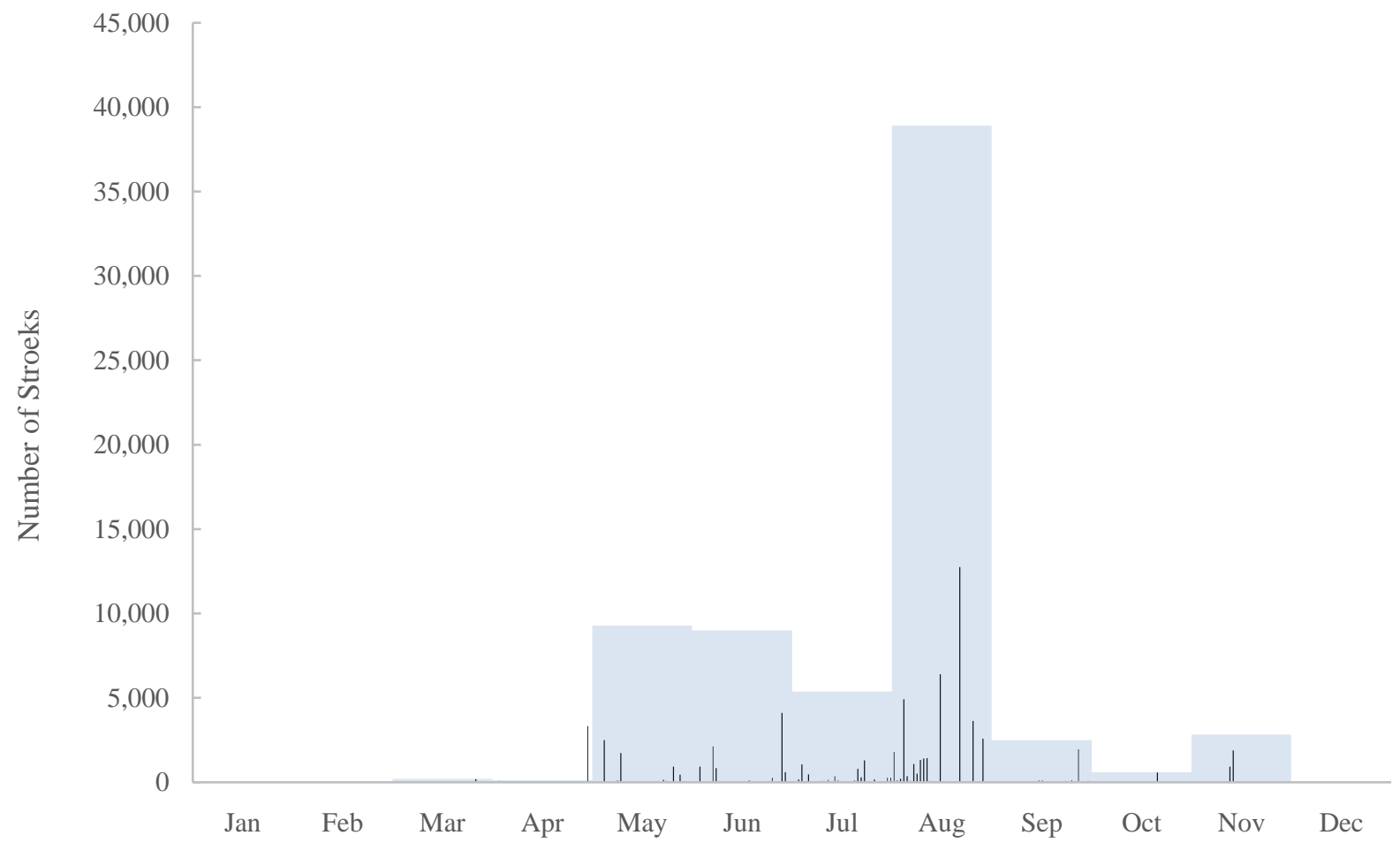

Figure 5.4 - Daily/monthly distributions of detected strokes within $100 \mathrm{~km}$ from the tower, 2003.

Table 5.4 - Monthly number of cloud-to-ground strokes and their peak current values, 2003.

\begin{tabular}{|l|l|l|l|l|l|l|l|l|}
\hline \multirow{2}{*}{ Month } & \multicolumn{2}{|l|}{ Number of strokes } & \multicolumn{2}{|l|}{ Avg. peak current } & \multicolumn{2}{l|}{ Max. peak current } & \multicolumn{2}{l|}{ Min. peak current } \\
\cline { 2 - 9 } & Positive & Negative & Positive & Negative & Positive & Negative & Positive & Negative \\
\hline Jan & 0 & 0 & - & - & - & - & - & - \\
\hline Feb & 0 & 2 & - & -16.65 & - & -17.40 & - & -15.90 \\
\hline Mar & 44 & 164 & 60.71 & -16.97 & 249.90 & -118.00 & 6.40 & -5.30 \\
\hline Apr & 50 & 79 & 56.03 & -16.08 & 184.10 & -47.20 & 7.30 & -5.50 \\
\hline May & 871 & 8,406 & 26.71 & -16.15 & 169.20 & -124.10 & 4.50 & -3.80 \\
\hline Jun & 633 & 8,373 & 24.80 & -13.90 & 137.60 & -112.50 & 4.50 & -3.70 \\
\hline Jul & 401 & 4,967 & 23.21 & -15.06 & 114.00 & -99.90 & 3.40 & -3.50 \\
\hline Aug & 1757 & 37,156 & 15.29 & -16.90 & 147.20 & -181.00 & 3.80 & -3.30 \\
\hline Sep & 291 & 2,211 & 32.13 & -15.73 & 182.20 & -75.60 & 4.70 & -4.40 \\
\hline Oct & 55 & 553 & 36.80 & -15.48 & 260.90 & -68.20 & 6.20 & -4.70 \\
\hline Nov & 455 & 2376 & 32.18 & -15.28 & 216.40 & -112.10 & 5.10 & -4.30 \\
\hline Dec & 0 & 0 & - & - & - & - & - & - \\
\hline Totals & $\mathbf{4 , 5 5 7}$ & $\mathbf{6 4 , 2 8 7}$ & $\mathbf{2 3 . 4 0}$ & $\mathbf{- 1 6 . 1 6}$ & $\mathbf{2 6 0 . 9 0}$ & $\mathbf{- 1 8 1 . 0 0}$ & $\mathbf{3 . 4 0}$ & $\mathbf{- 3 . 3 0}$ \\
\hline
\end{tabular}




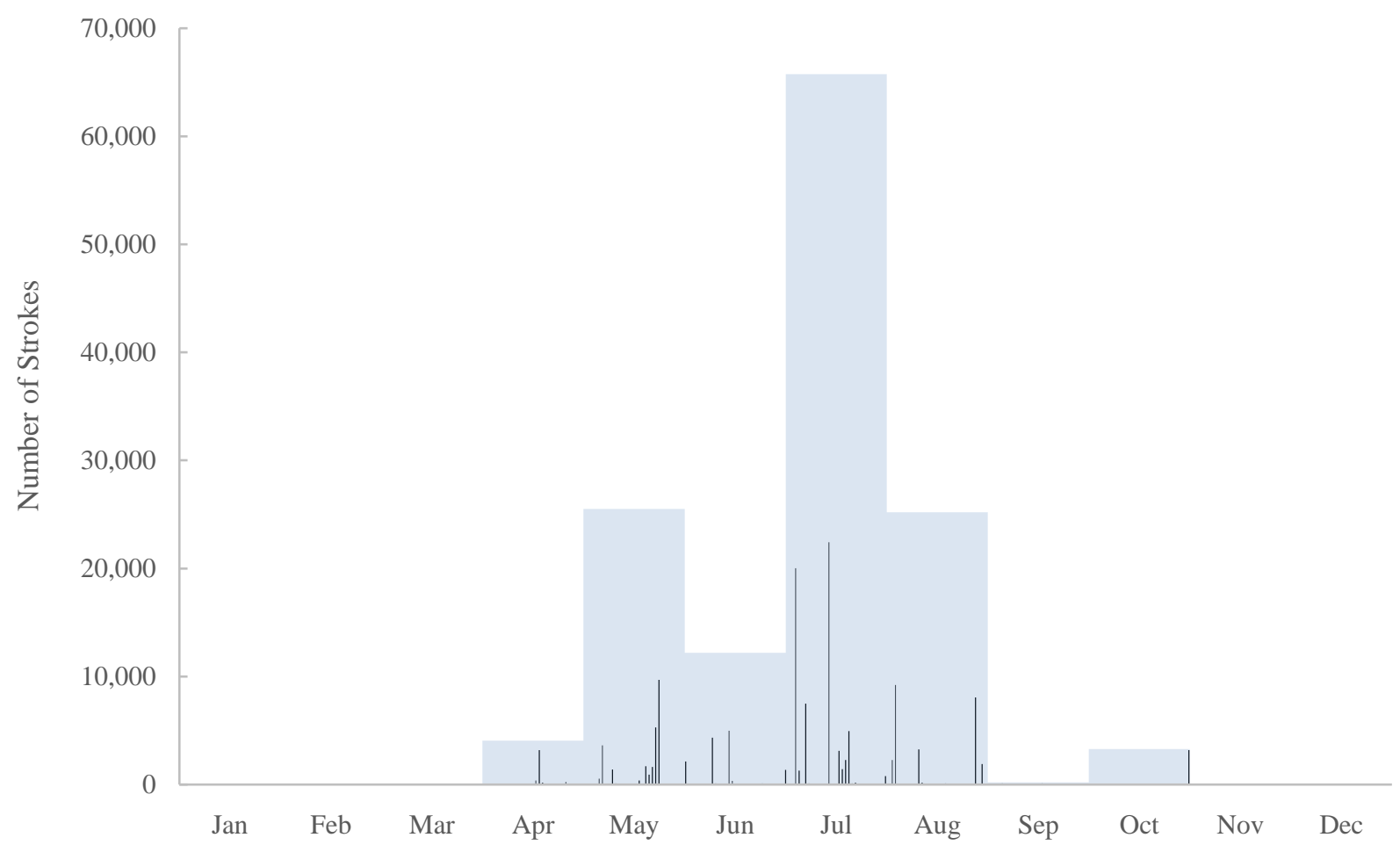

Figure 5.5 - Daily/monthly distributions of detected strokes within $100 \mathrm{~km}$ from the tower, 2004.

Table 5.5 - Monthly number of cloud-to-ground strokes and their peak current values, 2004.

\begin{tabular}{|l|l|l|l|l|l|l|l|l|}
\hline \multirow{2}{*}{ Month } & \multicolumn{2}{|l|}{ Number of strokes } & \multicolumn{2}{l|}{ Avg. peak current } & \multicolumn{2}{l|}{ Max. peak current } & \multicolumn{2}{l|}{ Min. peak current } \\
\cline { 2 - 10 } & Positive & Negative & Positive & Negative & Positive & Negative & Positive & Negative \\
\hline Jan & 7 & 14 & 35.63 & -18.02 & 82.10 & -48.90 & 8.80 & -7.90 \\
\hline Feb & 0 & 0 & - & - & - & - & - & - \\
\hline Mar & 1 & 7 & 60.70 & -19.57 & 60.70 & -32.00 & 60.70 & -10.70 \\
\hline Apr & 645 & 3,431 & 28.62 & -16.56 & 179.70 & -289.80 & 4.20 & -3.80 \\
\hline May & 1847 & 23,676 & 21.75 & -16.27 & 159.70 & -125.10 & 3.90 & -3.60 \\
\hline Jun & 929 & 11,265 & 21.06 & -14.60 & 128.30 & -98.50 & 3.80 & -3.50 \\
\hline Jul & 2485 & 63,272 & 17.67 & -17.79 & 155.10 & -163.50 & 3.60 & -3.30 \\
\hline Aug & 1092 & 24,111 & 16.41 & -18.70 & 130.10 & -157.70 & 3.60 & -3.50 \\
\hline Sep & 20 & 184 & 23.58 & -16.92 & 86.10 & -52.70 & 4.50 & -6.00 \\
\hline Oct & 200 & 3089 & 23.46 & -20.36 & 232.10 & -134.00 & 3.80 & -3.70 \\
\hline Nov & 1 & 6 & 96.10 & -104.12 & 96.10 & -284.10 & 96.10 & -7.80 \\
\hline Dec & 0 & 1 & - & -6.10 & - & -6.10 & - & -6.10 \\
\hline Totals & $\mathbf{7 , 2 2 7}$ & $\mathbf{1 2 9 , 0 5 6}$ & $\mathbf{2 0 . 1 5}$ & $\mathbf{- 1 7 . 4 3}$ & $\mathbf{2 3 2 . 1 0}$ & $\mathbf{- 2 8 9 . 8 0}$ & $\mathbf{3 . 6 0}$ & $\mathbf{- 3 . 3 0}$ \\
\hline
\end{tabular}




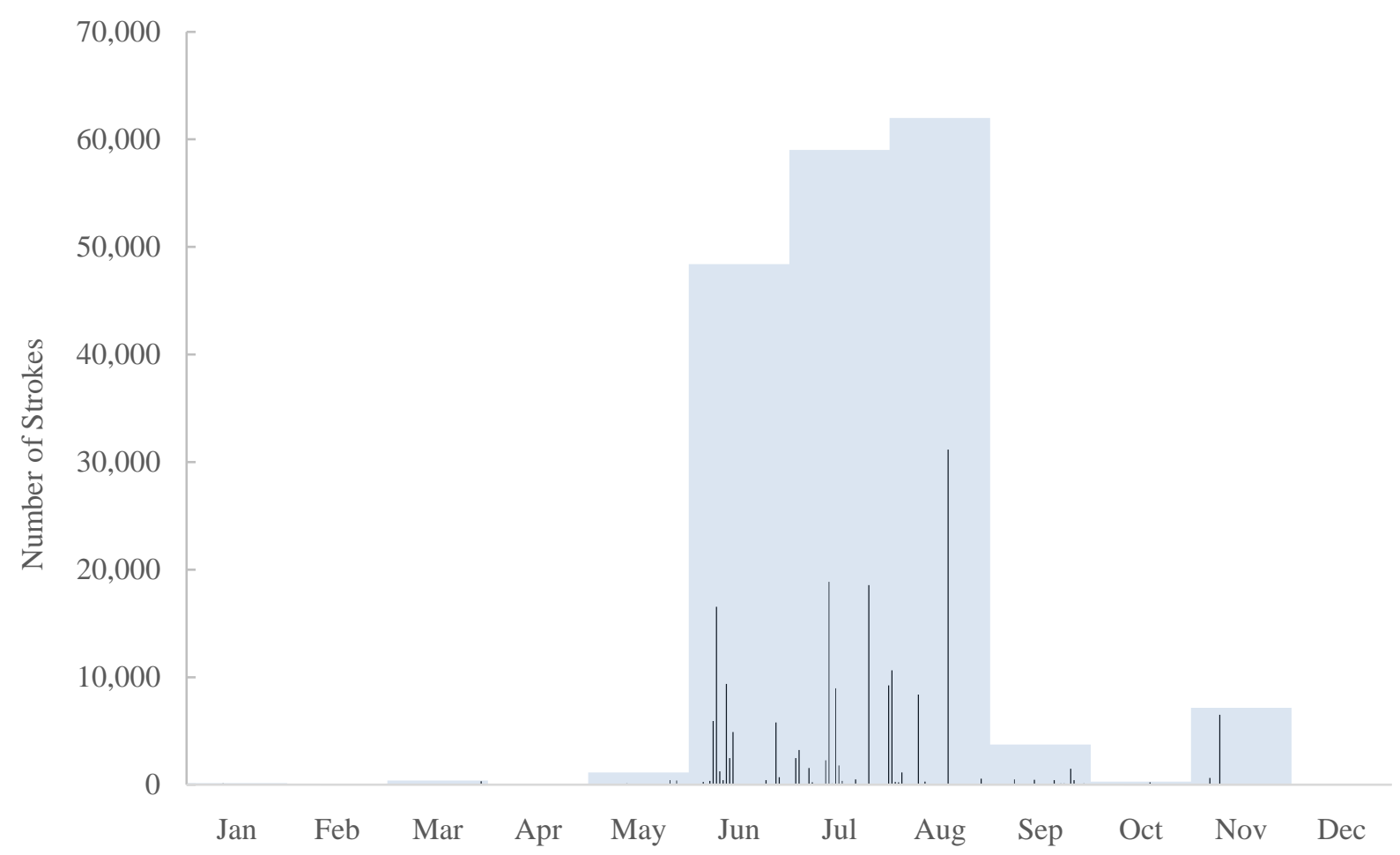

Figure 5.6 - Daily/monthly distributions of detected strokes within $100 \mathrm{~km}$ from the tower, 2005.

Table 5.6 - Monthly number of cloud-to-ground strokes and their peak current values, 2005.

\begin{tabular}{|l|l|l|l|l|l|l|l|l|}
\hline \multirow{2}{*}{ Month } & \multicolumn{2}{|l|}{ Number of strokes } & \multicolumn{2}{l|}{ Avg. peak current } & \multicolumn{2}{l|}{ Max. peak current } & \multicolumn{2}{l|}{ Min. peak current } \\
\cline { 2 - 9 } & Positive & Negative & Positive & Negative & Positive & Negative & Positive & Negative \\
\hline Jan & 25 & 135 & 40.89 & -22.56 & 133.70 & -11.50 & 4.50 & -4.70 \\
\hline Feb & 0 & 0 & - & - & - & - & - & - \\
\hline Mar & 53 & 332 & 41.34 & -15.28 & 214.00 & -81.00 & 5.50 & -3.30 \\
\hline Apr & 11 & 87 & 63.35 & -20.80 & 214.50 & -102.30 & 11.60 & -6.80 \\
\hline May & 216 & 923 & 33.25 & -15.52 & 192.30 & -146.30 & 4.70 & -4.40 \\
\hline Jun & 1771 & 46,626 & 16.72 & -17.62 & 131.70 & -136.60 & 3.80 & -3.60 \\
\hline Jul & 2582 & 56,442 & 13.69 & -17.77 & 184.20 & -150.10 & 3.60 & -3.60 \\
\hline Aug & 7206 & 54,782 & 11.19 & -16.27 & 123.50 & -132.50 & 3.30 & -2.90 \\
\hline Sep & 479 & 3,272 & 32.49 & -18.22 & 181.30 & -141.40 & 5.30 & -3.20 \\
\hline Oct & 38 & 231 & 36.28 & -16.07 & 149.60 & -164.10 & 6.40 & -4.90 \\
\hline Nov & 621 & 6514 & 23.27 & -25.86 & 262.70 & -208.40 & 5.40 & -4.30 \\
\hline Dec & 2 & 0 & 147.45 & - & 185.60 & - & 109.30 & - \\
\hline Totals & $\mathbf{1 3 , 0 0 4}$ & $\mathbf{1 6 9 , 3 4 4}$ & $\mathbf{1 4 . 4 8}$ & $\mathbf{- 1 7 . 5 5}$ & $\mathbf{2 6 2 . 7 0}$ & $\mathbf{- 2 0 8 . 4 0}$ & $\mathbf{3 . 3 0}$ & $\mathbf{- 2 . 9 0}$ \\
\hline
\end{tabular}




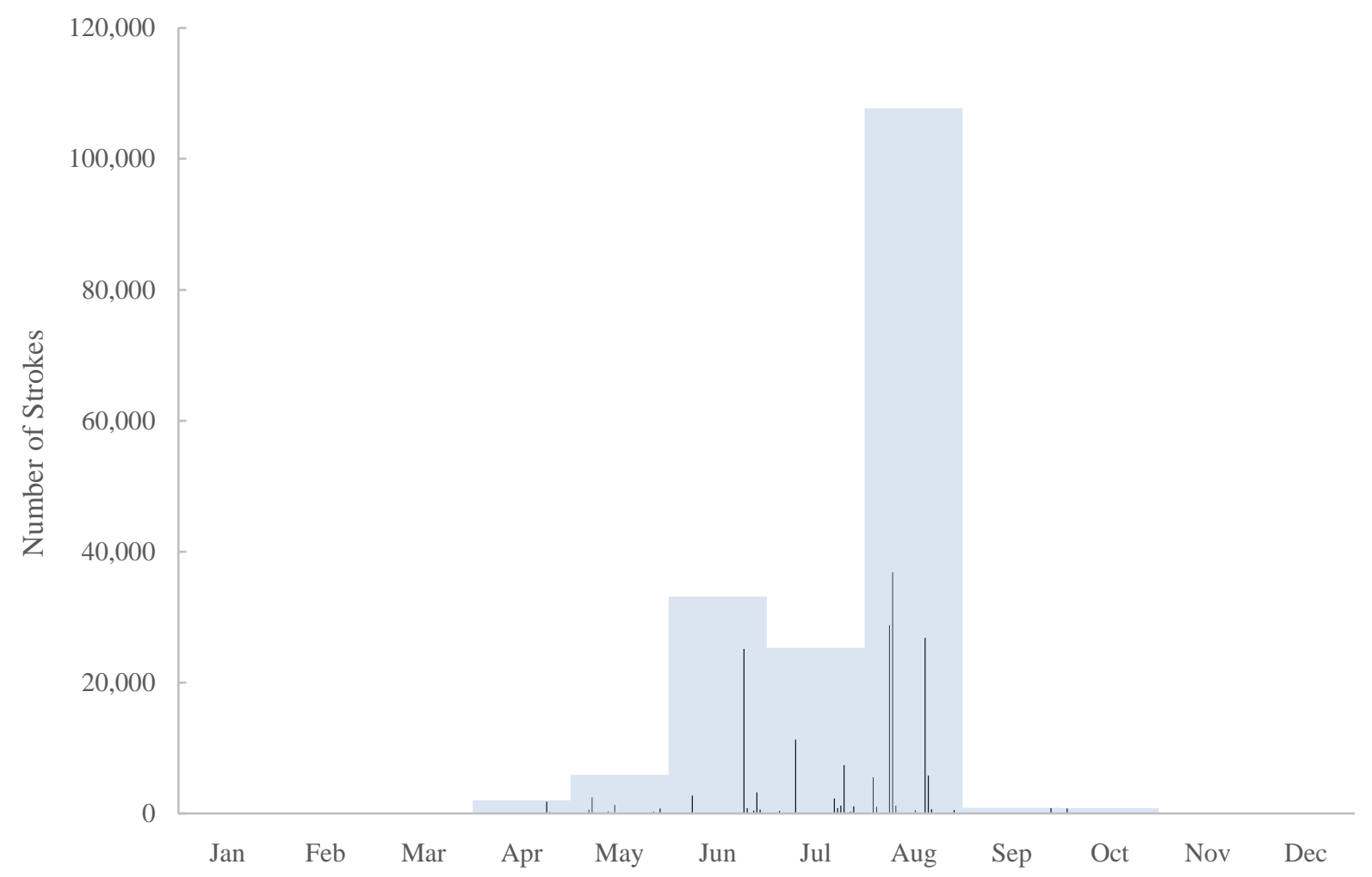

Figure 5.7 - Daily/monthly distributions of detected strokes within $100 \mathrm{~km}$ from the tower, 2009.

Table 5.7 - Monthly number of cloud-to-ground strokes and their peak current values, 2009.

\begin{tabular}{|l|l|l|l|l|l|l|l|l|}
\hline \multirow{2}{*}{ Month } & \multicolumn{2}{|l|}{ Number of strokes } & \multicolumn{2}{l|}{ Avg. peak current } & \multicolumn{2}{l|}{ Max. peak current } & \multicolumn{2}{l|}{ Min. peak current } \\
\cline { 2 - 9 } & Positive & Negative & Positive & Negative & Positive & Negative & Positive & Negative \\
\hline Jan & 0 & 0 & - & - & - & - & - & - \\
\hline Feb & 2 & 7 & 90.40 & -24.24 & 104.40 & -79.10 & 76.40 & -8.10 \\
\hline Mar & 33 & 125 & 46.08 & -17.42 & 118.40 & -112.60 & 15.90 & -3.50 \\
\hline Apr & 118 & 1,908 & 37.97 & -13.10 & 187.20 & -205.10 & 15.10 & -2.20 \\
\hline May & 572 & 5,309 & 42.35 & -14.58 & 221.20 & -139.00 & 15.00 & -2.10 \\
\hline Jun & 693 & 32,434 & 29.85 & -15.60 & 155.90 & -197.00 & 15.00 & -1.40 \\
\hline Jul & 702 & 24,607 & 34.30 & -16.31 & 281.10 & -213.70 & 15.00 & -1.50 \\
\hline Aug & 1910 & 105,837 & 26.27 & -15.18 & 221.10 & -222.10 & 15.00 & -1.50 \\
\hline Sep & 68 & 785 & 49.07 & -14.06 & 185.70 & -115.70 & 15.10 & -2.00 \\
\hline Oct & 84 & 751 & 49.80 & -16.98 & 344.40 & -213.40 & 15.10 & -1.60 \\
\hline Nov & 13 & 2 & 51.76 & -13.90 & 164.20 & -18.10 & 17.30 & -9.70 \\
\hline Dec & 0 & 82 & - & -15.78 & - & -81.60 & - & -4.10 \\
\hline Totals & $\mathbf{4 , 1 9 5}$ & $\mathbf{1 7 1 , 8 4 7}$ & $\mathbf{3 1 . 8 3}$ & $\mathbf{- 1 5 . 3 9}$ & $\mathbf{3 4 4 . 4 0}$ & $\mathbf{- 2 2 2 . 1 0}$ & $\mathbf{1 5 . 0 0}$ & $\mathbf{- 1 . 4 0}$ \\
\hline
\end{tabular}




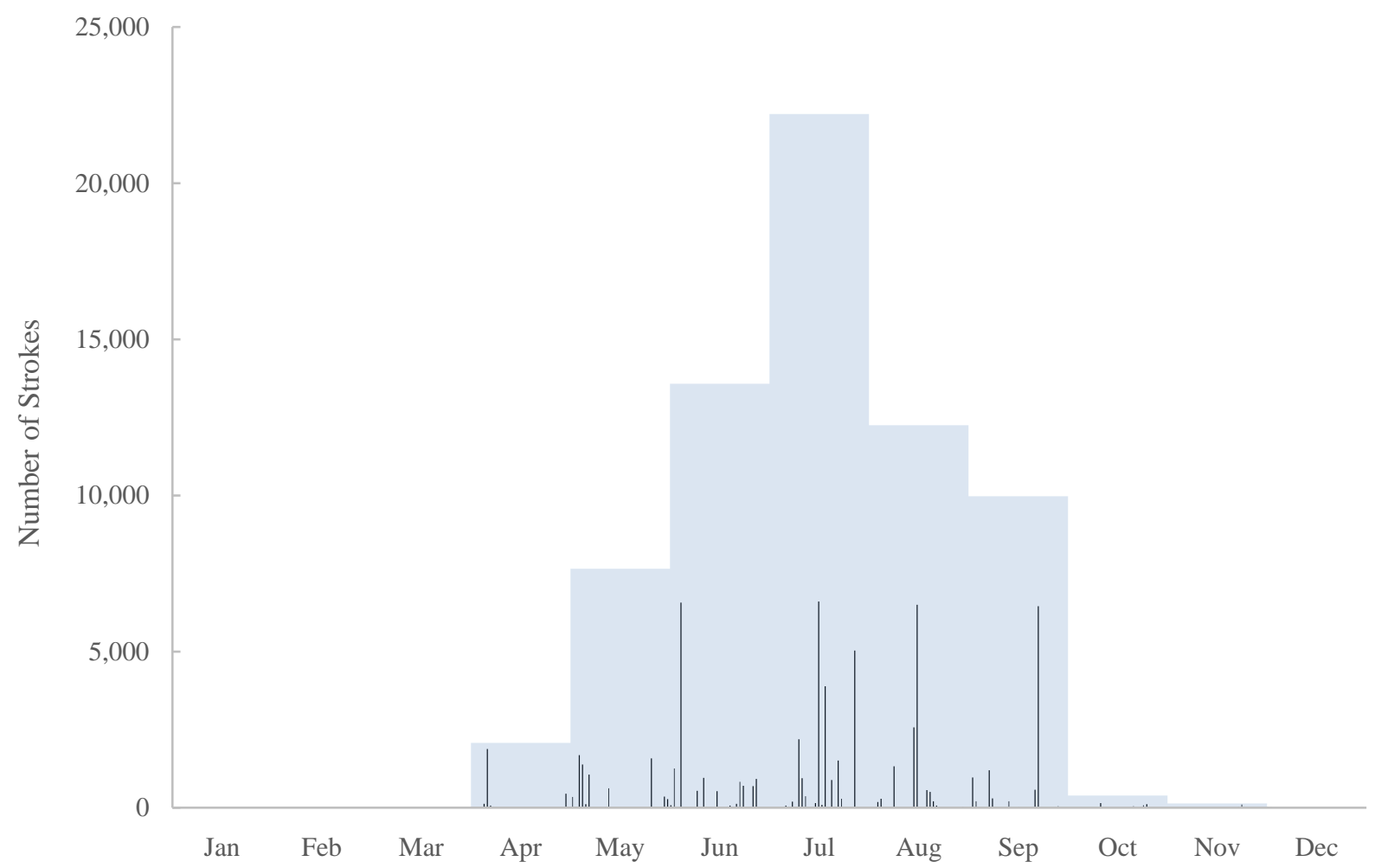

Figure 5.8 - Daily/monthly distributions of detected strokes within $100 \mathrm{~km}$ from the tower, 2010.

Table 5.8 - Monthly number of cloud-to-ground strokes and their peak current values, 2010.

\begin{tabular}{|l|l|l|l|l|l|l|l|l|}
\hline \multirow{2}{*}{ Month } & \multicolumn{2}{|l|}{ Number of strokes } & \multicolumn{2}{l|}{ Avg. peak current } & \multicolumn{2}{l|}{ Max. peak current } & \multicolumn{2}{l|}{ Min. peak current } \\
\cline { 2 - 9 } & Positive & Negative & Positive & Negative & Positive & Negative & Positive & Negative \\
\hline Jan & 0 & 0 & - & - & - & - & - & - \\
\hline Feb & 0 & 1 & - & -17.40 & - & -17.40 & - & -17.40 \\
\hline Mar & 0 & 0 & - & - & - & - & - & - \\
\hline Apr & 186 & 1,886 & 38.10 & -20.92 & 165.90 & -190.40 & 15.10 & -2.20 \\
\hline May & 705 & 6,950 & 41.83 & -15.39 & 289.00 & -162.70 & 15.00 & -1.60 \\
\hline Jun & 489 & 13,088 & 33.95 & -16.64 & 186.00 & -142.50 & 15.00 & -1.60 \\
\hline Jul & 624 & 21,590 & 31.49 & -15.23 & 252.60 & -212.30 & 15.00 & -1.60 \\
\hline Aug & 209 & 12,038 & 26.18 & -14.10 & 104.70 & -158.10 & 15.00 & -1.40 \\
\hline Sep & 307 & 9,668 & 32.23 & -15.08 & 250.30 & -252.20 & 15.00 & -1.50 \\
\hline Oct & 63 & 324 & 38.95 & -25.17 & 153.90 & -179.10 & 15.90 & -3.30 \\
\hline Nov & 49 & 86 & 60.17 & -14.84 & 208.40 & -47.00 & 15.10 & -4.00 \\
\hline Dec & 3 & 2 & 56.93 & -13.05 & 113.00 & -13.80 & 25.80 & -12.30 \\
\hline Totals & $\mathbf{2 , 6 3 5}$ & $\mathbf{6 5 , 6 3 3}$ & $\mathbf{3 5 . 5 8}$ & $\mathbf{- 1 5 . 5 1}$ & $\mathbf{2 8 9 . 0 0}$ & $\mathbf{- 2 5 2 . 2 0}$ & $\mathbf{1 5 . 0 0}$ & $\mathbf{- 1 . 4 0}$ \\
\hline
\end{tabular}




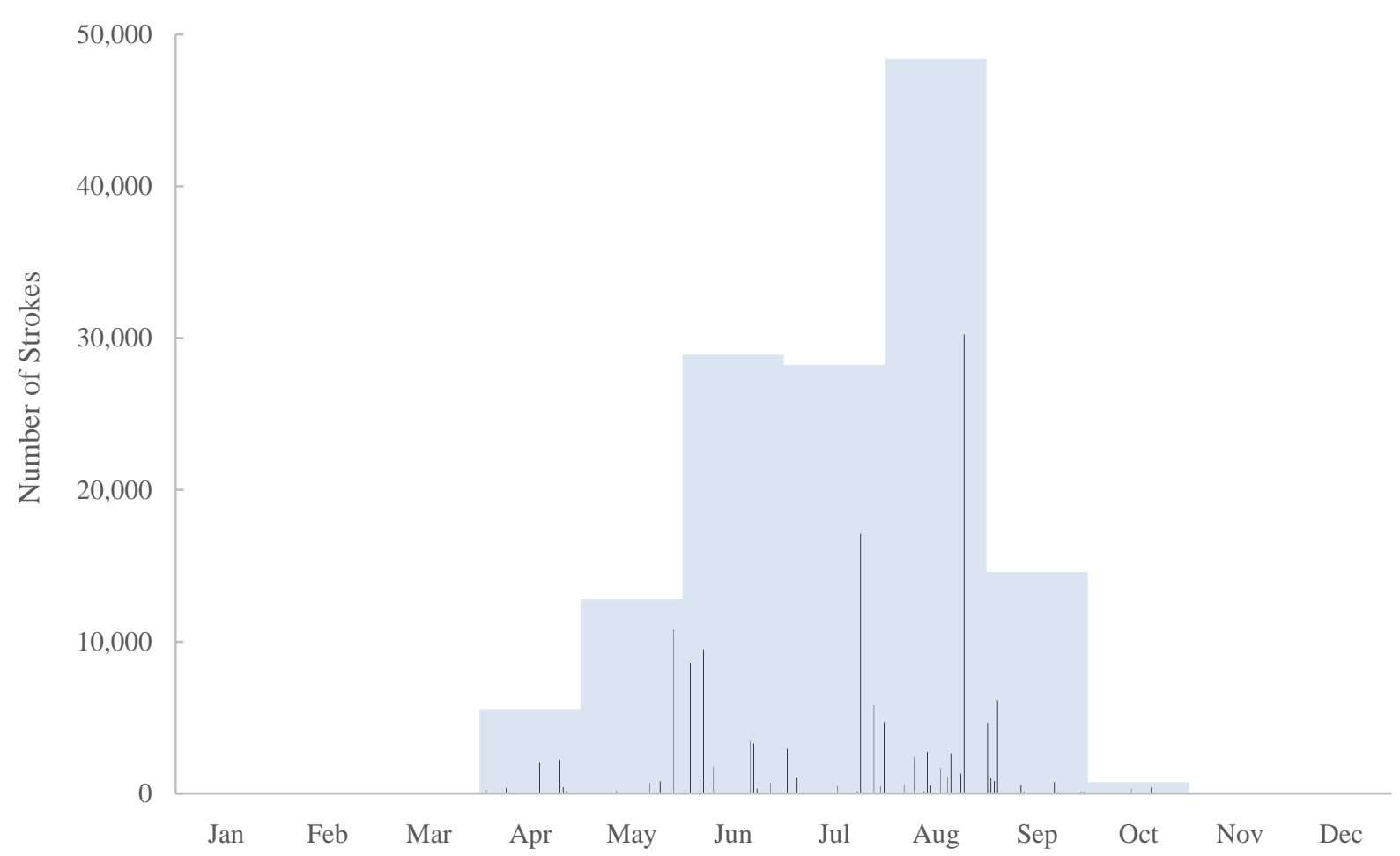

Figure 5.9 - Daily/monthly distributions of detected strokes within $100 \mathrm{~km}$ from the tower, 2011.

Table 5.9 - Monthly number of cloud-to-ground strokes and their peak current values, 2011.

\begin{tabular}{|l|l|l|l|l|l|l|l|l|}
\hline \multirow{2}{*}{ Month } & \multicolumn{2}{|l|}{ Number of strokes } & \multicolumn{2}{l|}{ Avg. peak current } & \multicolumn{2}{l|}{ Max. peak current } & \multicolumn{2}{l|}{ Min. peak current } \\
\cline { 2 - 9 } & Positive & Negative & Positive & Negative & Positive & Negative & Positive & Negative \\
\hline Jan & 6 & 1 & 73.02 & -10.50 & 118.10 & -10.50 & 19.40 & -10.50 \\
\hline Feb & 2 & 13 & 31.05 & -14.05 & 33.00 & -28.80 & 29.10 & -4.00 \\
\hline Mar & 17 & 20 & 73.67 & -18.95 & 261.80 & -42.10 & 16.20 & -2.80 \\
\hline Apr & 558 & 5,018 & 39.90 & -18.56 & 258.10 & -182.70 & 15.00 & -1.50 \\
\hline May & 632 & 12,144 & 32.87 & -18.03 & 204.80 & -179.70 & 15.00 & -1.60 \\
\hline Jun & 2220 & 26,686 & 48.11 & -14.48 & 215.50 & -165.40 & 15.00 & -1.50 \\
\hline Jul & 830 & 27,416 & 37.52 & -18.44 & 293.60 & -195.20 & 15.00 & -1.50 \\
\hline Aug & 1335 & 47,071 & 34.15 & -15.78 & 213.50 & -224.80 & 15.00 & -1.40 \\
\hline Sep & 547 & 14,039 & 34.51 & -17.47 & 131.80 & -272.00 & 15.00 & -1.60 \\
\hline Oct & 95 & 668 & 52.45 & -25.52 & 251.80 & -233.50 & 15.00 & -2.60 \\
\hline Nov & 17 & 17 & 52.43 & -14.71 & 139.90 & -40.50 & 17.60 & -4.80 \\
\hline Dec & 16 & 25 & 124.07 & -18.66 & 298.50 & -54.10 & 15.80 & -3.70 \\
\hline Totals & $\mathbf{6 , 2 7 5}$ & $\mathbf{1 3 3 , 1 1 8}$ & $\mathbf{4 0 . 6 5}$ & $\mathbf{- 1 6 . 6 1}$ & $\mathbf{2 9 8 . 5 0}$ & $\mathbf{- 2 7 2 . 0 0}$ & $\mathbf{1 5 . 0 0}$ & $\mathbf{- 1 . 4 0}$ \\
\hline
\end{tabular}




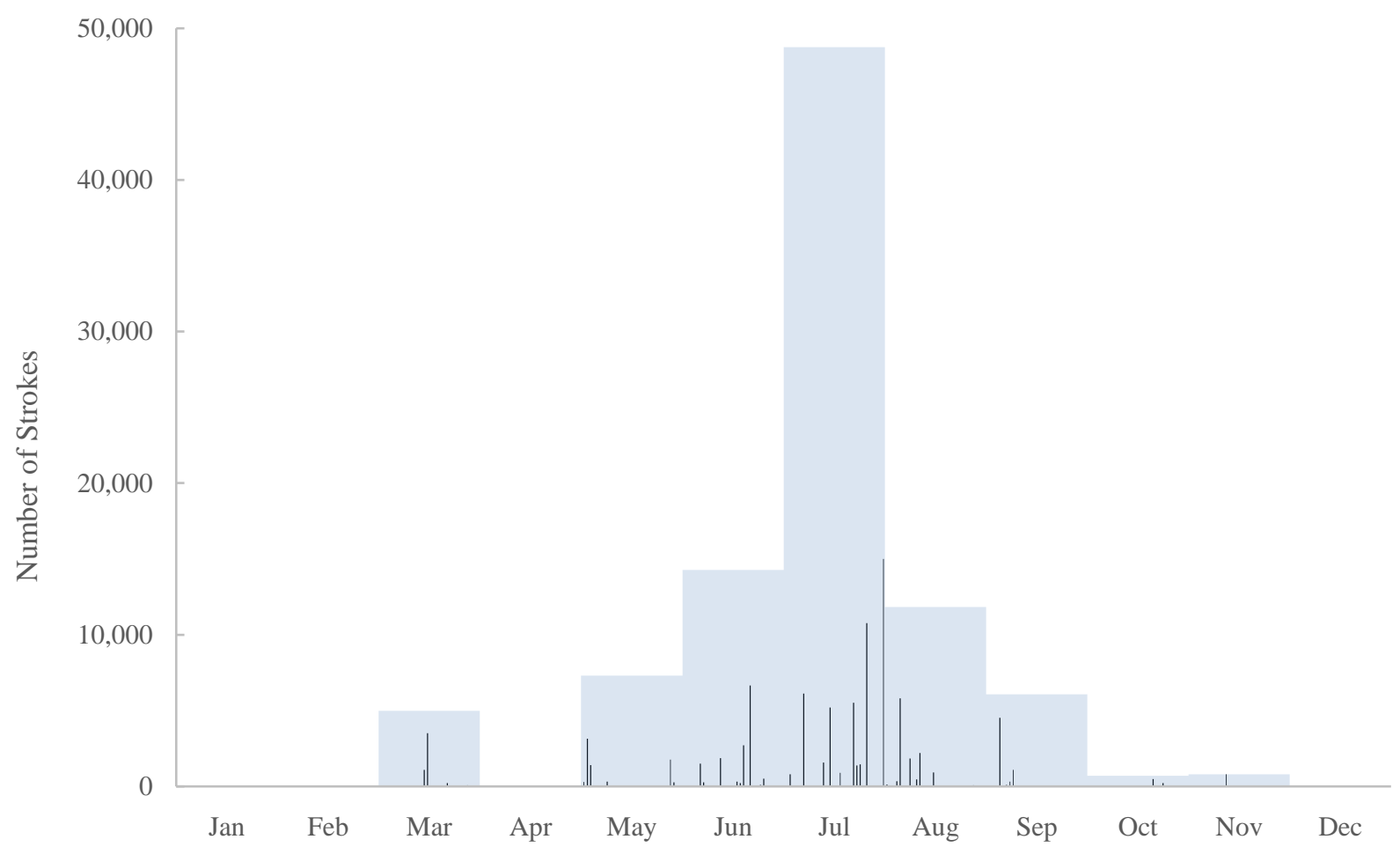

Figure 5.10 - Daily/monthly distributions of detected strokes within $100 \mathrm{~km}$ from the tower, 2012.

Table 5.10 - Monthly number of cloud-to-ground strokes and their peak current values, 2012.

\begin{tabular}{|l|l|l|l|l|l|l|l|l|}
\hline \multirow{2}{*}{ Month } & \multicolumn{2}{|l|}{ Number of strokes } & \multicolumn{2}{l|}{ Avg. peak current } & \multicolumn{2}{l|}{ Max. peak current } & \multicolumn{2}{l|}{ Min. peak current } \\
\cline { 2 - 9 } & Positive & Negative & Positive & Negative & Positive & Negative & Positive & Negative \\
\hline Jan & 0 & 0 & - & - & - & - & - & - \\
\hline Feb & 0 & 0 & - & - & - & - & - & - \\
\hline Mar & 338 & 4654 & 45.49 & -22.53 & 289.50 & -282.90 & 15.00 & -1.60 \\
\hline Apr & 2 & 13 & 32.65 & -33.32 & 45.60 & -129.00 & 19.70 & -12.40 \\
\hline May & 509 & 6,806 & 33.11 & -13.43 & 177.70 & -209.80 & 15.00 & -1.50 \\
\hline Jun & 401 & 13,868 & 34.61 & -13.89 & 216.30 & -204.50 & 15.00 & -1.50 \\
\hline Jul & 1399 & 47,348 & 34.01 & -15.37 & 171.90 & -201.70 & 15.00 & -1.40 \\
\hline Aug & 344 & 11,478 & 35.03 & -17.14 & 161.80 & -179.30 & 15.10 & -1.60 \\
\hline Sep & 406 & 5,660 & 33.59 & -21.66 & 244.30 & -291.40 & 15.10 & -1.60 \\
\hline Oct & 28 & 679 & 36.89 & -18.16 & 90.50 & -263.60 & 15.20 & -1.90 \\
\hline Nov & 50 & 749 & 33.80 & -35.41 & 304.20 & -228.20 & 15.70 & -1.60 \\
\hline Dec & 0 & 0 & - & - & - & - & - & - \\
\hline Totals & $\mathbf{3 , 4 7 7}$ & $\mathbf{9 1 , 2 5 5}$ & $\mathbf{3 5 . 1 4}$ & $\mathbf{- 1 6 . 1 6}$ & $\mathbf{3 0 4 . 2 0}$ & $\mathbf{- 2 9 1 . 4 0}$ & $\mathbf{1 5 . 0 0}$ & $\mathbf{- 1 . 4 0}$ \\
\hline
\end{tabular}




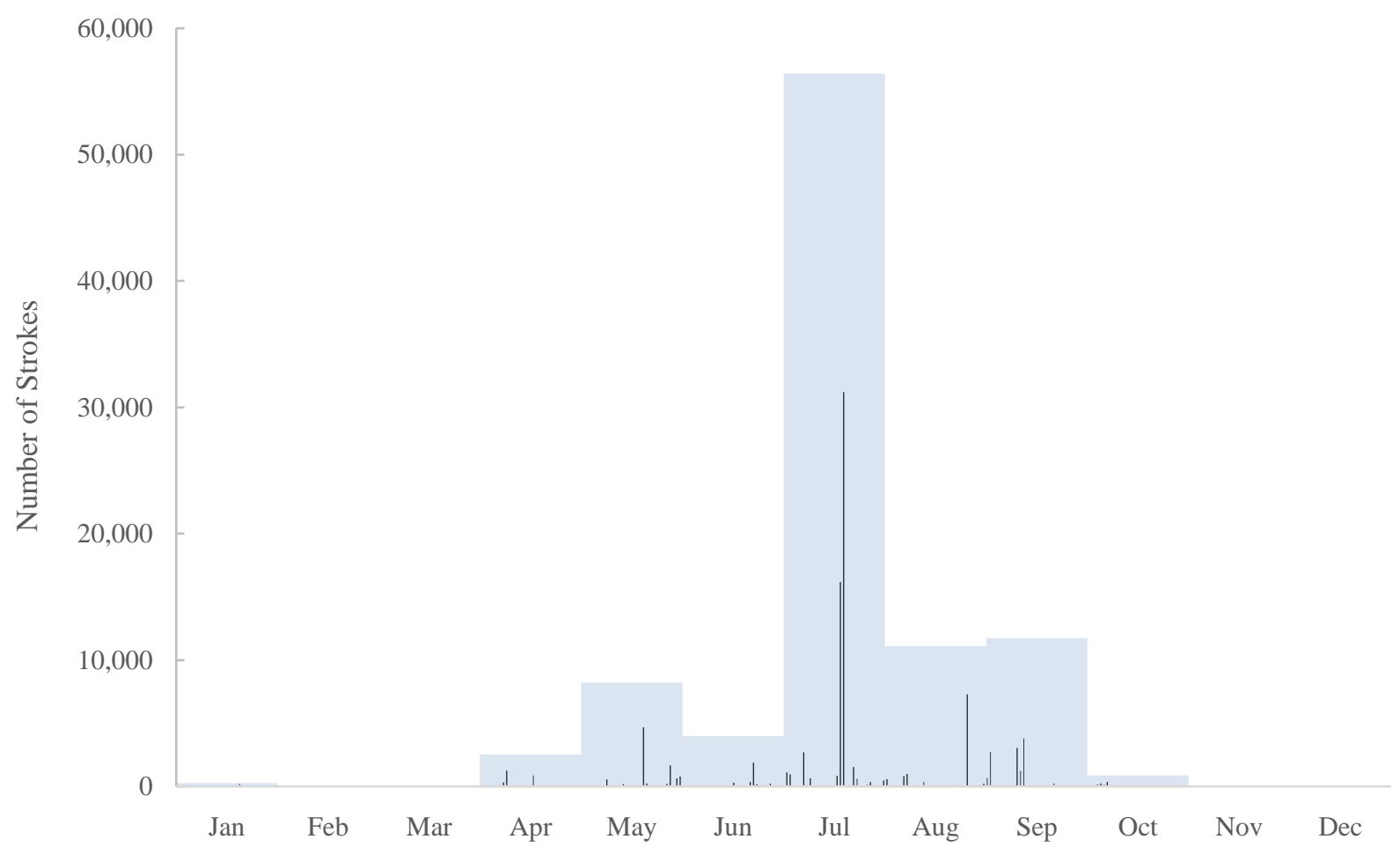

Figure 5.11 - Daily/monthly distributions of detected strokes within $100 \mathrm{~km}$ from the tower, 2013.

Table 5.11 - Monthly number of cloud-to-ground strokes and their peak current values, 2013.

\begin{tabular}{|l|l|l|l|l|l|l|l|l|}
\hline \multirow{2}{*}{ Month } & \multicolumn{2}{|l|}{ Number of strokes } & \multicolumn{2}{l|}{ Avg. peak current } & \multicolumn{2}{l|}{ Max. peak current } & \multicolumn{2}{l|}{ Min. peak current } \\
\cline { 2 - 10 } & Positive & Negative & Positive & Negative & Positive & Negative & Positive & Negative \\
\hline Jan & 8 & 245 & 45.06 & -19.04 & 100.80 & -102.70 & 17.00 & -3.60 \\
\hline Feb & 0 & 0 & - & - & - & - & - & - \\
\hline Mar & 0 & 0 & - & - & - & - & - & - \\
\hline Apr & 302 & 2,221 & 55.74 & -19.10 & 354.60 & -152.10 & 15.10 & -2.00 \\
\hline May & 832 & 7,391 & 31.17 & -16.40 & 226.10 & -221.40 & 15.00 & -2.00 \\
\hline Jun & 196 & 3,769 & 39.61 & -16.28 & 213.20 & -151.90 & 15.00 & -1.40 \\
\hline Jul & 1135 & 55,291 & 28.26 & -15.44 & 186.30 & -194.40 & 15.00 & -1.00 \\
\hline Aug & 621 & 10,464 & 38.74 & -19.17 & 253.90 & -222.90 & 15.10 & -1.20 \\
\hline Sep & 594 & 11,152 & 32.70 & -15.14 & 166.10 & -204.80 & 15.00 & -1.20 \\
\hline Oct & 91 & $\mathbf{7 7 9}$ & 34.95 & -20.89 & 87.50 & -212.80 & 15.10 & -2.00 \\
\hline Nov & 2 & 8 & 17.70 & -7.50 & 19.20 & -12.50 & 16.20 & -5.40 \\
\hline Dec & 2 & 1 & 49.70 & -6.70 & 56.60 & -6.70 & 42.80 & -6.70 \\
\hline Totals & $\mathbf{3 , 7 8 3}$ & $\mathbf{9 1 , 3 2 1}$ & $\mathbf{3 4 . 3 0}$ & $\mathbf{- 1 6 . 0 9}$ & $\mathbf{3 5 4 . 6 0}$ & $\mathbf{- 2 2 2 . 9 0}$ & $\mathbf{1 5 . 0 0}$ & $\mathbf{- 1 . 0 0}$ \\
\hline
\end{tabular}


Figure 5.12 displays the combined daily and monthly stroke distribution for the about mentioned 11 year. As shown in the figure, it's safe to say that the highest lightning activities take place during the summer months of each year. July, August and June are the three most active months, lightning-activity wise, during the year. Followed with May, September and April with much less lightning activity in the 100-km area around the CN Tower. The three months of Winter, December, January and February, are the least to have lightning activity since the combined number of strokes detected in winter represents less than $1 \%$ of all strokes detected during the year. Therefore, it is possible to say that winter season is the safest period for any maintenance work of sensitive installations such as; electric power lines and large industrial plants.

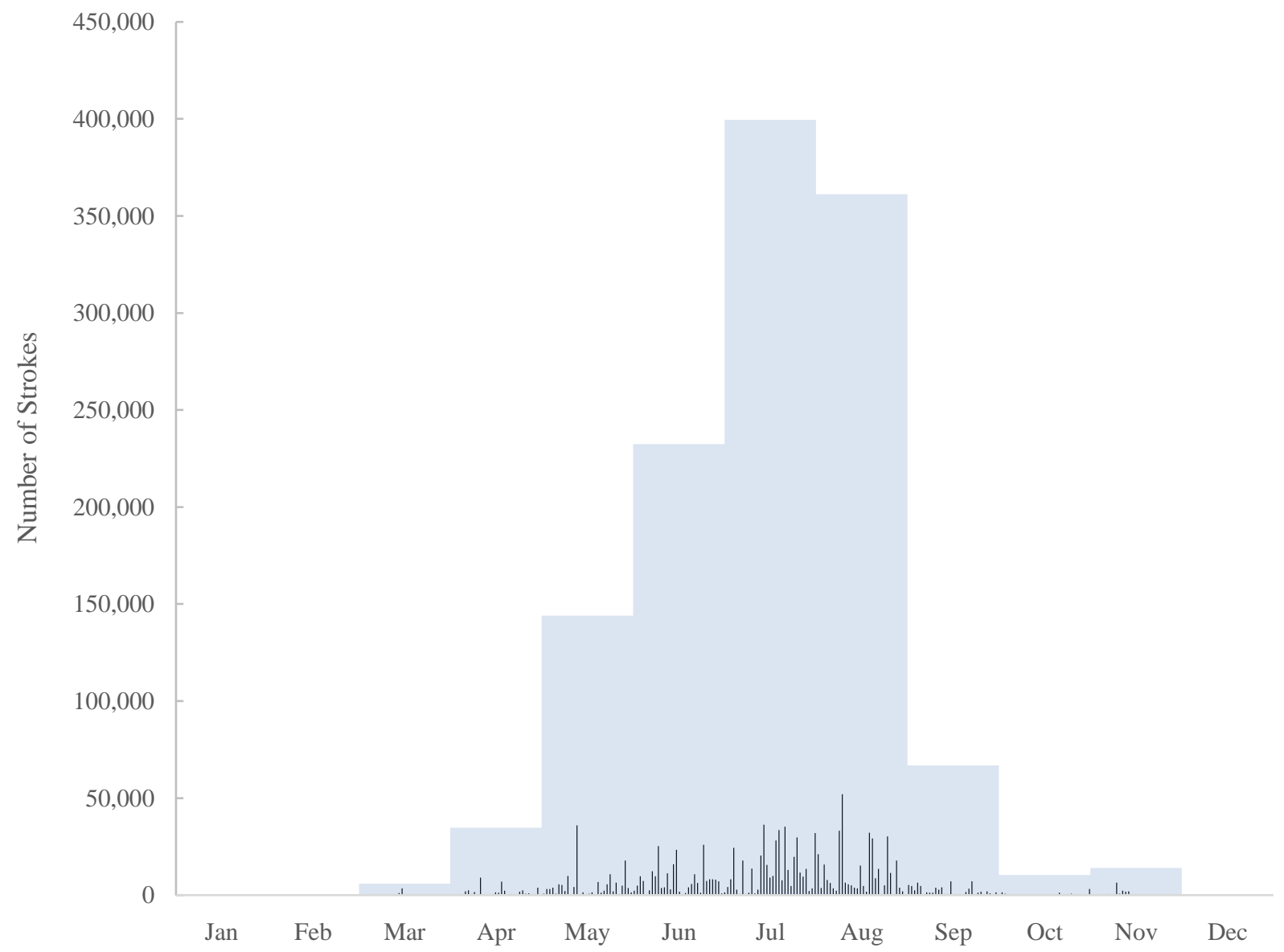

Figure 5.12 - The 11-year combined daily/monthly distribution of detected strokes within 100 $\mathrm{km}$ from the tower. 
Moreover, the total number of strokes detected each year is presented in Table 5.12. On average, the month with the highest number of detected strokes represents about $44 \%$ of the overall yearly detected lightning strokes. And the highest day represents an average of $20 \%$ of the yearly detected strokes and $48 \%$ of the monthly detected strokes. These numbers are graphically represented in Fig. 5.13, showing the highest and lowest number of detected strokes each year.

Table 5.12 - Total number of strokes for each year

\begin{tabular}{|c|c|c|c|c|c|c|c|c|}
\hline \multirow{2}{*}{ Year } & \multirow{2}{*}{$\begin{array}{c}\text { Total } \\
\text { number } \\
\text { of strokes }\end{array}$} & \multirow{2}{*}{$\begin{array}{l}\text { Month with } \\
\text { highest } \\
\text { number of } \\
\text { strokes }\end{array}$} & \multirow{2}{*}{$\begin{array}{l}\text { Day with } \\
\text { highest } \\
\text { number } \\
\text { of strokes }\end{array}$} & \multicolumn{2}{|c|}{$\begin{array}{l}\text { Highest number of } \\
\text { strokes detected in } \\
\text { a month }\end{array}$} & \multicolumn{3}{|c|}{$\begin{array}{c}\text { Highest number of strokes } \\
\text { detected on a day }\end{array}$} \\
\hline & & & & & $\begin{array}{c}\% \text { of the } \\
\text { year }\end{array}$ & & $\begin{array}{l}\% \text { of the } \\
\text { month }\end{array}$ & $\begin{array}{c}\% \text { of the } \\
\text { year }\end{array}$ \\
\hline 2000 & 142,322 & May & May $13^{\text {th }}$ & 48,934 & $34.4 \%$ & 34,757 & $71.0 \%$ & $24.4 \%$ \\
\hline 2001 & 48,873 & August & Aug. $28^{\text {th }}$ & 15,447 & $31.6 \%$ & 9,694 & $62.8 \%$ & $19.8 \%$ \\
\hline 2002 & 117,790 & July & July $22^{\text {nd }}$ & 50,913 & $43.2 \%$ & 30,539 & $60.0 \%$ & $25.9 \%$ \\
\hline 2003 & 68,844 & August & Aug. $22^{\text {nd }}$ & 38,913 & $56.5 \%$ & 12,741 & $32.7 \%$ & $18.5 \%$ \\
\hline 2004 & 136,283 & July & July $14^{\text {th }}$ & 65,757 & $48.2 \%$ & 22,416 & $34.1 \%$ & $16.4 \%$ \\
\hline 2005 & 182,348 & August & Aug. $19^{\text {th }}$ & 61,988 & $34.0 \%$ & 31,157 & $50.3 \%$ & $17.1 \%$ \\
\hline 2009 & 176,042 & August & Aug. $10^{\text {th }}$ & 107,747 & $61.2 \%$ & 36,846 & $34.2 \%$ & $20.9 \%$ \\
\hline 2010 & 68,268 & July & July $17^{\text {th }}$ & 22,214 & $32.5 \%$ & 6,603 & $29.7 \%$ & $9.7 \%$ \\
\hline 2011 & 139,393 & August & Aug. $24^{\text {th }}$ & 48,406 & $34.7 \%$ & 30,247 & $62.5 \%$ & $21.7 \%$ \\
\hline 2012 & 94,732 & July & July $31^{\text {st }}$ & 48,747 & $51.5 \%$ & 15,005 & $30.8 \%$ & $15.8 \%$ \\
\hline 2013 & 95,104 & July & July $20^{\text {th }}$ & 56,426 & $59.3 \%$ & 31,215 & $55.3 \%$ & $32.8 \%$ \\
\hline
\end{tabular}

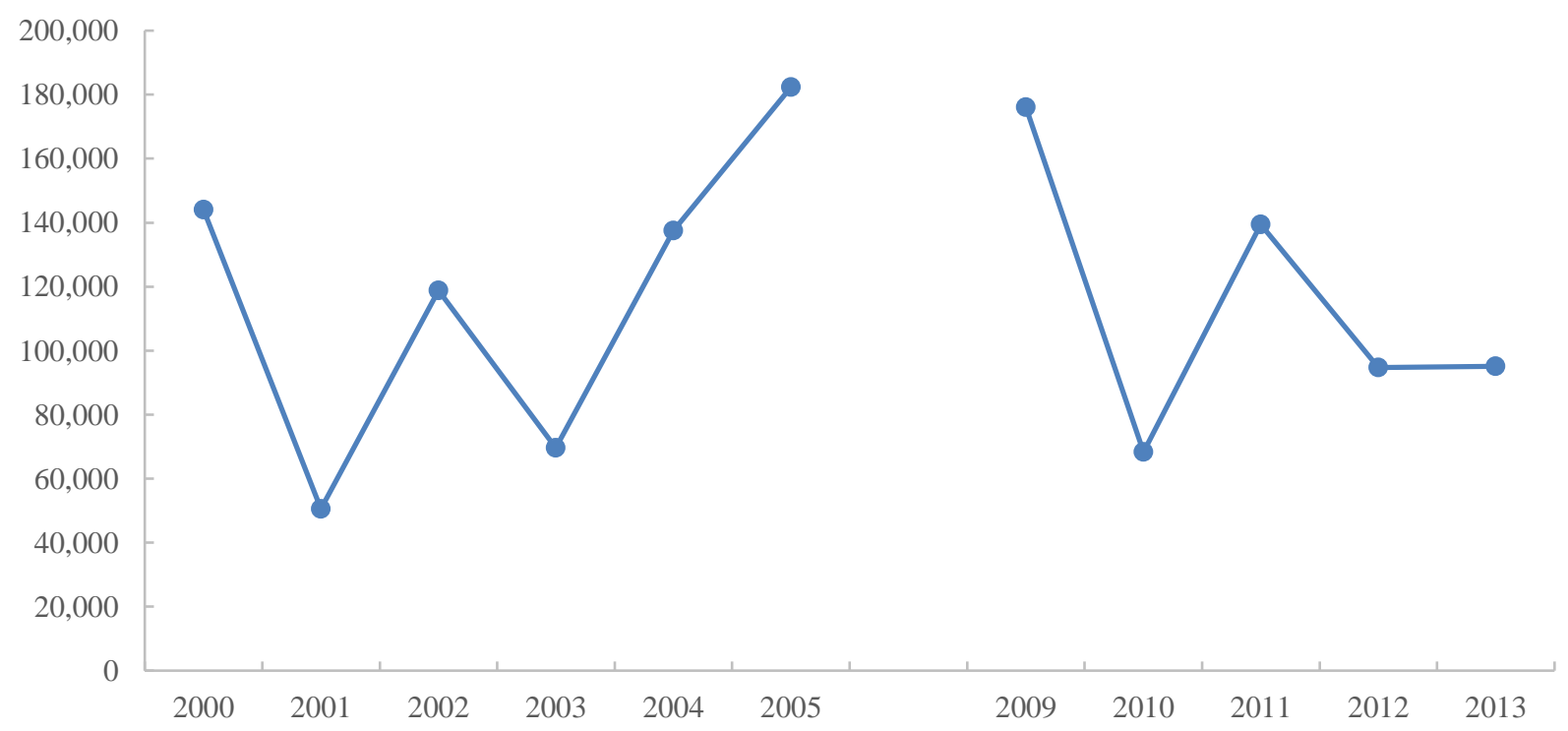

Figure 5.13 - NALDN-detected strokes within $100 \mathrm{~km}$ from the CN Tower in each year. 


\subsection{Peak Currents of Positive and Negative Strokes}

The total number of strokes detected each year has been divided based on their polarity and is shown in Table 5.13. The table also shows the percentage of both positive and negative strokes per year. Overall, the positive strokes account for an average of only $5 \%$ of all strokes detected per year, while the negative strokes account for the remaining $95 \%$.

Table 5.13 - Total number of positive and negative strokes and their percentage per year.

\begin{tabular}{|l|l|l|l|l|}
\hline \multirow{2}{*}{ Year } & \multicolumn{2}{|c|}{ Positive } & \multicolumn{2}{c|}{ Negative } \\
\cline { 2 - 5 } & Total Number & Percentage & Total Number & Percentage \\
\hline 2000 & 8,921 & $6.3 \%$ & 133,401 & $93.7 \%$ \\
\hline 2001 & 2,903 & $5.9 \%$ & 45,970 & $94.1 \%$ \\
\hline 2002 & 3,694 & $3.1 \%$ & 114,096 & $96.9 \%$ \\
\hline 2003 & 4,557 & $6.6 \%$ & 64,287 & $93.4 \%$ \\
\hline 2004 & 7,227 & $5.3 \%$ & 129,056 & $94.7 \%$ \\
\hline 2005 & 13,004 & $7.1 \%$ & 169,344 & $92.9 \%$ \\
\hline 2009 & 4,195 & $2.4 \%$ & 171,847 & $97.6 \%$ \\
\hline 2010 & 2,635 & $3.9 \%$ & 65,633 & $96.1 \%$ \\
\hline 2011 & 6,275 & $4.5 \%$ & 133,118 & $95.5 \%$ \\
\hline 2012 & 3,477 & $3.7 \%$ & 91,255 & $96.3 \%$ \\
\hline 2013 & 3,783 & $4.0 \%$ & 91,321 & $96.0 \%$ \\
\hline
\end{tabular}

Furthermore, the return-stroke estimated peak currents are displayed in Table 5.14. Overall, the average positive peak values showed $66 \%$ higher than that of the negative strokes. While max positive peak values are $29.5 \%$ higher than that of the negative strokes.

Table 5.14 - Summary of the total number of positive and negative strokes detected by NALDN per year along with the average, maximum and minimum values of their estimated peak current.

\begin{tabular}{|l|l|l|l|l|l|l|l|l|}
\hline & \multicolumn{2}{l}{ Number of strokes } & \multicolumn{2}{l}{ Avg. peak current } & \multicolumn{2}{l|}{ Max. peak current } & \multicolumn{2}{l|}{ Min. peak current } \\
\cline { 2 - 10 } & Positive & Negative & Positive & Negative & Positive & Negative & Positive & Negative \\
\hline 2000 & 8,921 & 133,401 & 25.72 & -20.42 & 283.30 & -229.80 & 0.10 & -2.60 \\
\hline 2001 & 2,903 & 45,970 & 30.06 & -20.91 & 328.20 & -179.50 & 0.10 & -4.80 \\
\hline 2002 & 3,694 & 114,096 & 25.75 & -19.11 & 285.10 & -155.20 & 0.30 & -4.10 \\
\hline 2003 & 4,557 & 64,287 & 23.40 & -16.16 & 260.90 & -181.00 & 3.40 & -3.30 \\
\hline 2004 & 7,227 & 129,056 & 20.15 & -17.43 & 232.10 & -289.80 & 3.60 & -3.30 \\
\hline 2005 & 13,004 & 169,344 & 14.48 & -17.55 & 262.70 & -208.40 & 3.30 & -2.90 \\
\hline 2009 & 4,195 & 171,847 & 31.83 & -15.39 & 344.40 & -222.10 & 15.00 & -1.40 \\
\hline 2010 & 2,635 & 65,633 & 35.58 & -15.51 & 289.00 & -252.20 & 15.00 & -1.40 \\
\hline 2011 & 6,275 & 133,118 & 40.65 & -16.61 & 298.50 & -272.00 & 15.00 & -1.40 \\
\hline 2012 & 3,477 & 91,255 & 35.14 & -16.16 & 304.20 & -291.40 & 15.00 & -1.40 \\
\hline 2013 & 3,783 & 91,321 & 34.30 & -16.09 & 354.60 & -222.90 & 15.00 & -1.00 \\
\hline
\end{tabular}




\subsection{Flash Multiplicity}

The multiplicity of lightning flashes detected by the NALDN, within $100 \mathrm{~km}$ from the CN Tower, over six years (2005 and 2009-2013) varies between 1 and 15. The majority of flashes contain a single return stroke each, which represent $53 \%$ of all flashes. Table 5.15 shows the percentage of flashes with different multiplicities ranging from 1 to 15 over the considered six years. The average flash multiplicities for each year are displayed in Table 5.16, the overall average flash multiplicity is found to be 2.39 .

Additionally, the number of flashes versus flash multiplicity for the six years is shown in Fig. 5.14. The number of flashes decrease exponentially as the multiplicity increases, as shown in the figure. Flashes with multiplicity equals to 10 or higher represent less than $1 \%$ each.

Table 5.15 - Percentage of flashes with different multiplicities over six years.

\begin{tabular}{|l|l|l|l|l|l|l|}
\hline Multiplicity & 2005 & 2009 & 2010 & 2011 & 2012 & 2013 \\
\hline 1 & $51.68 \%$ & $51.70 \%$ & $53.06 \%$ & $54.55 \%$ & $54.21 \%$ & $56.36 \%$ \\
\hline 2 & $17.55 \%$ & $16.67 \%$ & $18.52 \%$ & $16.73 \%$ & $16.24 \%$ & $15.68 \%$ \\
\hline 3 & $9.70 \%$ & $9.23 \%$ & $9.78 \%$ & $8.75 \%$ & $9.61 \%$ & $8.81 \%$ \\
\hline 4 & $6.38 \%$ & $6.11 \%$ & $5.81 \%$ & $5.63 \%$ & $6.27 \%$ & $5.80 \%$ \\
\hline 5 & $4.64 \%$ & $4.45 \%$ & $4.08 \%$ & $4.03 \%$ & $4.22 \%$ & $4.15 \%$ \\
\hline 6 & $3.24 \%$ & $3.41 \%$ & $3.00 \%$ & $2.96 \%$ & $3.07 \%$ & $2.83 \%$ \\
\hline 7 & $2.35 \%$ & $2.54 \%$ & $1.93 \%$ & $2.15 \%$ & $2.16 \%$ & $2.08 \%$ \\
\hline 8 & $1.60 \%$ & $1.88 \%$ & $1.32 \%$ & $1.62 \%$ & $1.54 \%$ & $1.47 \%$ \\
\hline 9 & $1.07 \%$ & $1.34 \%$ & $1.00 \%$ & $1.16 \%$ & $1.01 \%$ & $1.04 \%$ \\
\hline 10 & $0.67 \%$ & $0.99 \%$ & $0.59 \%$ & $0.84 \%$ & $0.64 \%$ & $0.76 \%$ \\
\hline 11 & $0.48 \%$ & $0.65 \%$ & $0.32 \%$ & $0.58 \%$ & $0.40 \%$ & $0.43 \%$ \\
\hline 12 & $0.26 \%$ & $0.39 \%$ & $0.23 \%$ & $0.40 \%$ & $0.28 \%$ & $0.27 \%$ \\
\hline 13 & $0.17 \%$ & $0.27 \%$ & $0.18 \%$ & $0.23 \%$ & $0.14 \%$ & $0.18 \%$ \\
\hline 14 & $0.10 \%$ & $0.16 \%$ & $0.09 \%$ & $0.15 \%$ & $0.10 \%$ & $0.07 \%$ \\
\hline 15 & $0.10 \%$ & $0.20 \%$ & $0.08 \%$ & $0.24 \%$ & $0.10 \%$ & $0.09 \%$ \\
\hline
\end{tabular}


Table 5.16 - Average flash multiplicity per year.

\begin{tabular}{|l|l|}
\hline & Average Flash Multiplicity \\
\hline 2005 & 2.43 \\
\hline 2009 & 2.55 \\
\hline 2010 & 2.31 \\
\hline 2011 & 2.41 \\
\hline 2012 & 2.35 \\
\hline 2013 & 2.31 \\
\hline
\end{tabular}

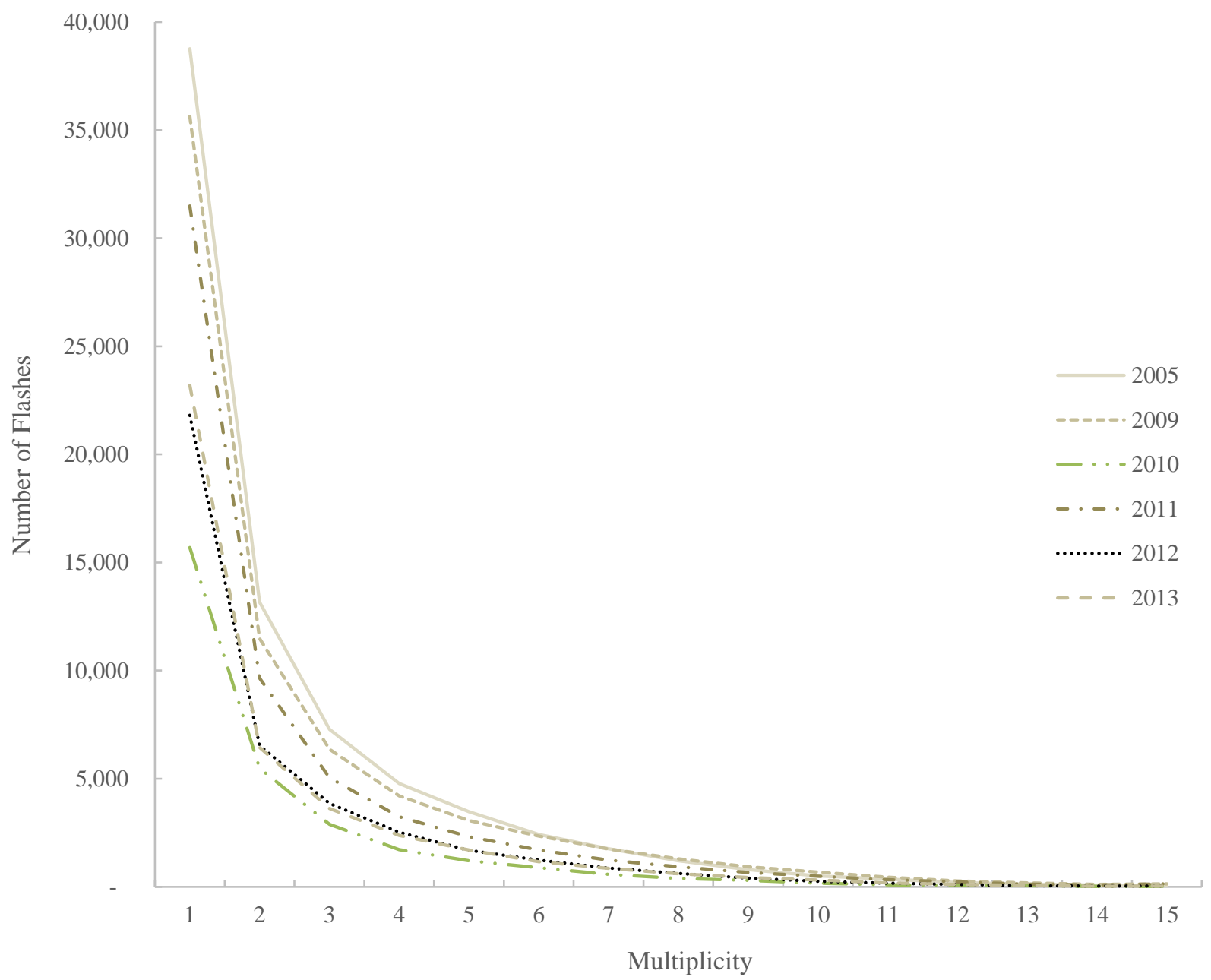

Figure 5.14 - Number of flashes versus flash multiplicity for different years. 


\subsection{Flash and Strokes Densities}

The 100-km area around the CN Tower corresponds to $31,415.93 \mathrm{~km}^{2}$. Flash and stroke densities area calculated in Table 5.17. Flash density was not available for years 2000-2004, and it ranged between 0.94 and 2.38 for the remaining 6 years $(2005,2009-2013)$. Stroke density, on the other hand, ranged between 1.56 and 5.8. Year 2005 had the largest number of detected flashes and strokes, and hence highest flash and stroke densities. Stroke density for each year is graphically represented in Fig. 5.15, where the overall average stroke density is 3.7 strokes per square kilometer.

Table 5.17 - Flash and stroke densities each year based on an area of $31,415.93 \mathrm{~km}^{2}$

\begin{tabular}{|l|l|l|l|l|}
\hline \multicolumn{1}{|c|}{ Year } & \multicolumn{1}{|c|}{ Flashes } & \multicolumn{1}{c|}{ Strokes } & \multicolumn{1}{c|}{ Flash Density } & \multicolumn{1}{c|}{ Stroke Density } \\
\hline 2000 & N/A & 142,322 & N/A & 4.53 \\
\hline 2001 & N/A & 48,873 & N/A & 1.56 \\
\hline 2002 & N/A & 117,790 & N/A & 3.75 \\
\hline 2003 & N/A & 68,844 & N/A & 2.19 \\
\hline 2004 & N/A & 136,283 & N/A & 4.34 \\
\hline 2005 & 74,999 & 182,348 & 2.38 & 5.80 \\
\hline 2009 & 68,938 & 176,042 & 2.19 & 5.60 \\
\hline 2010 & 29,576 & 68,268 & 0.94 & 2.17 \\
\hline 2011 & 57,733 & 139,393 & 1.84 & 4.44 \\
\hline 2012 & 40,234 & 94,732 & 1.28 & 3.02 \\
\hline 2013 & 41,167 & 95,104 & 1.31 & 3.03 \\
\hline
\end{tabular}




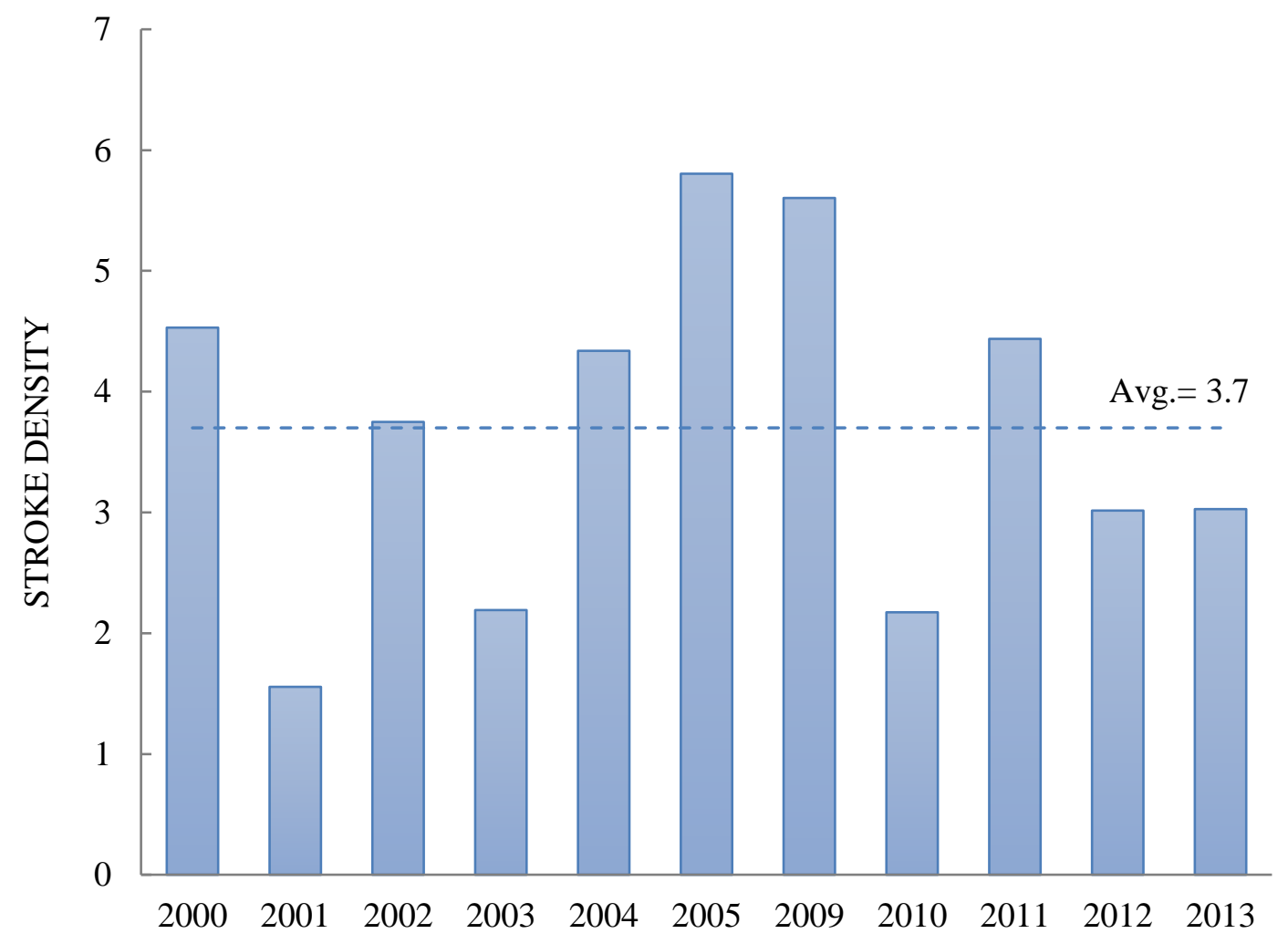

Figure 5.15 - Yearly stroke density per year within $100 \mathrm{~km}$ from the tower, including CN tower strokes.

\subsection{Stroke locations and Density}

Stroke locations provided by the NALDN for the area of up to $100 \mathrm{~km}$ around the CN Tower for the entire years of 2005 and 2011, separately, are presented in Figs. 5.16 and 5.17, respectively. Where the $\mathrm{CN}$ Tower is placed at the center and the blue drawing outlines the lakes in this area (Lake Simcoe to the north, and Lake Ontario south of the tower). The areas with higher density of return strokes are easily noticed from the two figures. In 2005 (Fig. 5.16), the area northwest from the tower, as well as the southeast area, have substantially higher density than the remaining areas. On the other hand, in 2011 (Fig. 5.17), it is noticed that the area west of Lake Simcoe as well as the middle of Lake Ontario, have less lightning strokes density.

This information, if extended to many years, will give a very useful visual representation of lightning activities through the years. Which would be fundamental to the federal and 
municipal governments when planning for new communities and projects. Accordingly, lightning prone areas could be avoided when building sensitive installations, such as; power lines, industrial buildings, and airports.

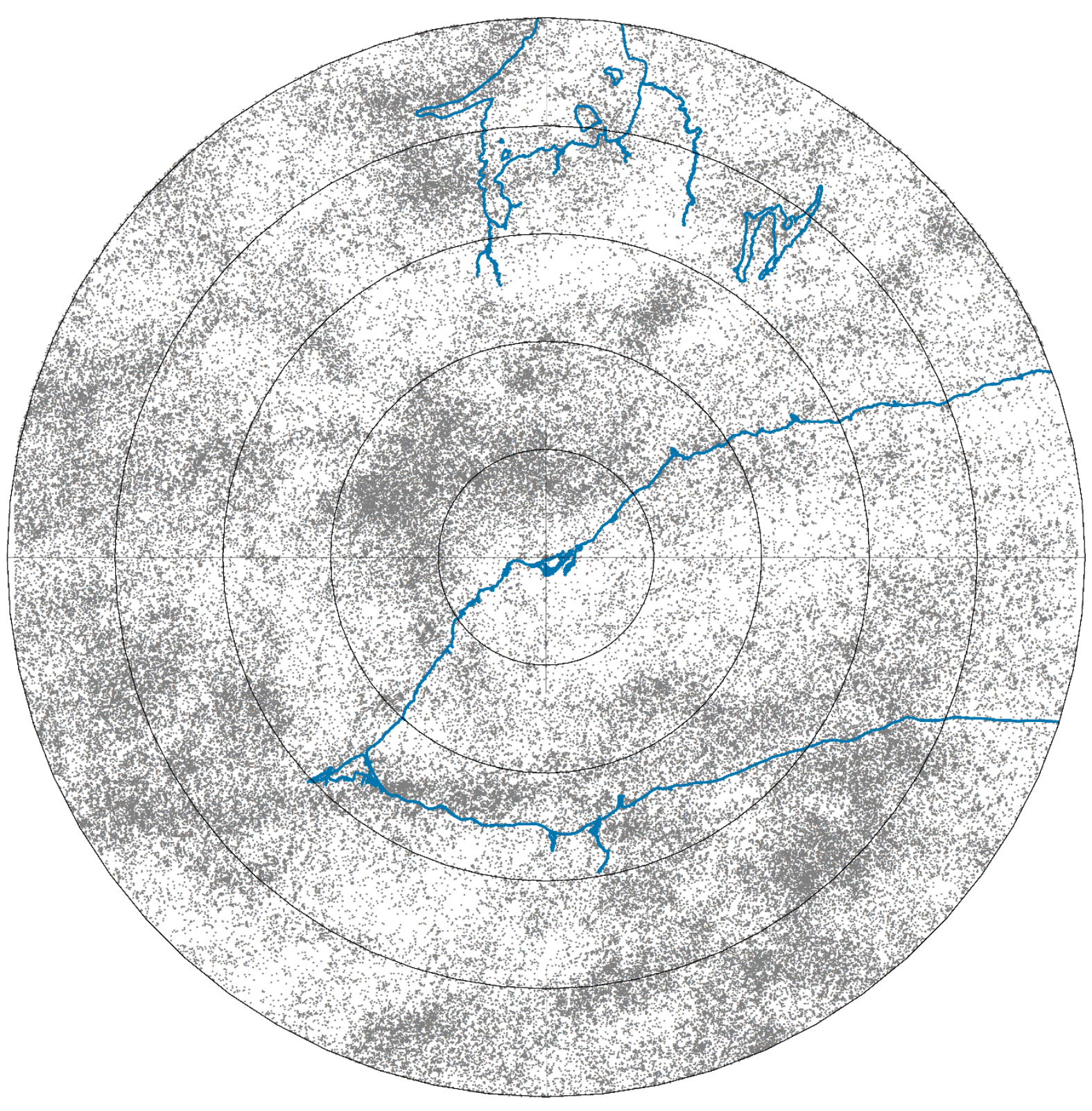

Figure 5.16 - Stroke locations within $100 \mathrm{~km}$ (20-km grid) from the CN Tower during 2005. 


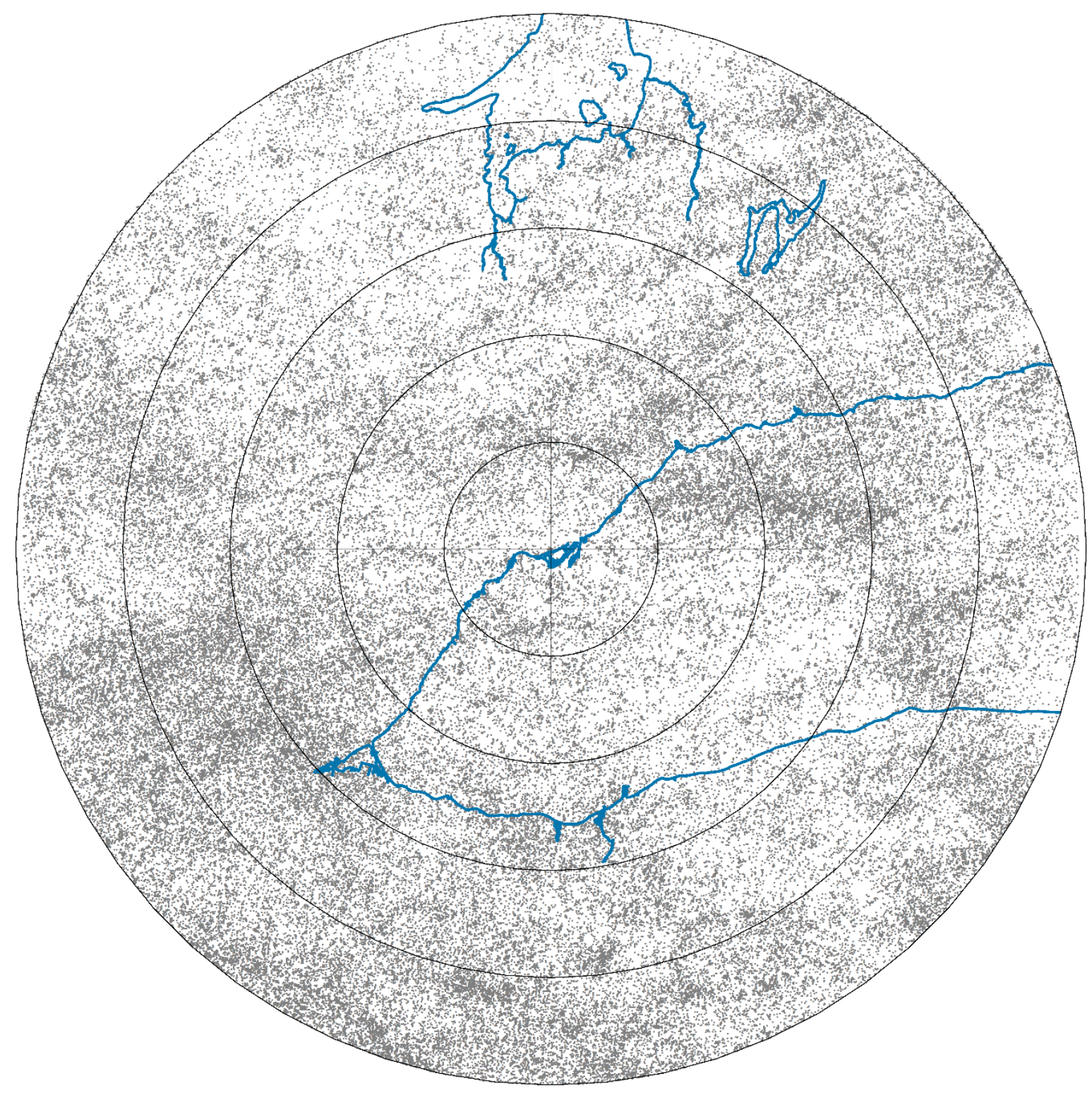

Figure 5.17 - Stroke locations within $100 \mathrm{~km}$ (20-km grid) from the CN Tower during 2011. 


\section{Chapter 6}

\section{Major Storms at the CN Tower}

In this chapter, major storms are defined as storms with the largest number of direct lightning strikes to the $\mathrm{CN}$ Tower and the largest number of strokes detected in one day. The $\mathrm{CN}$ Tower return strokes are detected by the current derivative measurement system, as discussed in chapter 4. These CN Tower strokes are matched with those detected by the NALDN network. The first major storm discussed in this chapter occurred on August 19, 2005, and the second one took place on August 24, 2011. During the first major storm, the tower was struck with 6 flashes, containing 38 return strokes, within 90 minutes, whereas during the second major storm the tower was hit with 52 flashes, containing 161 return strokes, within 84 minutes and 6.9 seconds.

This chapter focuses on analyzing NALDN detected lightning strokes and flashes in the vicinity of the $\mathrm{CN}$ Tower during two major storms. The lightning parameters addressed here are: the time distribution (monthly, daily and minutely) of strokes, stroke location and density, flash multiplicity and density, polarity, and peak current estimate. 


\subsection{CN Tower Major Storm}

In 2005, within $100 \mathrm{~km}$ from the tower, NALDN detected 74,999 lightning flashes, containing 182,348 strokes, resulting in a flash multiplicity of 2.43. Based on these data, the densities of flashes and strokes per square kilometers are found to be: 2.38 and 5.80, respectively.

A major lightning storm took place on August 19, 2005. Within $100 \mathrm{~km}$ from the CN Tower, the NALDN network detected 31,157 lightning strokes, which translates to $50.3 \%$ of the total strokes detected in that month (August 2005) and 17.1\% of those detected in the entire year. The strokes distribution over the whole year is shown previously in Fig. 5.6, where August 19, 2005 is noticed to have the highest number of strokes detected in one day.

The lightning environment in the vicinity of the CN Tower during the 2005 storm is presented in the following subsections. It is important to note that during this storm, the returnstroke current derivative data was recorded by the LeCroy LT342L digitizer and the old Rogowski coil. The GPS system was also operational, providing time stamps with $1 \mu$ s resolution [27].

\subsubsection{Stroke Locations}

The NALDN raw stroke location data comes as coordinates of latitude and longitude in degrees. This data has been translated into distance measured in kilometers and azimuth angles in degrees with respect to the coordinates of the CN Tower, as per the Canadian Spatial Reference System. Figure 6.1 displays the locations of the 31,157 lightning strokes detected by the NALDN during August 19, 2005 within $100 \mathrm{~km}$ from the CN Tower, where the CN Tower is located at its center. The areas enclosed by blue lines outline the location of lakes, including Lake Ontario (mainly south-east of the tower) and Lake Simcoe (mostly north of the tower). 


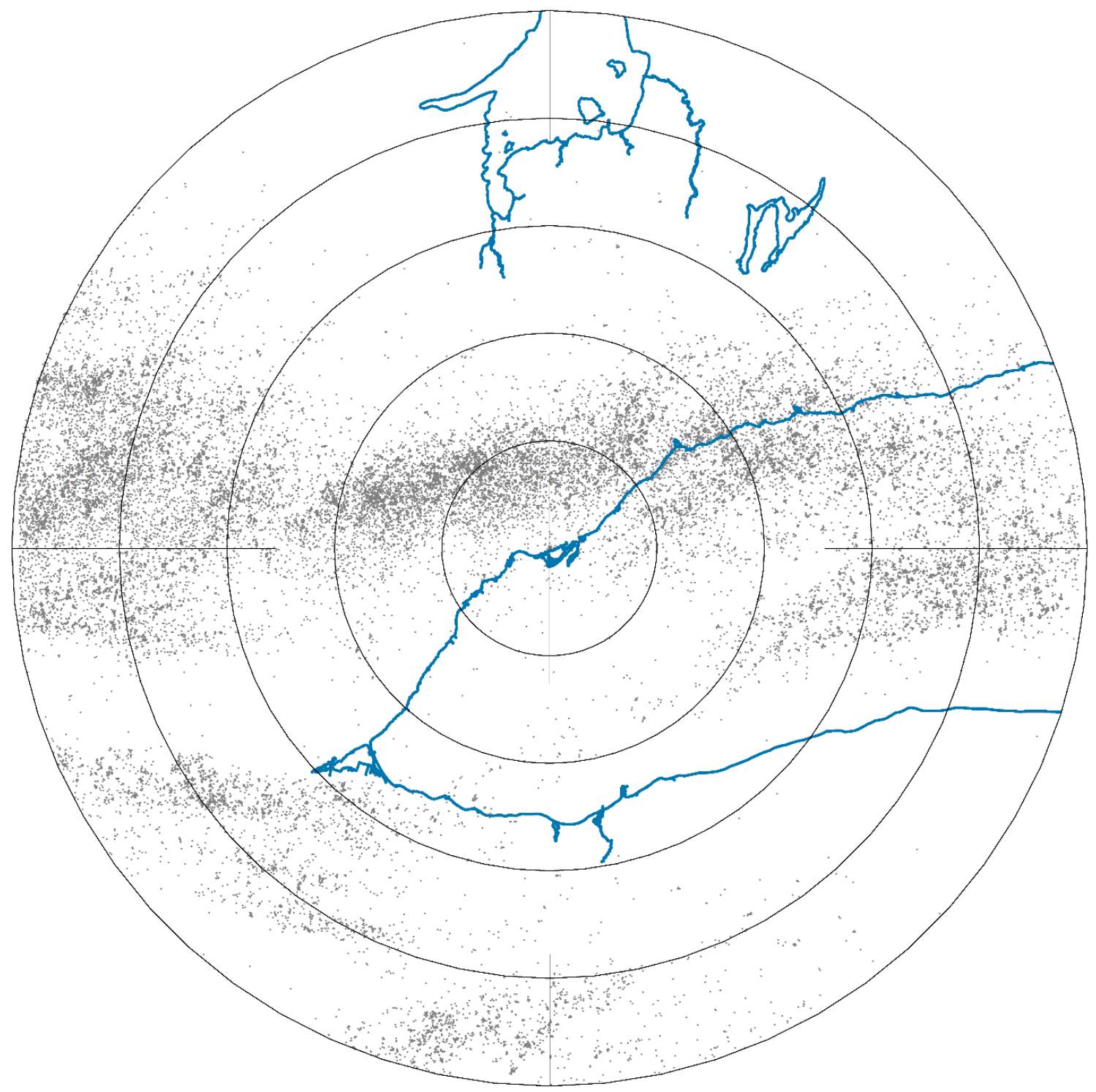

Figure 6.1 - Locations of all NALDN-detected strokes on August 19, 2005 within $100 \mathrm{~km}$ from the tower, 20-km grid. Total number of strokes $=31,157$.

\subsubsection{Time Distribution}

On August 19, 2005, lightning activities started early in the morning. According to the network (NALDN) data, cloud-to-ground lightning activity within $100 \mathrm{~km}$ from the tower was first detected at 03:28:20 a.m. local Toronto time. The storm had an average activity and lasted for a few hours only to start hitting the same area $(100 \mathrm{~km}$ around the tower) again in the afternoon 
(12:27:37 p.m.) with higher activity until it ended at 19:57:16 p.m. Figure 6.2 displays the time distribution of the number of strokes detected in each minute; represented by the blue vertical lines.

The CN Tower current derivative measurement system recorded 6 flashes, containing 38 strokes. Although these six flashes were reported by the network, only 21 of the measured 38 strokes were detected. In order to carefully study the lightning environment in the vicinity of the $\mathrm{CN}$ Tower, a limited area within $20 \mathrm{~km}$ from the tower was considered. Figure 6.3 presents the time distribution of the number of strokes, detected each minute, within $20 \mathrm{~km}$ from the tower. Each blue vertical line represents the total number of strokes reported within one minute, while the horizontal red line represents the time duration of $\mathrm{CN}$ Tower strikes and its height represents the number of strokes that hit the tower and was detected by the network (21). The figure shows that the tower was hit prior to or at the very beginning of the storm and continued up to the core of it.

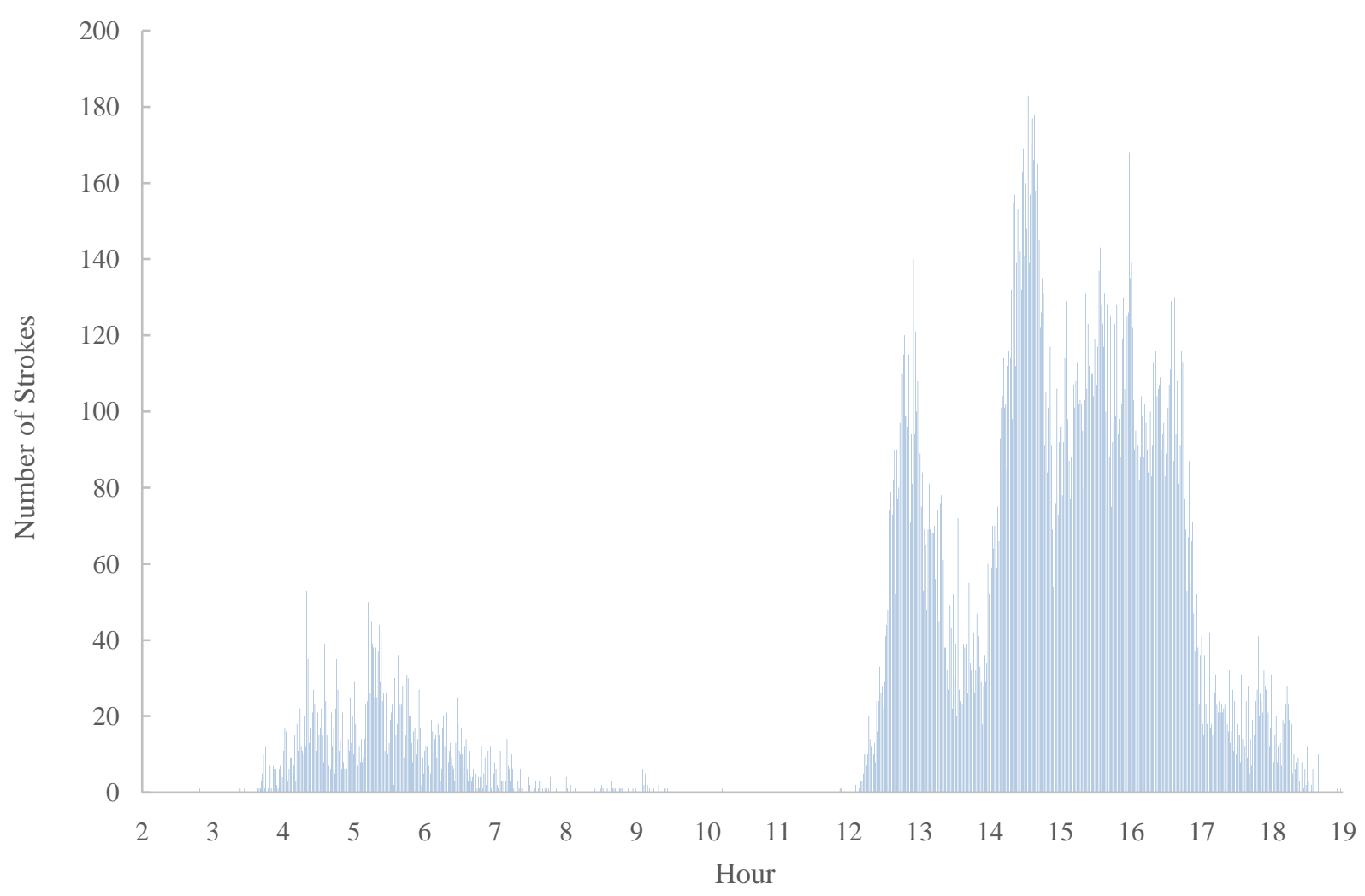

Figure 6.2 - Time distribution of strokes, within $100 \mathrm{~km}$ from the tower, August 19, 2005. 


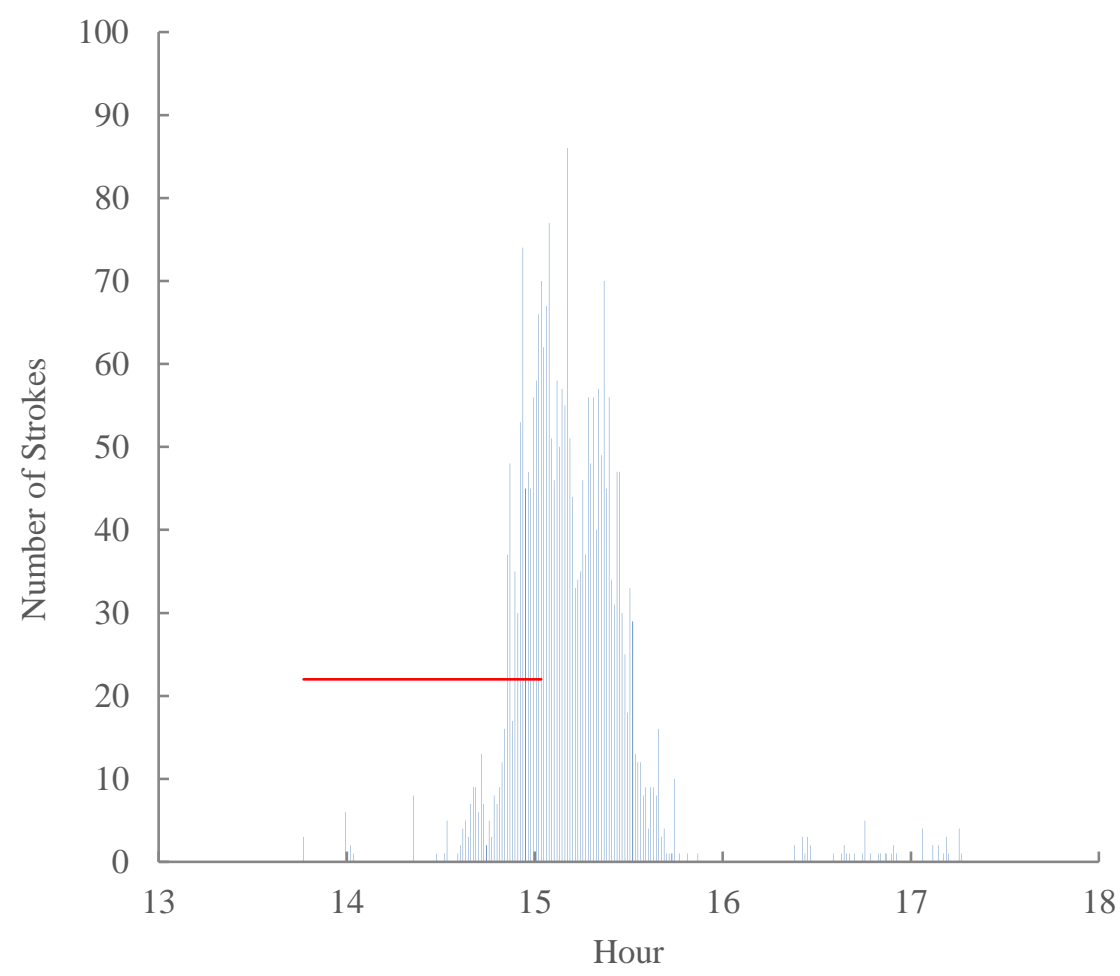

Figure 6.3 - Time distribution of strokes, within $20 \mathrm{~km}$ from the tower, August 19, 2005.

\subsubsection{Stroke Density}

In order to investigate the lightning return-stroke density in the vicinity of the tower, while the tower was heavily struck with lightning, Fig. 6.4 was constructed. The density of return strokes as a function of distance from the tower was determined using two different methods. The first method is calculating the stroke density every $1 \mathrm{~km}$ from the tower, represented by the black solid line. In order to calculate the average stroke density over identical areas, the second method is used based on an elemental area of $4 \pi \mathrm{km}^{2}$, which corresponds to the area of a circle centered at the tower and has a 2-km radius, represented by the blue dotted line.

The spiky nature of the stroke density calculated using the fixed area method is expected due to the smaller area considered, especially away from the tower, in comparison with the first method when the area further away from the tower increase markedly with the distance from the tower. 


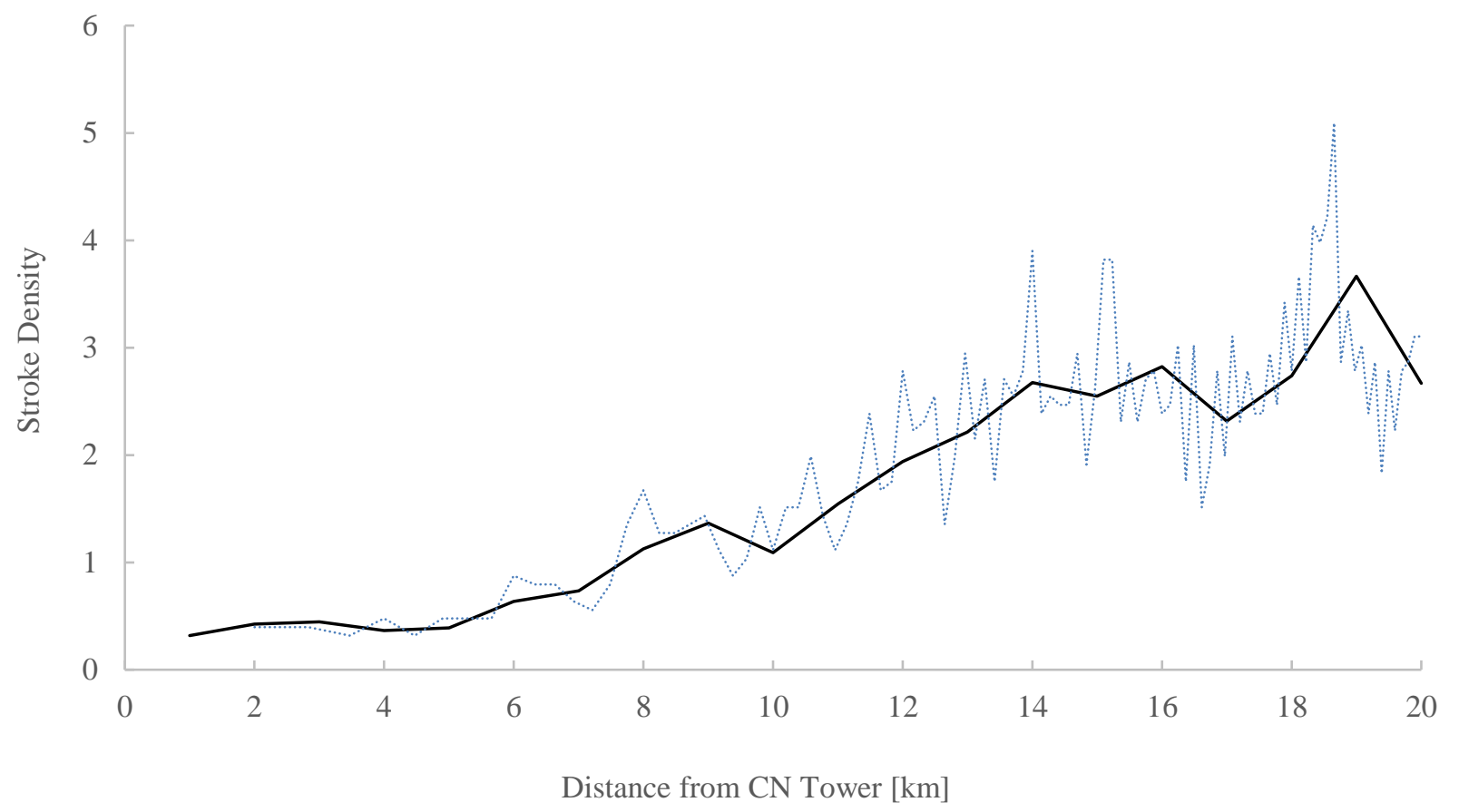

Figure 6.4 - Density of non-CN Tower strokes within $20 \mathrm{~km}$ from the CN Tower, on August 19, 2005. Total number of strokes $=2,718$.

\subsubsection{Flash Multiplicity}

The flash multiplicity is defined as the number of strokes per flash, the variation of the average flash multiplicity of non-CN Tower flashes as a function of distance from the tower (20km range) during August 19, 2005 is presented in Fig. 6.5. The NALDN detected data comprises 1,295 non-CN Tower flashes, containing 2,643 strokes, resulting in an overall average multiplicity of 2.04 within $20 \mathrm{~km}$ from the tower.

Figure 6.5 displays the average flash multiplicity variation as a function of the distance from the tower, using the two different methods, similar to those used in calculating the stroke density. The first method is calculating the average flash multiplicity every $1 \mathrm{~km}$ from the tower, represented by the black solid line. In order to calculate the average flash multiplicity over identical areas, the second method is used based on an elemental area of $4 \pi \mathrm{km}^{2}$, which corresponds to the area of a circle centered at the tower and has a 2-km radius, represented by the blue dotted line. The average flash multiplicities based on NALDN-detected and CN Tower-measured flashes were 
found to be 3.5 and 6.33, respectively. The NALDN-detected and CN Tower-measured average flash multiplicities are represented by blue ' $X$ ' and ' $\nabla$ ' marks on the vertical axis, respectively.

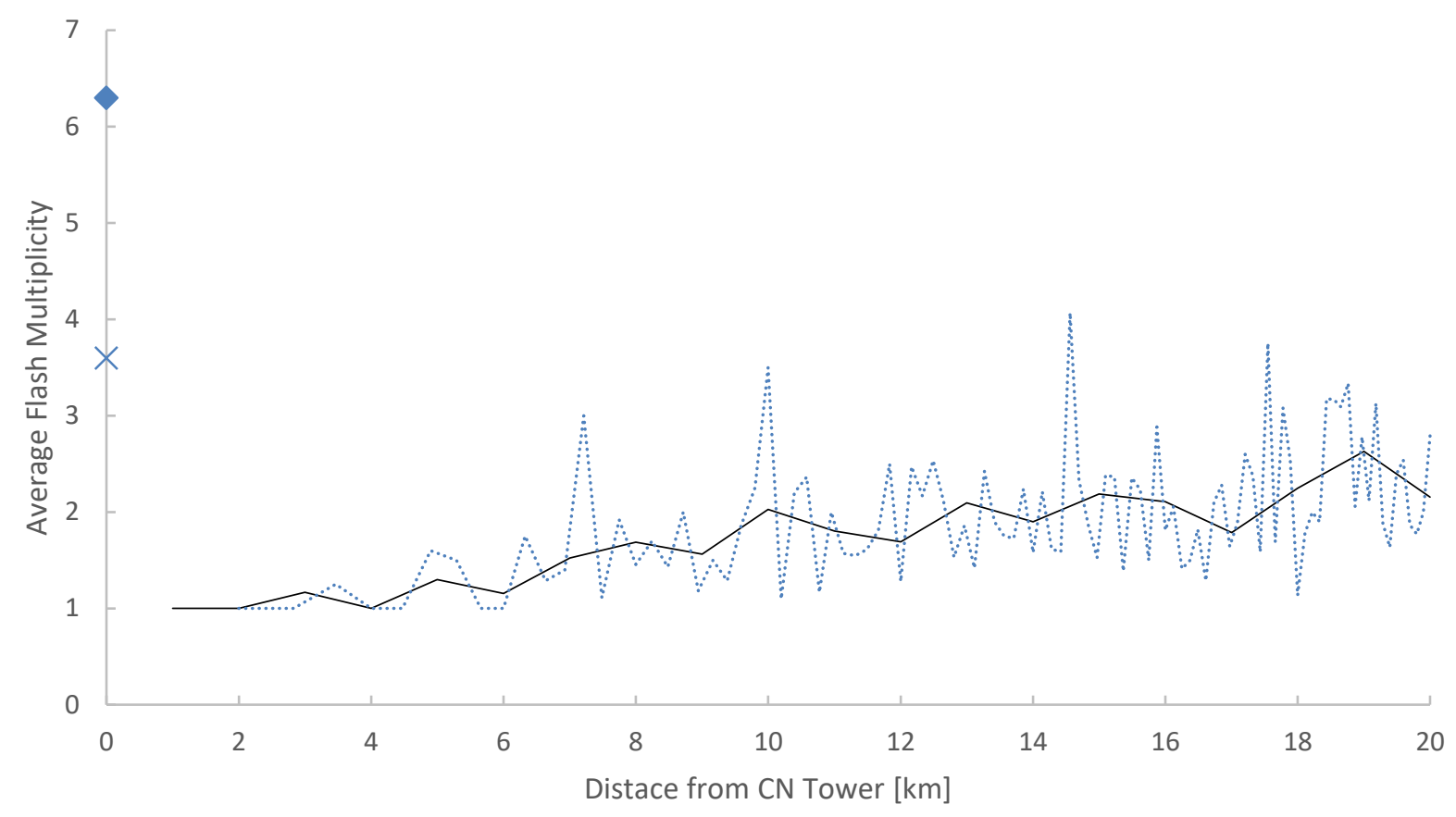

Figure 6.5 - Average flash multiplicity of non-CN Tower flashes within $20 \mathrm{~km}$ from the tower on August 19, 2005.

\subsubsection{Estimated Peak Current}

For convenience, a 90 minute and 4 seconds' time window is defined as the storm duration on August 19, 2005. It starts when the first flash struck the tower and ends with the final one. Figure 6.6 displays the estimated NALDN location and peak current for each of the detected 206 positive strokes (red lines) and 546 negative strokes (blue lines). The peak current average of positive strokes is $11.29 \mathrm{kA}$ (horizontal dashed red line) and that for negative strokes is $16.96 \mathrm{kA}$ (horizontal blue dashed line). However, the maximum current peak of negative strokes is $89.3 \mathrm{kA}$, more than three time higher than that of positive strokes $(26.8 \mathrm{kA})$. The average estimated peak currents for $\mathrm{CN}$ Tower strokes are represented by a blue ' $\mathrm{X}$ ' mark on the vertical axis of Fig. 6.6, which are calculated to be $23.93 \mathrm{kA}$. 


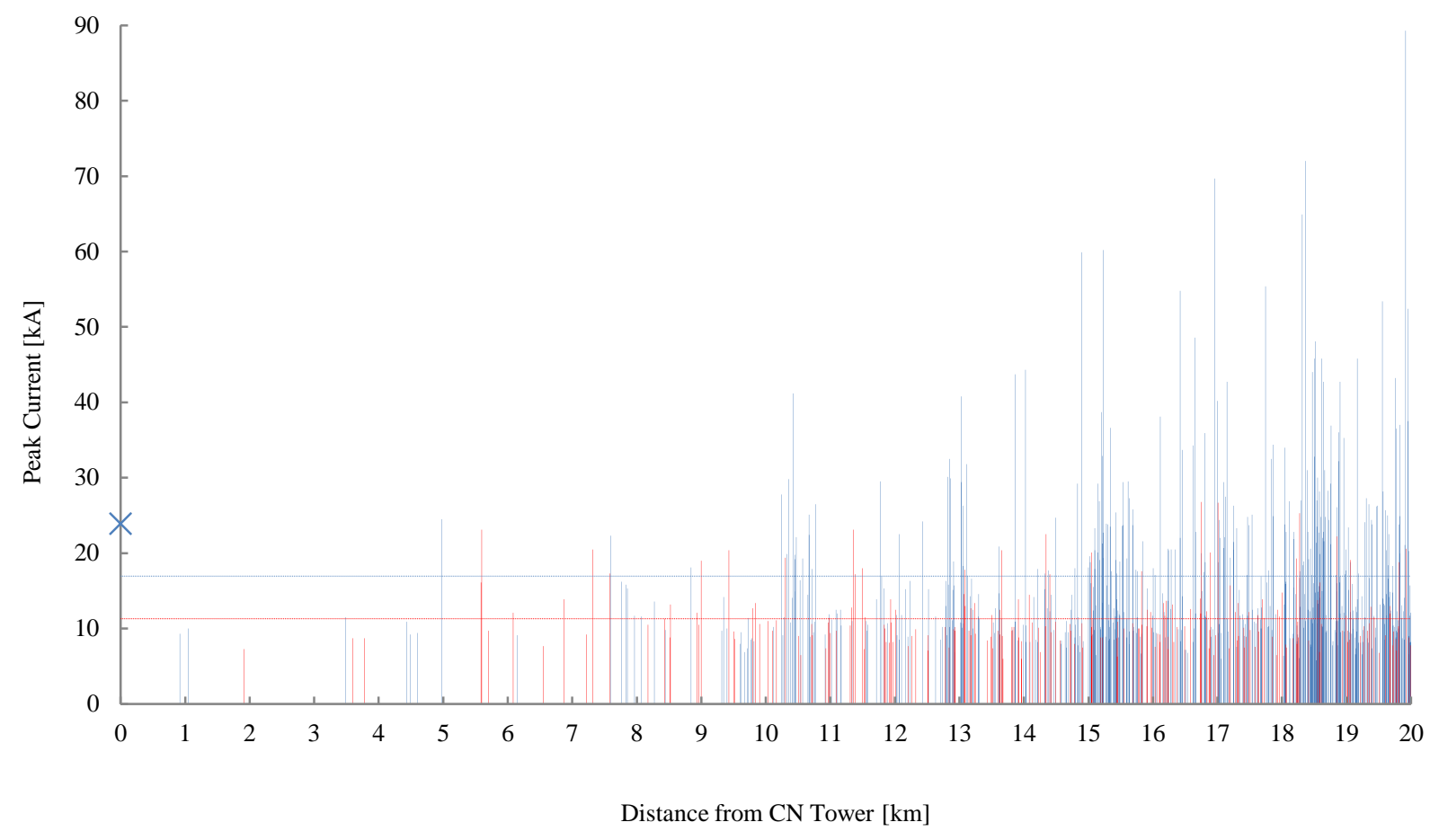

Figure 6.6 - NALDN-estimated peak current for negative (blue) and positive (red) non-CN Tower strokes, within $20 \mathrm{~km}$ from the tower during August, 192005 storm.

Figure 6.7 shows the cumulative probability distribution (CPD) of the multiplicity of CN Tower flashes (6 flashes, dotted blue line), non-CN Tower negative flashes (213 flashes, blue line) and non-CN Tower bipolar and positive flashes (151 flashes, red line) during the storm duration on August 19, 2005. The figure indicates that the flash multiplicities of bipolar and positive flashes are generally lower than that for negative strokes, whether $\mathrm{CN}$ Tower or non-CN Tower. 


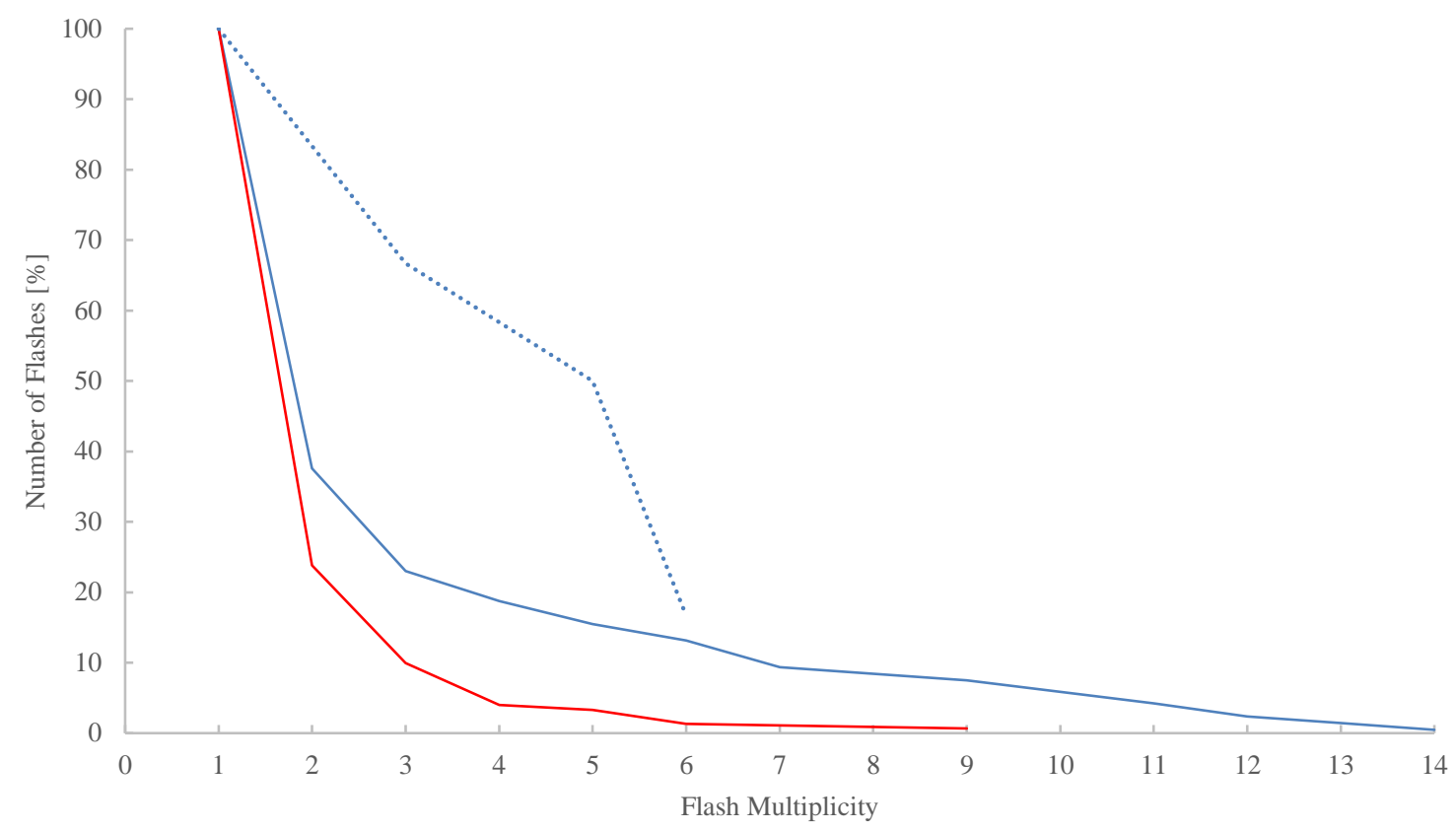

Figure 6.7 - Cumulative probability distribution of flash multiplicity for CN Tower flashes (dotted blue line), non-CN Tower negative flashes (blue line) and non-CN Tower bipolar and positive flashes (red line) during August 19, 2005 storm duration.

\subsubsection{Estimated Stroke Locations within $5 \mathrm{~km}$ from the tower}

A zoomed-in map of the immediate 5-km area around the $\mathrm{CN}$ Tower is presented in Fig. 6.8. The map shows the estimated locations of NALDN-detected lightning strokes on August 19, 2005. Where the blue dots represent the non-CN Tower strokes, red dots represent the CN Tower strokes, black hollow circle in the center represents the location of the CN Tower and the area enclosed by turquoise line outlines Lake Ontario. The figure shows 31 non-CN Tower strokes and $21 \mathrm{CN}$ Tower strokes. It is also worth mentioning that the closest non-CN Tower stroke was detected at $912.8 \mathrm{~m}$ from the tower. Figure 6.9 is showing the same map in Fig. 6.8 with the CN Tower strokes (21) excluded. 


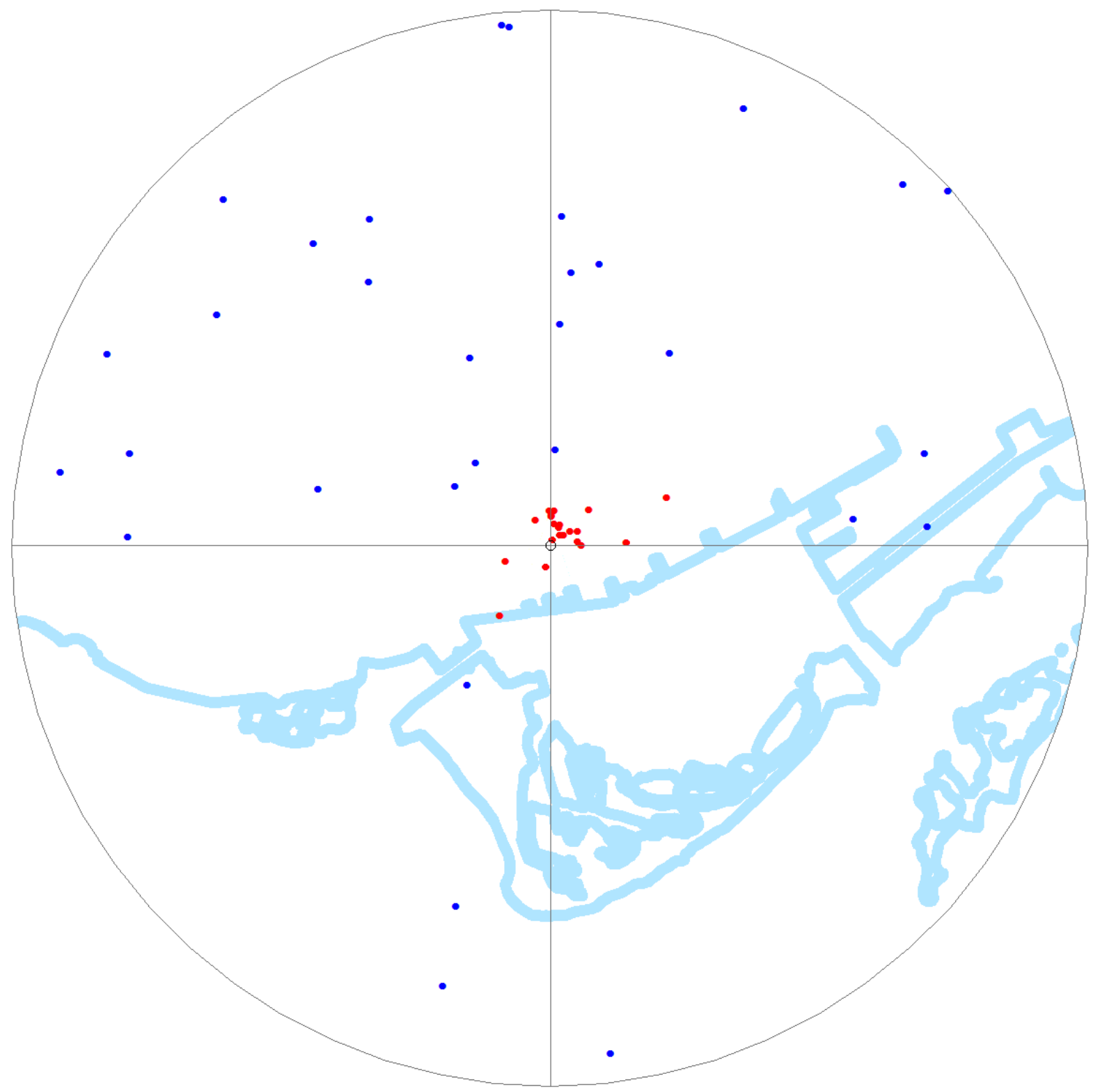

Figure 6.8 - NALDN estimated locations of lightning strokes detected on August 19, 2005 within $5 \mathrm{~km}$ from the $\mathrm{CN}$ Tower. Blue dots represent non-CN Tower strokes, while red dots represent $\mathrm{CN}$ Tower-detected strokes. 


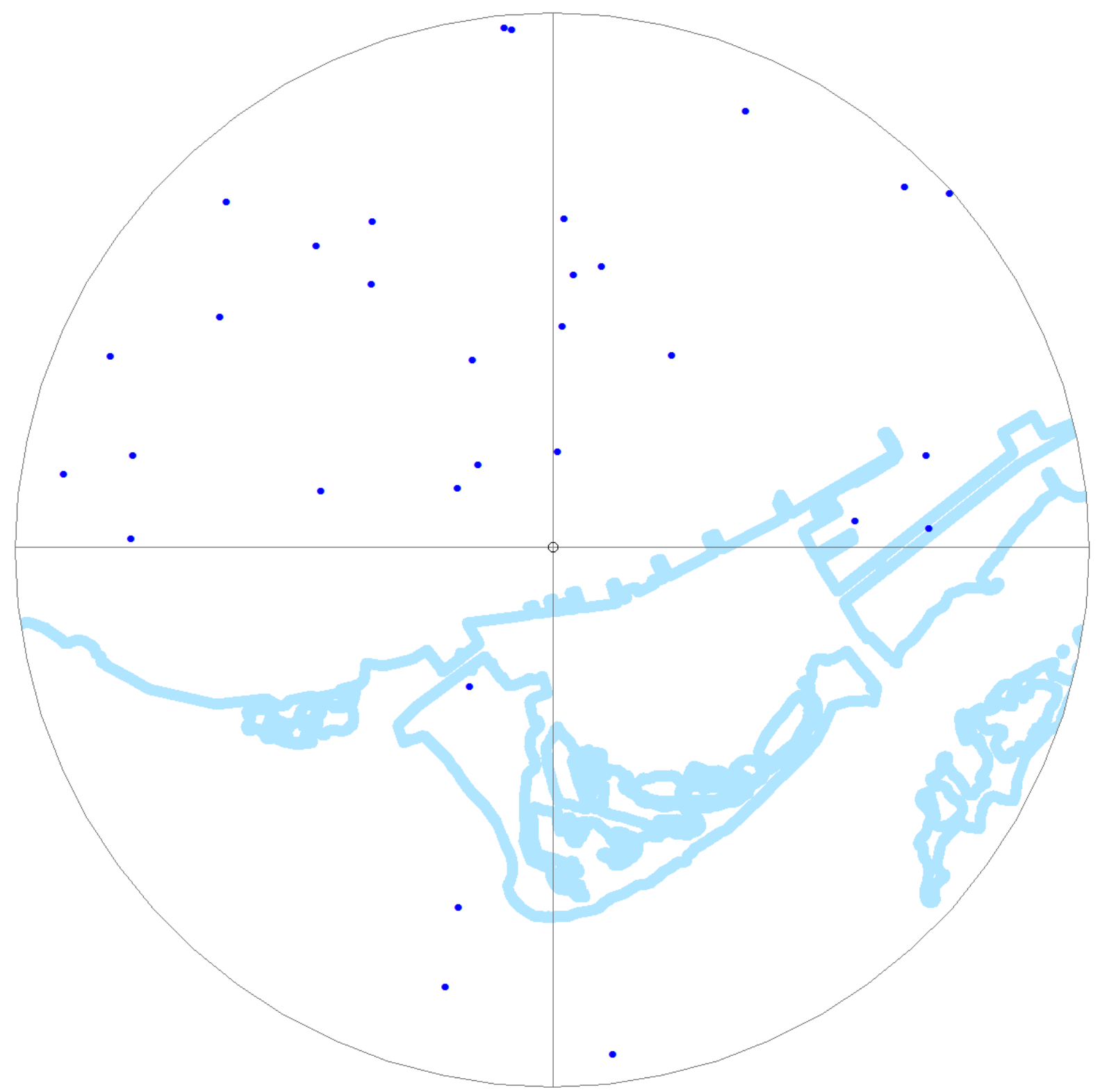

Figure 6.9 - NALDN estimated locations of lightning strokes detected on August 19, 2005 within $5 \mathrm{~km}$ from the $\mathrm{CN}$ Tower, $\mathrm{CN}$ Tower strokes excluded. 


\subsubsection{Detection Efficiency}

Stroke detection efficiency is the ratio between the total number of strokes detected by NALDN and those measured at the CN Tower. Table 6.1 shows the total number of flashes recorded by the current derivative measurement system located at the $\mathrm{CN}$ Tower (first column), the number of strokes in each measured flash (second column), and the number of strokes detected by NALDN (third column). The network detected all six flashes, resulting in $100 \%$ flash detection efficiency. While, the stroke detection efficiency was found to be $55 \%$ as only 21 out of the 38 measured strokes were detected by the network [16].

Table 6.1 - Number of NALDN-detected and CN Tower-measured strokes

\begin{tabular}{|c|c|c|}
\hline CN Tower Flash Number & \# of Strokes measured at the CN & $\begin{array}{c}\text { \# of Strokes detected by } \\
\text { NALDN }\end{array}$ \\
\hline 1 & 10 & 3 \\
\hline 2 & 10 & 6 \\
\hline 3 & 7 & 2 \\
\hline 4 & 1 & 1 \\
\hline 5 & 4 & 4 \\
\hline 6 & 6 & 5 \\
\hline Total & $\mathbf{3 8}$ & $\mathbf{2 1}$ \\
\hline
\end{tabular}




\subsection{CN Tower Major Storm}

In 2011, within $100 \mathrm{~km}$ from the tower, NALDN detected 57,733 lightning flashes, containing 139,393 strokes, resulting in a flash multiplicity of 2.414. Based on these data, the densities of flashes and strokes per square kilometers are found to be: 1.838 and 4.437, respectively.

The daily and monthly distribution of strokes within the entire year is previously displayed in Fig. 5.9. The figure shows large concentration of lightning activity in the summer. August was the month with the highest lighting activity. It is also noted that $64 \%$ of all detected strokes in August occurred in one day; August 24.

The second major storm discussed in this chapter occurred on August 24, 2011. Similar to the previous section (2005 storm), the lightning environment in the vicinity of the CN Tower during the 2011 storm is presented in this section. It is important to note that during the 2011 storm, current data was obtained by the old Rogowski coil and recorded by the NI PCI 5114 digitizer.

Unfortunately, the LeCroy LT342L digitizer did not operate neither did the high-speed digital imaging system (Phantom v5.0) during this storm [31].

\subsubsection{Stroke Locations}

Figure 6.10 displays the locations of the 30,803 lightning strokes detected by the NALDN during August 24, 2011 within $100 \mathrm{~km}$ (with 20-km grid) from the CN Tower, where the CN Tower is located at its center. This figure is showing the storm activity in the area during that day, where the storm is extending diagonally (Northeast/Southwest) passing through the CN Tower. 


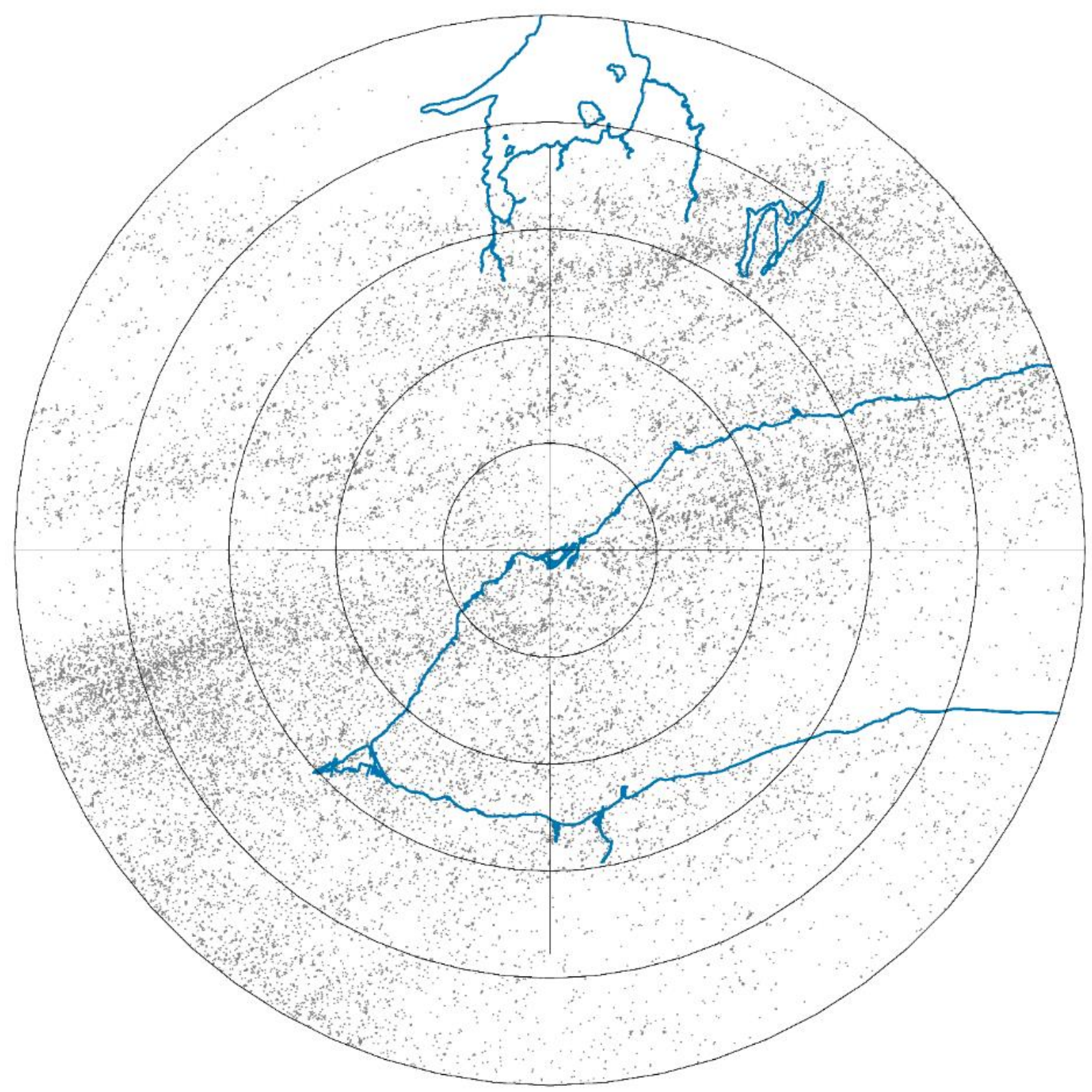

Figure 6.10 - Location of all strokes within $100 \mathrm{~km}$ from the tower. with $20 \mathrm{~km}$ grid, on August 24,2011 . Total number of strokes $=30,803$.

\subsubsection{Time Distribution}

On August 24, 2011, lightning activities started late afternoon. According to the network (NALDN) data, cloud-to-ground lightning activity within $100 \mathrm{~km}$ from the tower was first detected at 6:15:33 pm and the storm started picking up until it reached its peak at 9:57 pm, then it gradually 
declined until it ended right after midnight. During the whole day, the network detected a total of 30,803 lightning return strokes (Fig. 6.10).

In Fig. 6.11, the time distribution of the number of strokes detected in each minute is displayed. During just two hours (9:00 pm - 11 pm), the network detected 23,254 out of 30,803 strokes within $100 \mathrm{~km}$ from the tower, which is equivalent to $75.5 \%$ of all strokes detected that day.

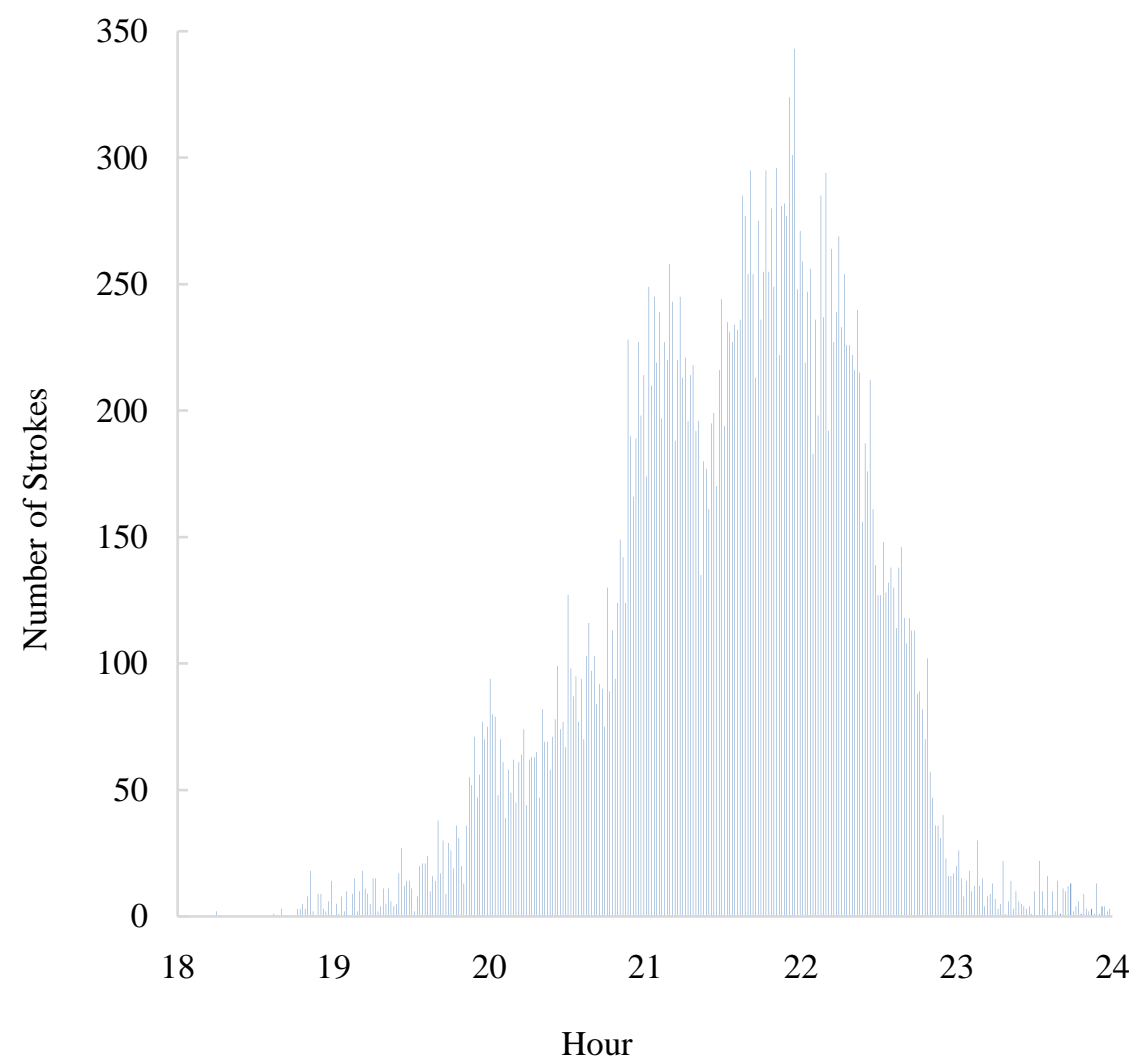

Figure 6.11 - Time distribution of strokes, within $100 \mathrm{~km}$ from the tower, August 24, 2011.

Figure 6.12 also presents the time distribution of the number of strokes, detected each minute, within $20 \mathrm{~km}$ from the tower. Each blue vertical line represents the total number of strokes reported within one minute, while the horizontal red line represents the time duration of CN Tower strikes and its height represents the number of strokes that hit the tower and was detected by the network (84). The figure proves that the tower started to be hit at the decaying part of the storm. This fact was eye witnessed from a location at $4.73 \mathrm{~km}$ north east of the tower, where video observation of $\mathrm{CN}$ Tower lightning is stationed. 


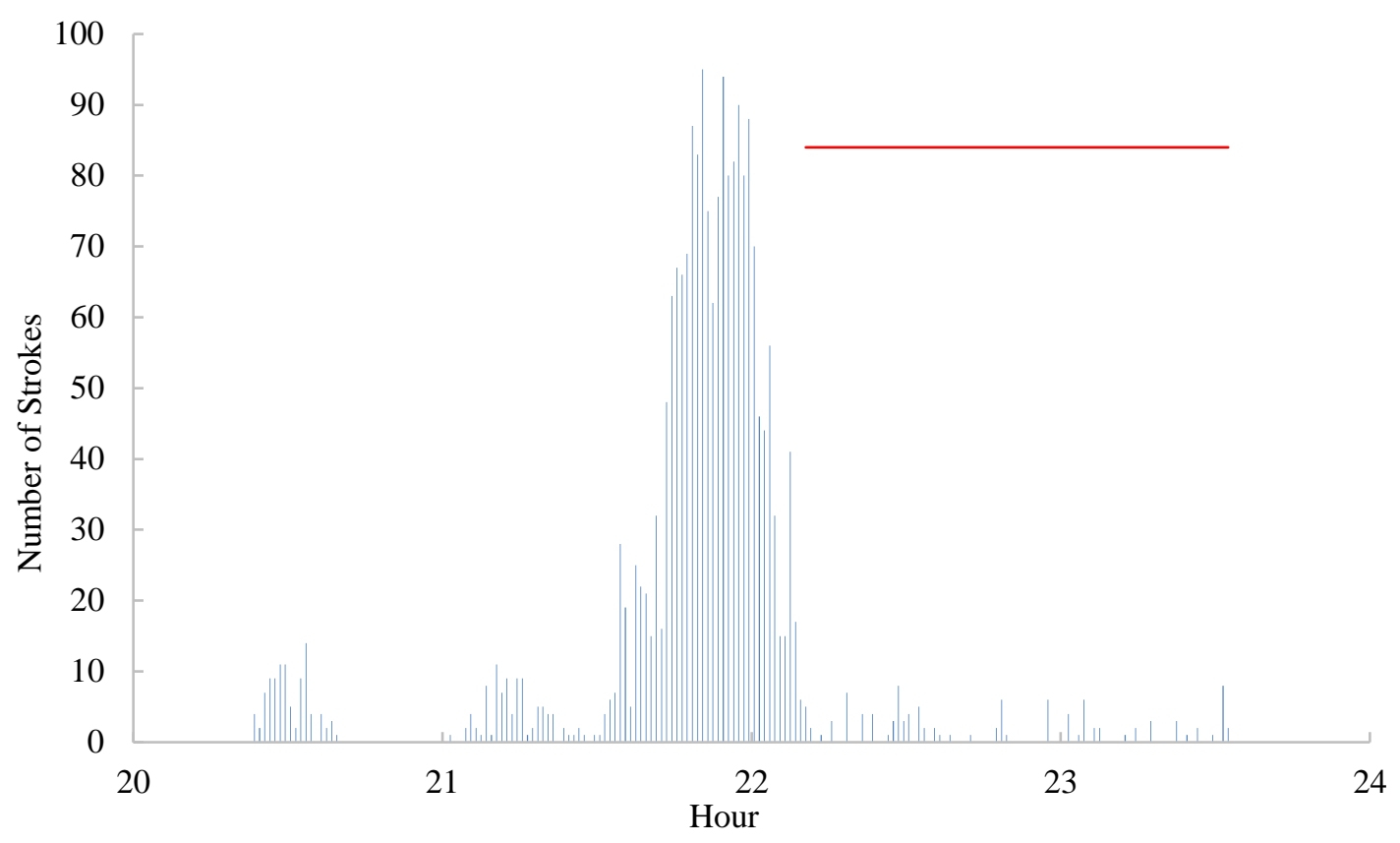

Figure 6.12 - Time distribution of strokes within $20 \mathrm{~km}$ from the tower

\subsubsection{Stroke Density}

In order to investigate the lightning return-stroke density in the vicinity of the tower, while the tower was heavily struck with lightning, Fig. 6.13 was constructed. The density of return strokes as a function of distance from the tower was determined using two different methods. The first method is calculating the stroke density every $1 \mathrm{~km}$ from the tower, represented by the black solid line. In order to calculate the average stroke density over identical areas, the second method is used based on an elemental area of $4 \pi \mathrm{km}^{2}$, which corresponds to the area of a circle centered at the tower and has a $2-\mathrm{km}$ radius, represented by the blue dotted line.

The spiky nature of the stroke density variation is a result of fixing the size of the base area element, which is proportional to the square of the distance from the tower, resulting in a fast increase in data points as the distance increases. The spiky changes are expected to subsidize as the base area element increases. 


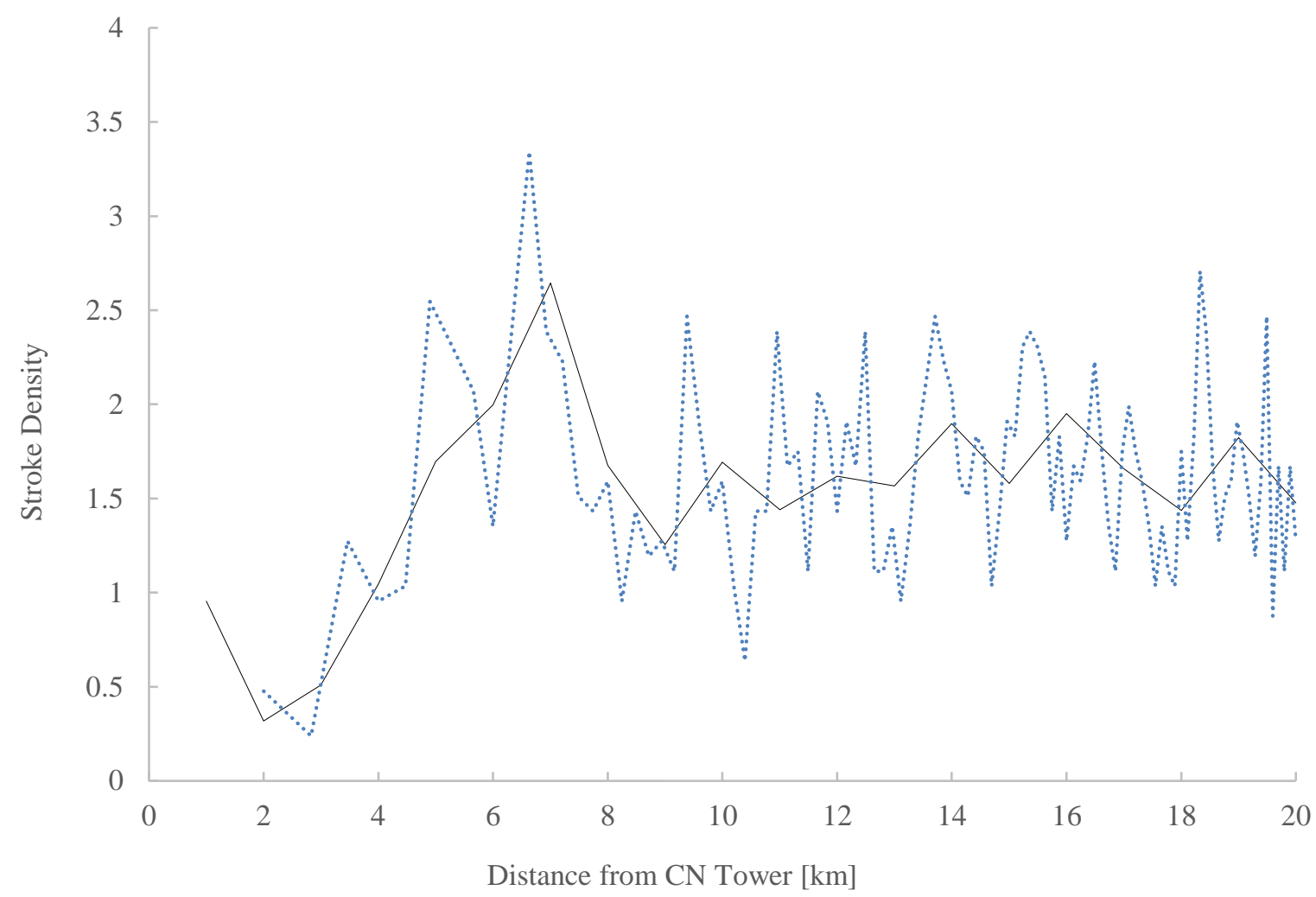

Figure 6.13 - Density of non-CN Tower strokes within $20 \mathrm{~km}$ from the CN Tower on August 24, 2011. Total number of strokes $=2,062$.

On August 24, 2011, the city of Toronto witnessed one of the severest storms in many years. The CN Tower was continually struck with 52 flashes within 84 minutes and 6.9 seconds, resulting in an average inter-flash time of 99 seconds. For convenience, a 104-minute time window is defined. It starts 10 minutes before the first flash that struck the tower and ends about 10 minutes after the tower's final flash.

In an expanded scale, Fig. 6.14 shows the locations of 324 non-CN Tower strokes that took place during the defined 104-minute time window and within $20 \mathrm{~km}$ from the tower. As Fig. 6.14 indicates, the locations of the three closest non-CN Tower strokes to the tower are found to be within the range: $3.506 \mathrm{~km}-3.9 \mathrm{~km}$. It is important to realize the none existence of ground strokes within $3.5 \mathrm{~km}$ radius from the tower during 104-minute time window, while the tower was struck with 52 flashes containing 161 impulses, assumed to be return strokes [27]. Thus, it is possible to ponder that either the presence of the tower provided some protection to the area in its immediate 
vicinity or all CN Tower flashes were self-initiated. However, based on video analysis of all CN Tower flashes, it was confirmed that each flash contained an initial continuous current [28], proving that all flashes were upward initiated. Thus, one option remains that all flashes were indeed self-initialed.

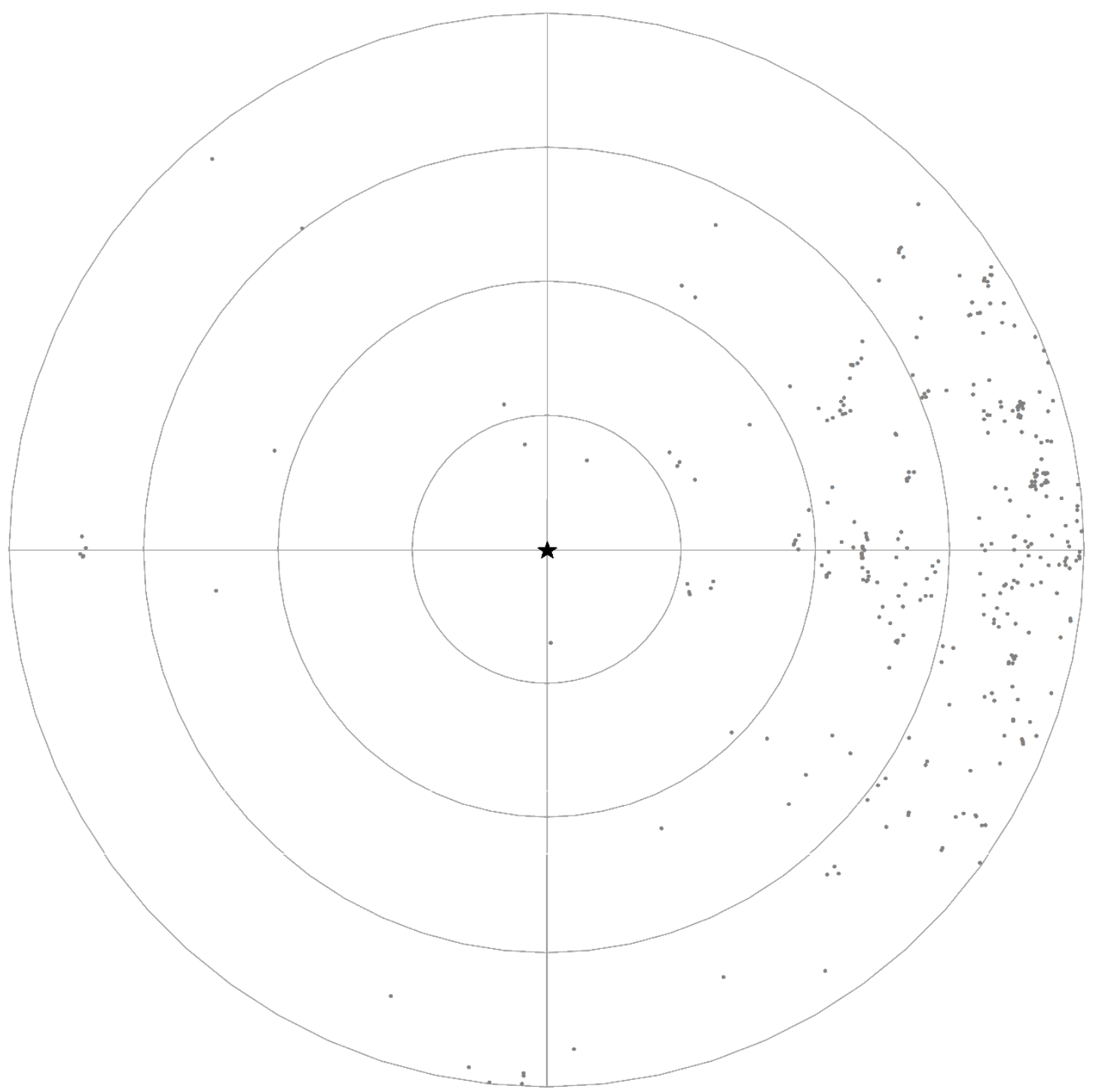

Figure 6.14 - Locations of non-CN Tower strokes detected within $20 \mathrm{~km}$ from the tower $(5-\mathrm{km}$ grid), during the 104-minute time window. 


\subsubsection{Flash Multiplicity}

The variation of the average flash multiplicity of non-CN Tower flashes as a function of distance from the tower (20-km range) during August 24, 2011 is presented in Fig. 6.15. The NALDN detected data comprise 728 non-CN Tower flashes containing 2,061 strokes, resulting in an overall average multiplicity of 2.83 within $20 \mathrm{~km}$ from the tower. Figure 6.15 displays the average flash multiplicity variation as a function of the distance from the tower, using two different methods, similar to those used in calculating the stroke density. The first method is calculating the average flash multiplicity every $1 \mathrm{~km}$ from the tower, represented by the black solid line. In order to calculate the average the flash multiplicity over identical areas, the second method is based on an elemental area of $4 \pi \mathrm{km}^{2}$, which corresponds to the area of a circle centered at the tower and has a 2-km radius, represented by the blue dotted line. The average flash multiplicities based on NALDN-detected and CN Tower-measured flashes were found to be 2.625 and 5.03, respectively. For comparison, the NALDN-detected and $\mathrm{CN}$ Tower-measured overall average flash multiplicities are represented by blue ' $\mathrm{X}$ ' and ' $\diamond$ ' marks on the vertical axis, respectively.

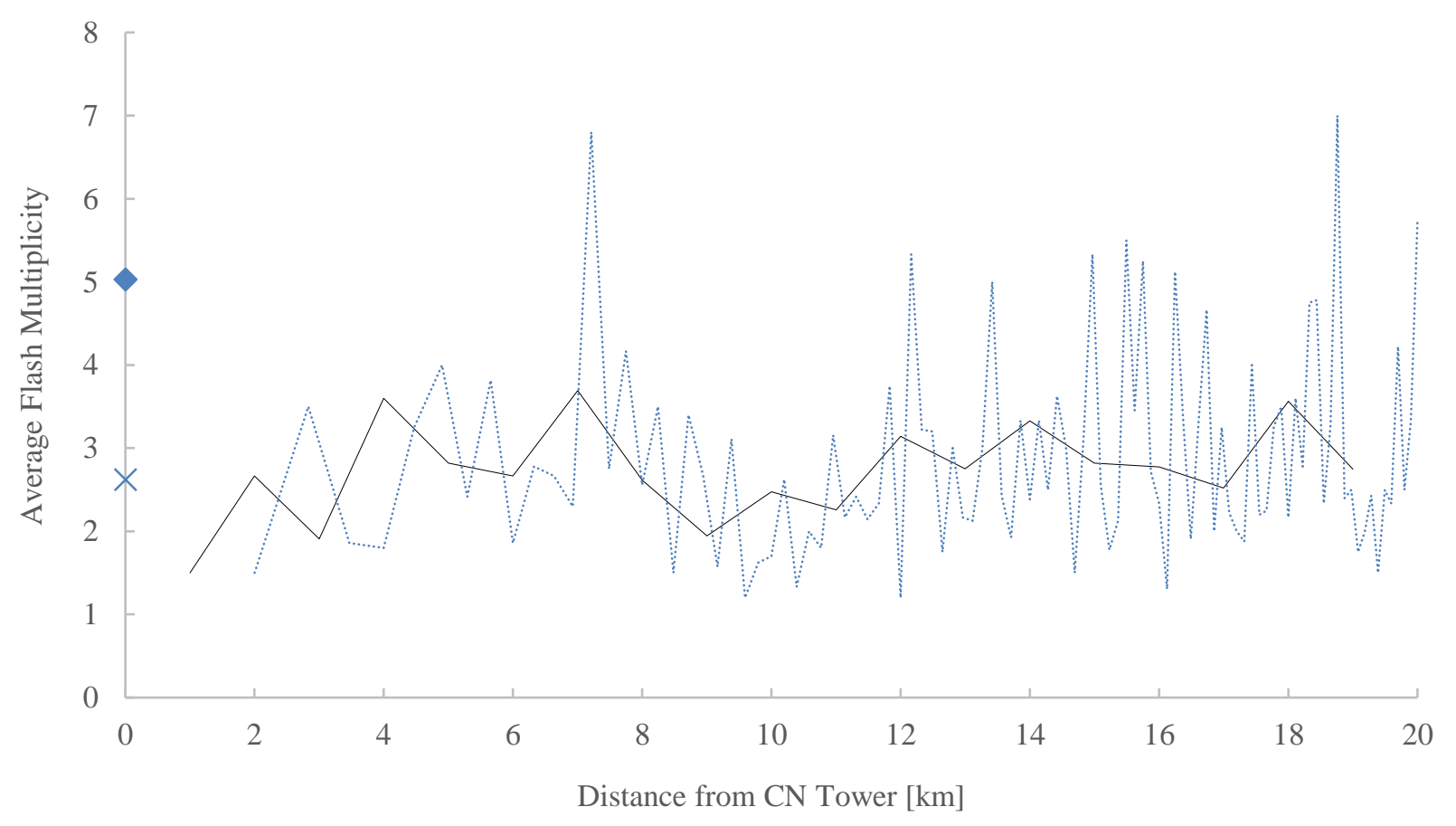

Figure 6.15 - Average flash multiplicity of non-CN Tower flashes within $20 \mathrm{~km}$ from the tower on August 24, 2011. 
The flash multiplicity during the defined 104-minute storm duration, which includes the time when the tower was struck with 52 flashes, is examined within $20 \mathrm{~km}$ radius from the tower. Figure 6.16 shows the multiplicity of each NALDN-detected non-CN Tower flashes, as a function of distance from the tower. Within the described time window, the total number of detected flashes is found to be 115. These flashes contain a total of 316 strokes. The figure shows that flash multiplicity varies between 1 and 11 . Based on these data, the average flash multiplicity is found to be 2.748 , which is $13.8 \%$ larger than that obtained based on the whole year, within $100 \mathrm{~km}$ from the tower. It is worth mentioning that $\mathrm{CN}$ Tower average flash multiplicity, based on the current derivative signals recorded at the tower within about 84 minutes, is 4.97; substantially higher than that for flashes taking place in the vicinity of the tower [27]. It is also to be noted that NALDN detected only $84 \mathrm{CN}$ Tower strokes out of the recorded 161 strokes, resulting in $52.17 \%$ stroke detection efficiency [31].

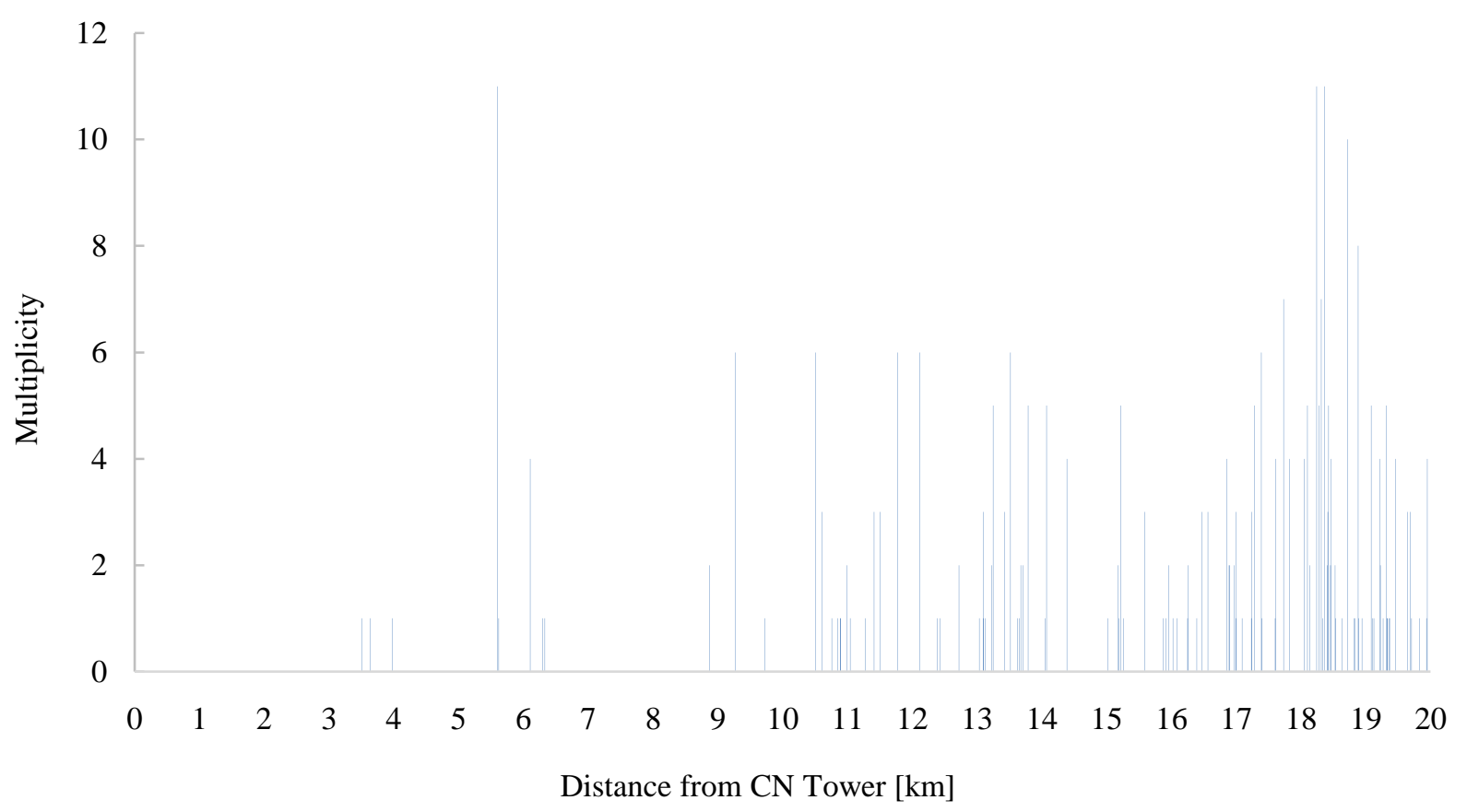

Figure 6.16 - Flash multiplicity of non-CN Tower flashes detected within $20 \mathrm{~km}$ from the tower, during the 104-minute time window. Total number of flashes $=115$. 
Furthermore, Fig. 6.17 shows the cumulative probability distribution (CPD) of multiplicity of CN Tower flashes (32 flashes, dotted blue line), non-CN Tower negative flashes (108 flashes, blue line) and non-CN Tower bipolar and positive flashes (15 flashes, red line) during the storm duration on August 24, 2011.

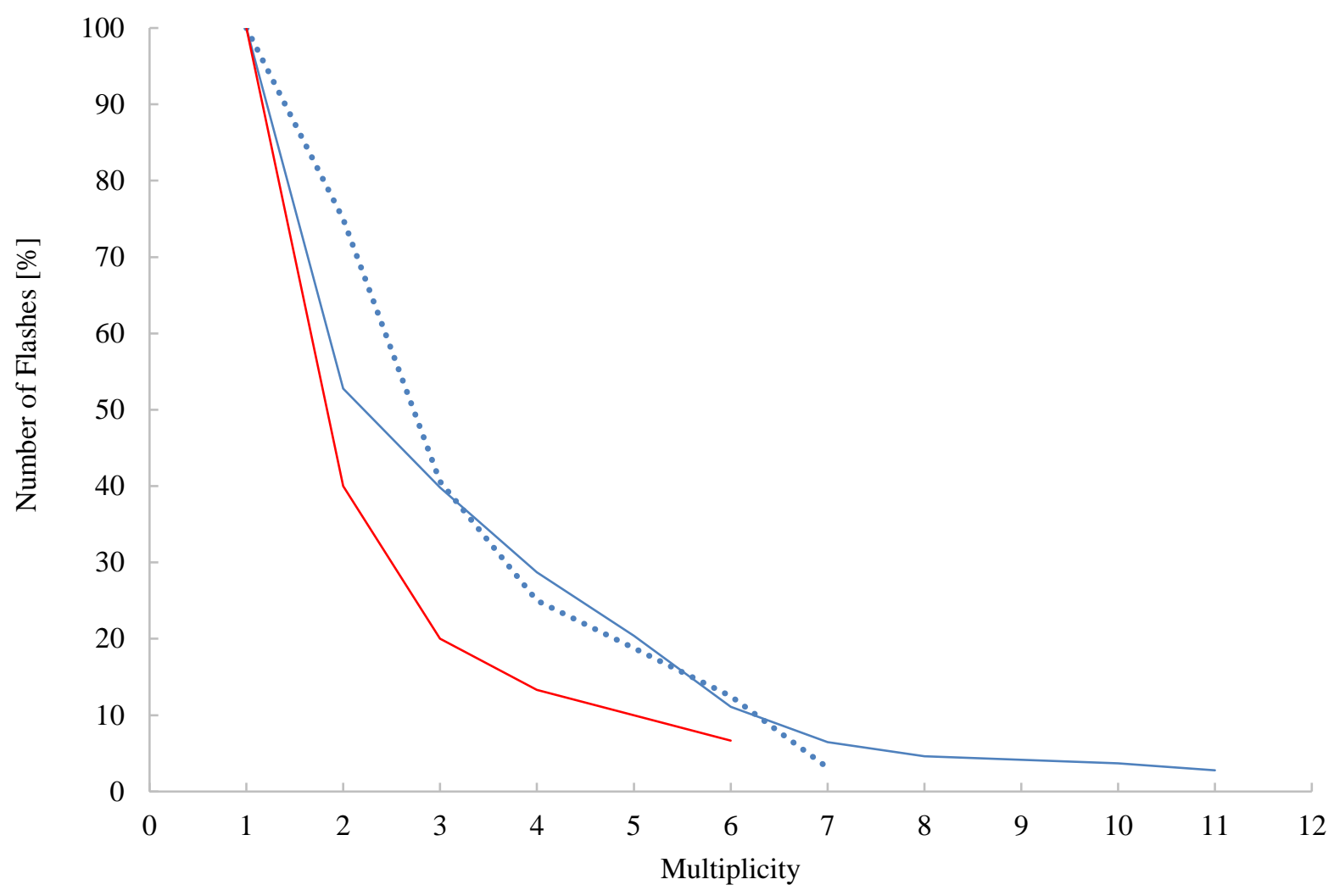

Figure 6.17 - Cumulative probability distribution of multiplicity of CN T flashes (dotted blue line), non-CN Tower negative flashes (blue line) and non-CN Tower bipolar and positive flashes (red line) during the storm duration on August 242011. 


\subsubsection{Estimated Peak Current}

Figure 6.18 displays the NALDN location and estimated peak current for each of the 324 non-CN Tower strokes that took place within $20 \mathrm{~km}$ from the tower on August 24, 2011, during the 104-minute time window. The NALDN detected 15 positive strokes (red lines) and 309 negative strokes (blue lines). The number of positive strokes is only $4.6 \%$ of the total number of detected strokes. The peak current average of positive strokes is $28.01 \mathrm{kA}$ (horizontal dashed red line), which is $52 \%$ higher than that for negative strokes (18.44 kA, horizontal blue dashed line). However, the maximum current peak of positive strokes is $82.3 \mathrm{kA}, 27 \%$ higher than that for negative strokes. The average estimated peak current for $\mathrm{CN}$ Tower strokes is represented by a blue ' $\mathrm{X}$ ' mark on the vertical axis, which is calculated to be $24.95 \mathrm{kA}$.

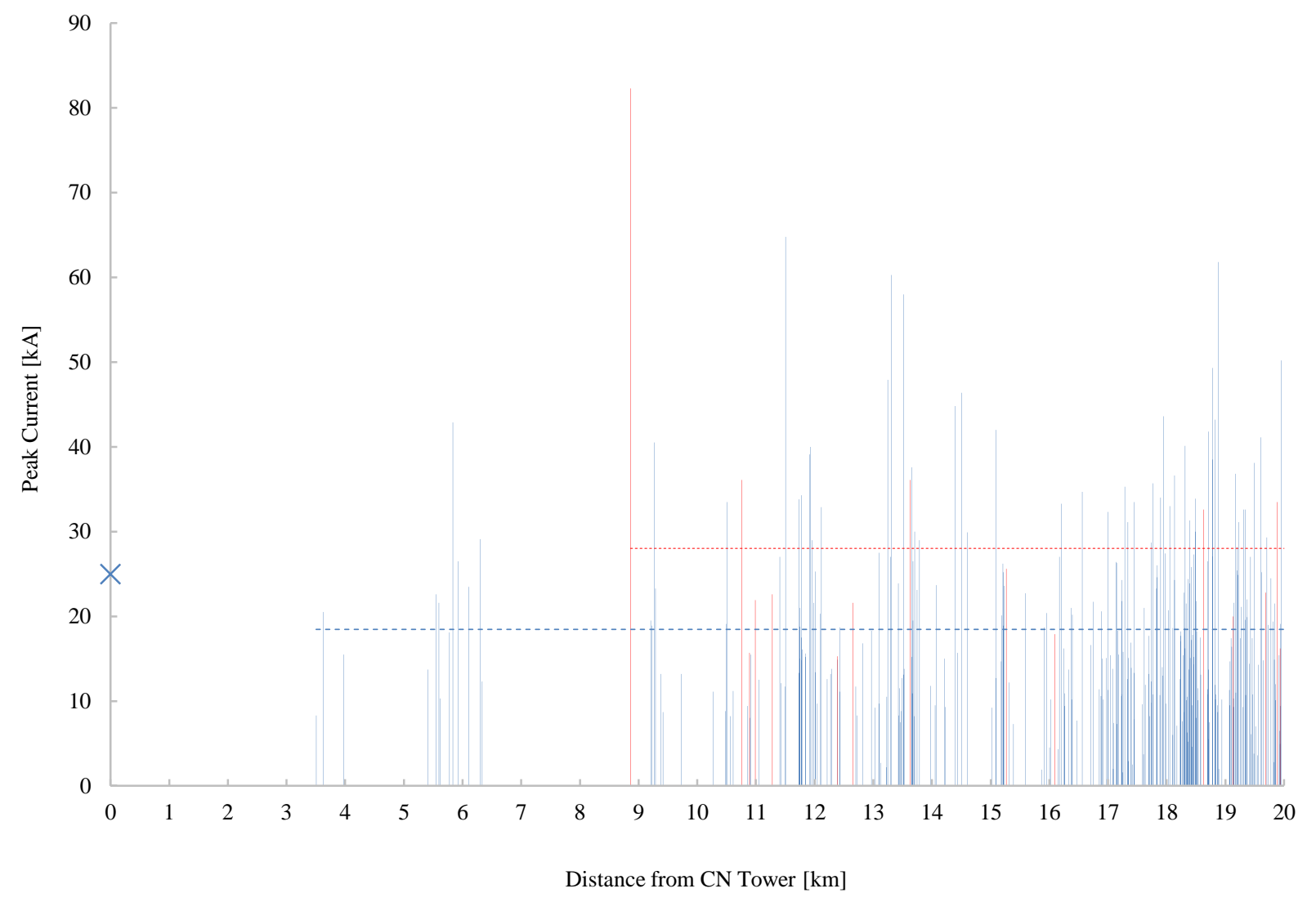

Figure 6.18 - NALDN estimated peak current for negative (blue, 309) and positive (red, 15) nonCN Tower strokes, within $20 \mathrm{~km}$ from the tower during August 24, 2011 storm. 
Figure 6.19 shows the cumulative probability distribution (CPD) of NALDN estimated peak current for $\mathrm{CN}$ Tower strokes (84, all negative) in dotted blue line. The figure also includes the CPDs of NALDN estimated peak current for negative (309 strokes, blue line) and positive (15 strokes, red line) non-CN Tower strokes within $20 \mathrm{~km}$ from the tower and during the 104-minute time window, within which the $\mathrm{CN}$ Tower was struck with 161 strokes. The figure indicates that the peak current for positive strokes is generally higher than that for negative strokes, whether $\mathrm{CN}$ Tower or non-CN Tower. Furthermore, it is evident from the figure that the minimum current peak of positive strokes $(15.3 \mathrm{kA})$ is substantially higher than the minimum current peak of negative non-CN Tower strokes $(1.6 \mathrm{kA})$. The figure also shows that for negative polarity strokes, $\mathrm{CN}$ Tower stroke peak current is clearly higher than those for non-CN Tower strokes. This observation is very likely related to the markedly higher speed of propagation within the tower [16], [30].

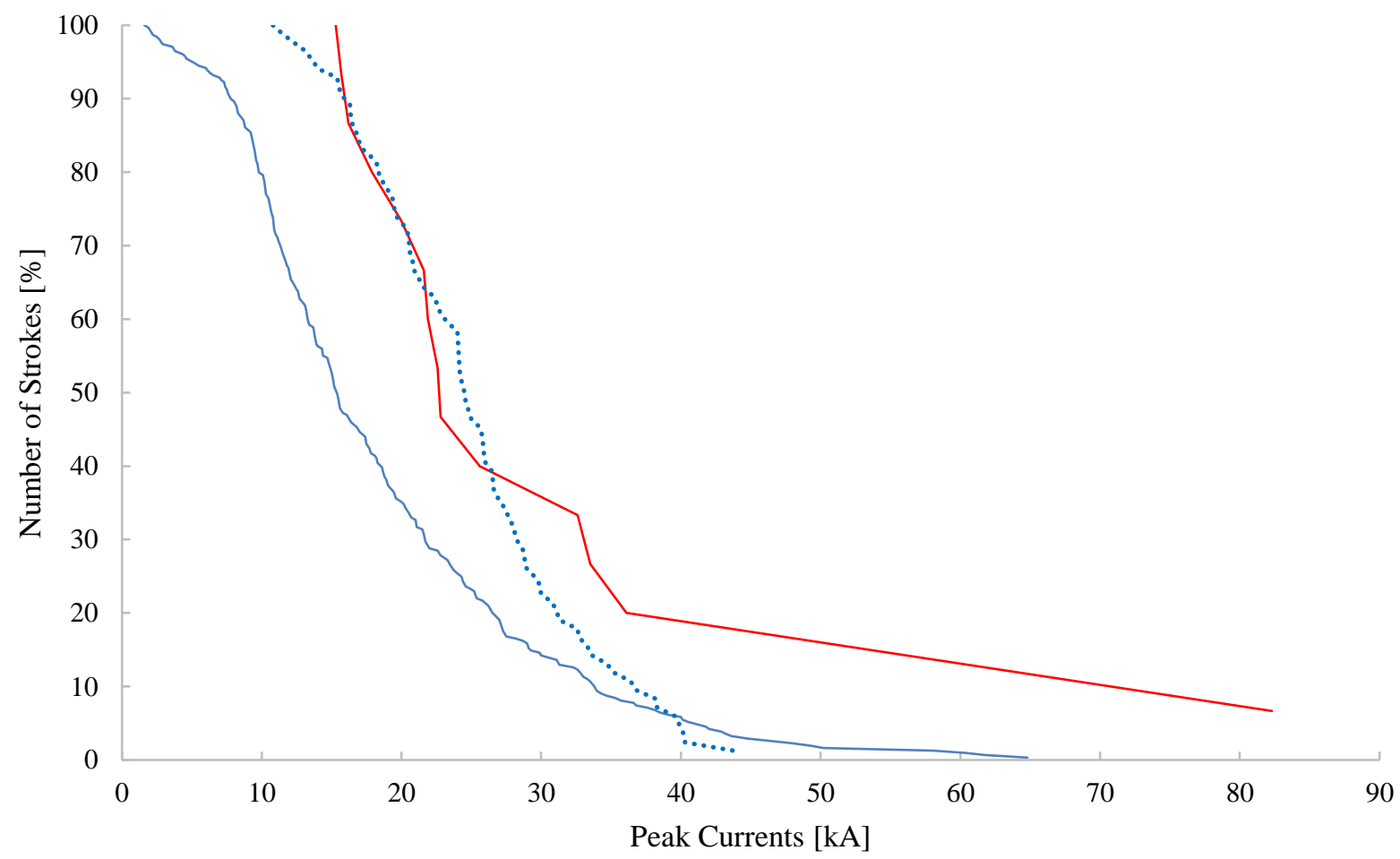

Figure 6.19-Cumulative probability distributions of NALDN-estimated peak current for CN Tower strokes (dotted blue line) and non-CN Tower strokes (negative, blue line; positive, red line). 


\subsubsection{Estimated Stroke Locations within $5 \mathrm{~km}$ from the tower}

A zoomed-in map of the immediate 5-km area around the $\mathrm{CN}$ Tower is presented in Fig. 6.20. The map shows the estimated locations of NALDN-detected lightning strokes on August 24, 2011. Where the blue dots represent the non-CN Tower strokes, red dots represent the CN Tower strokes, black hollow circle in the center represents the location of the $\mathrm{CN}$ Tower and the turquoise drawing outlines Lake Ontario. The figure shows 85 non-CN Tower strokes and $84 \mathrm{CN}$ Tower strokes. It is also worth mentioning that the closest non-CN Tower stroke was detected at $217.8 \mathrm{~m}$ from the tower. Even though, during the 104-minute storm duration there were no non-CN Tower strokes detected for up to $3.5 \mathrm{~km}$ from the CN Tower [32].

Moreover, NALDN estimated the location of two CN Tower strokes at a substantially far distance from the tower. The locations of these two strokes were estimated to be 2.59 and $1.78 \mathrm{~km}$ away from the CN Tower (south west corner), as seen in Fig. 6.20. These two strokes were confirmed to have been detected by 2 network sensors only; yielding a higher percentage of location error. The average number of sensors reporting lightning events in this area is found to be 8.8 sensors, with a maximum of 15 sensors and a minimum of 2 sensors recording a single stroke.

Figure 6.21 is showing the same map in Fig. 6.20 with the CN Tower strokes (84) excluded. 


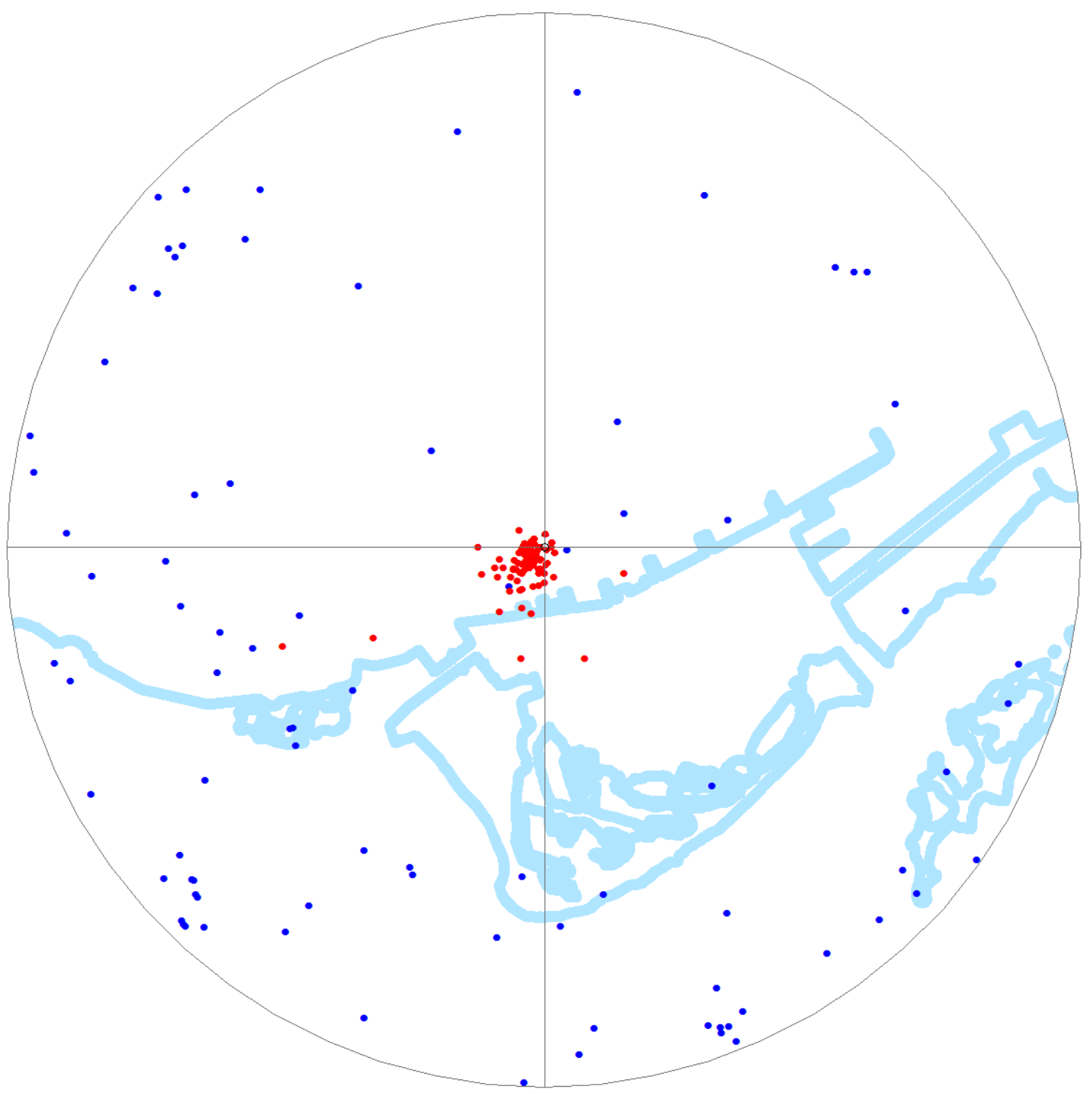

Figure 6.20 - NALDN estimated locations of lightning strokes detected on August 24, 2011 within $5 \mathrm{~km}$ from the $\mathrm{CN}$ Tower. Blue dots represent the non-CN Tower strokes, while red dots represent the $\mathrm{CN}$ Tower-matched strokes. 


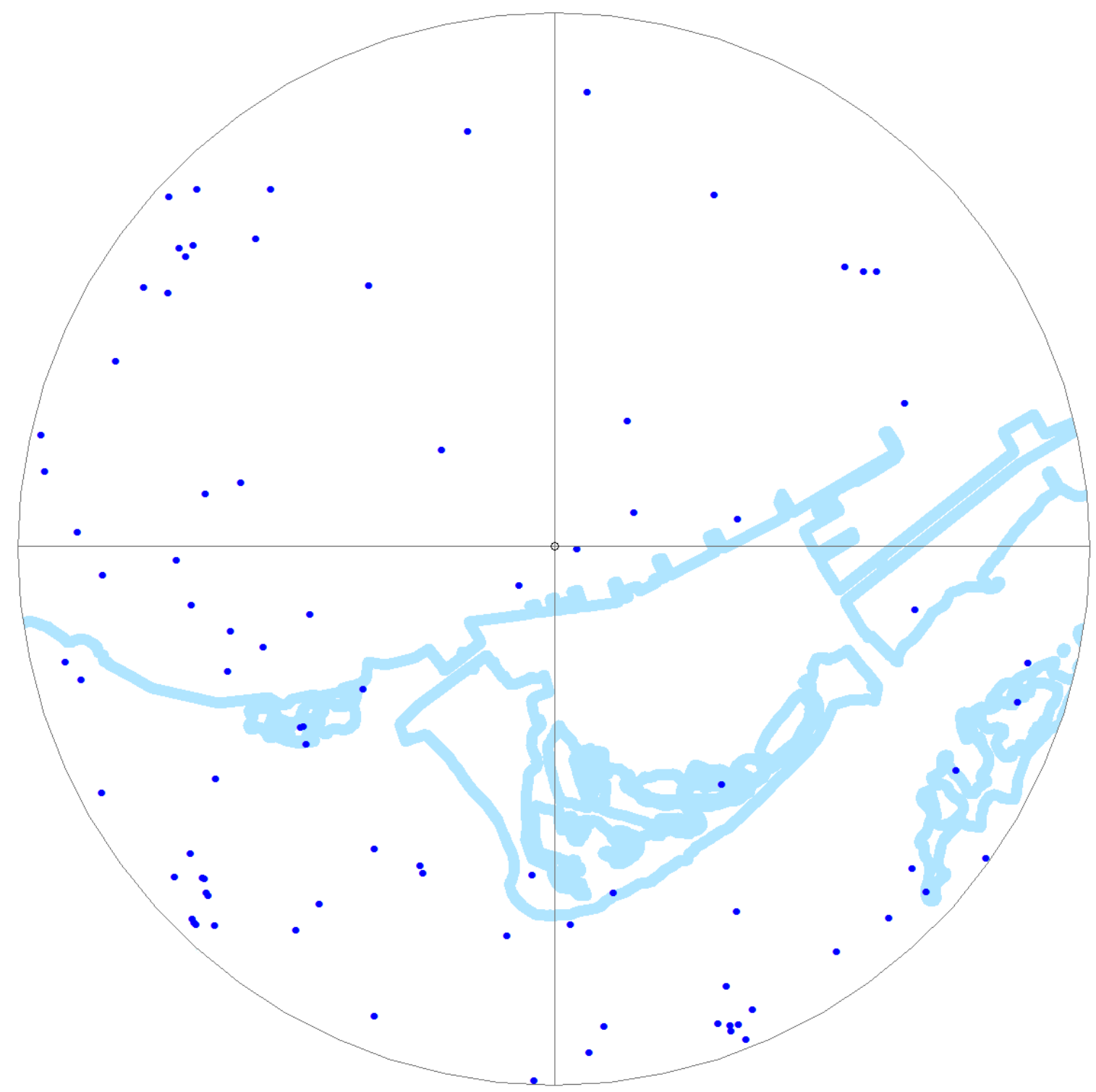

Figure 6.21 - NALDN estimated locations of lightning strokes detected on August 19, 2005 within $5 \mathrm{~km}$ from the $\mathrm{CN}$ Tower, $\mathrm{CN}$ Tower strokes excluded. 


\subsubsection{Detection Efficiency}

Stroke detection efficiency is calculated as the ratio between the total number of strokes detected by NALDN and those measured at the CN Tower. Table 6.2 is showing the total number of flashes recorded by the current derivative measurement system located at the CN Tower (first column), the number of strokes in each measured flash (second column), and the number of strokes detected by NALDN (third column). NALDN detected only $84 \mathrm{CN}$ Tower strokes out of the recorded 161 strokes, resulting in $52.17 \%$ stroke detection efficiency [31].

It is important to note that the network didn't detect four flashes; numbered as 11, 15, 18 and 19 in Table 6.2. These four flashes contained a total of 12 return strokes.

It was also noticed that any flash that contained an interstroke time exceeded $500 \mathrm{~ms}$ was captured by NALDN as two separate flashes. This incident can be seen in two flashes out of the $32 \mathrm{CN}$ Tower-measured flashes; flash 1 and flash 21. Flash 1 has 5 return strokes, 3 of which were

matched with 3 NALDN-detected strokes, but because the interstroke time between the $2^{\text {nd }}$ and $5^{\text {th }}$ measured strokes is $571.340 \mathrm{~ms}$, the first and second detected strokes were grouped together as one flash with multiplicity $=2$ and the third detected stroke was considered as a separate flash with multiplicity $=1$, as per NALDN. Figure 6.22 shows the current derivative signal of flash 1, interstroke time between the three detected strokes, and how NALDN grouped them as separate flashes.

Similarly, in flash 21, the interstroke time between the third and fourth matched strokes is $750.640 \mathrm{~ms}$, hence, NALDN considered the first three strokes as a flash with multiplicity = 3 and considered the fourth stroke as a separate flash with multiplicity $=1$. Figure 6.23 is showing the current derivative signal of flash 21 and the illustrative comments. 
Table 6.2 - Number of NALDN-detected and CN Tower-measured strokes.

\begin{tabular}{|c|c|c|}
\hline CN Flash Number & $\begin{array}{l}\text { \# of Strokes measured at the } \\
\text { CN }\end{array}$ & $\begin{array}{c}\text { \# of Strokes detected by } \\
\text { NALDN }\end{array}$ \\
\hline 1 & 5 & 3 \\
\hline 2 & 3 & 2 \\
\hline 3 & 3 & 1 \\
\hline 4 & 4 & 4 \\
\hline 5 & 3 & 3 \\
\hline 6 & 1 & 1 \\
\hline 7 & 5 & 2 \\
\hline 8 & 12 & 6 \\
\hline 9 & 4 & 3 \\
\hline 10 & 7 & 4 \\
\hline 11 & 1 & Not Detected \\
\hline 12 & 12 & 5 \\
\hline 13 & 11 & 2 \\
\hline 14 & 2 & 2 \\
\hline 15 & 7 & Not Detected \\
\hline 16 & 6 & 2 \\
\hline 17 & 12 & 6 \\
\hline 18 & 1 & Not Detected \\
\hline 19 & 3 & Not Detected \\
\hline 20 & 7 & 5 \\
\hline 21 & 9 & 4 \\
\hline 22 & 4 & 1 \\
\hline 23 & 6 & 6 \\
\hline 24 & 3 & 2 \\
\hline 25 & 2 & 2 \\
\hline 26 & 1 & 1 \\
\hline 27 & 2 & 2 \\
\hline 28 & 3 & 3 \\
\hline 29 & 2 & 2 \\
\hline 30 & 1 & 1 \\
\hline 31 & 14 & 7 \\
\hline 32 & 5 & 2 \\
\hline Total & 161 & 84 \\
\hline
\end{tabular}




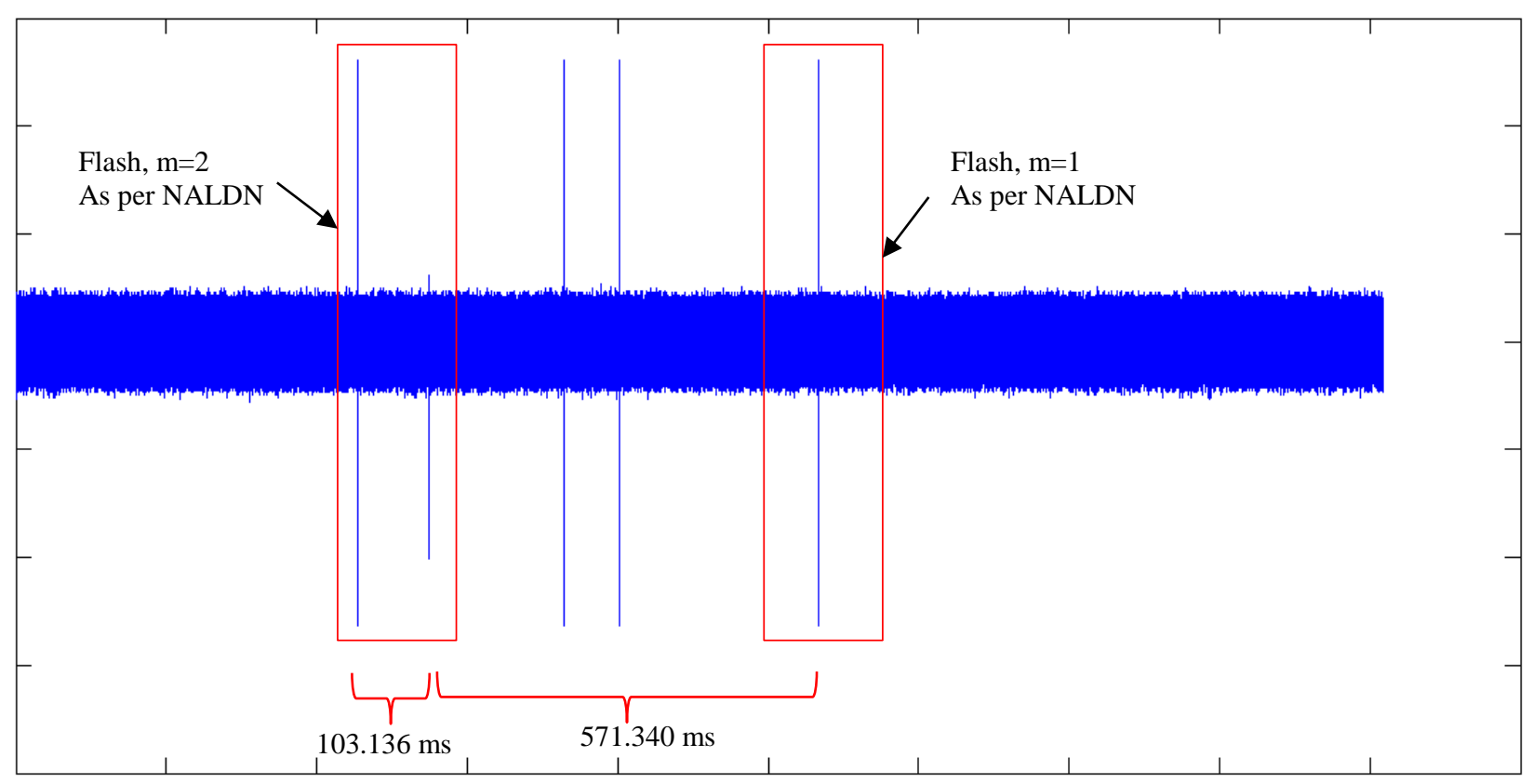

Figure 6.22 - Return-stroke current derivative signals of flash 1.

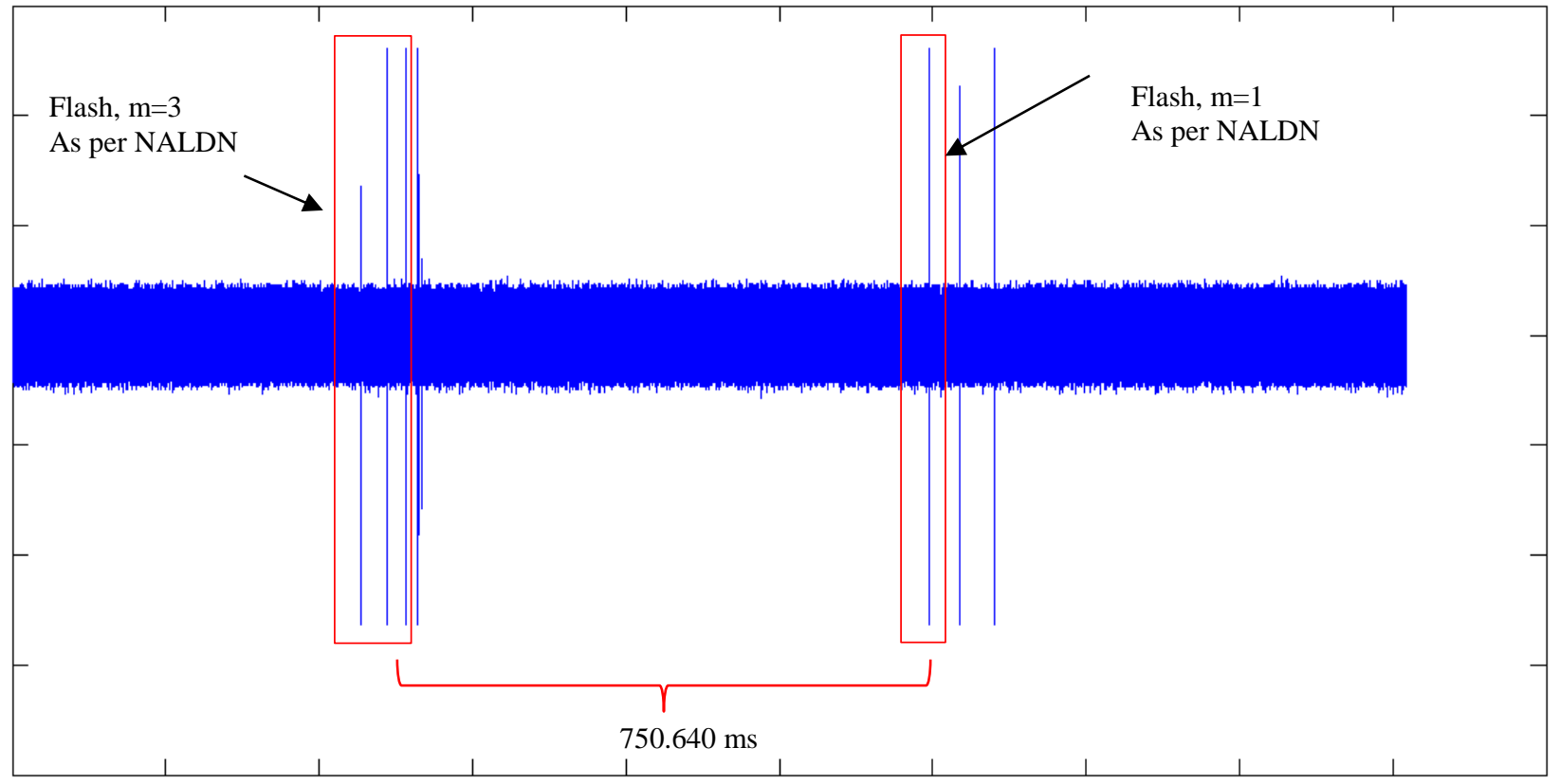

Figure 6.23 - Return-stroke current derivative signals of flash 21. 


\subsubsection{Analysis of Multi-Stroke Flashes}

Multi-stroke flashes are those containing 2 return strokes or more. On August 24, 2011, within $20 \mathrm{~km}$ from the tower, NALDN detected 412 multi-stroke flashes including $24 \mathrm{CN}$ Tower flashes. These flashes contained a total of 1,795 strokes. The characteristics of the 412 flashes that are studied and discussed in details in this subsection are: flash multiplicity and flash duration for CN Tower and non-CN Tower flashes, as well as peak currents for positive and negative strokes.

On August 24, 2011, NALDN detected 758 flashes, including 346 single-stroke flashes, within $20 \mathrm{~km}$ from the $\mathrm{CN}$ Tower. The number of strokes in each of the multi-stroke flashes varies from 2 to 15 . Figure 6.24 shows a cumulative distribution of flash multiplicity of the 758 detected flashes.

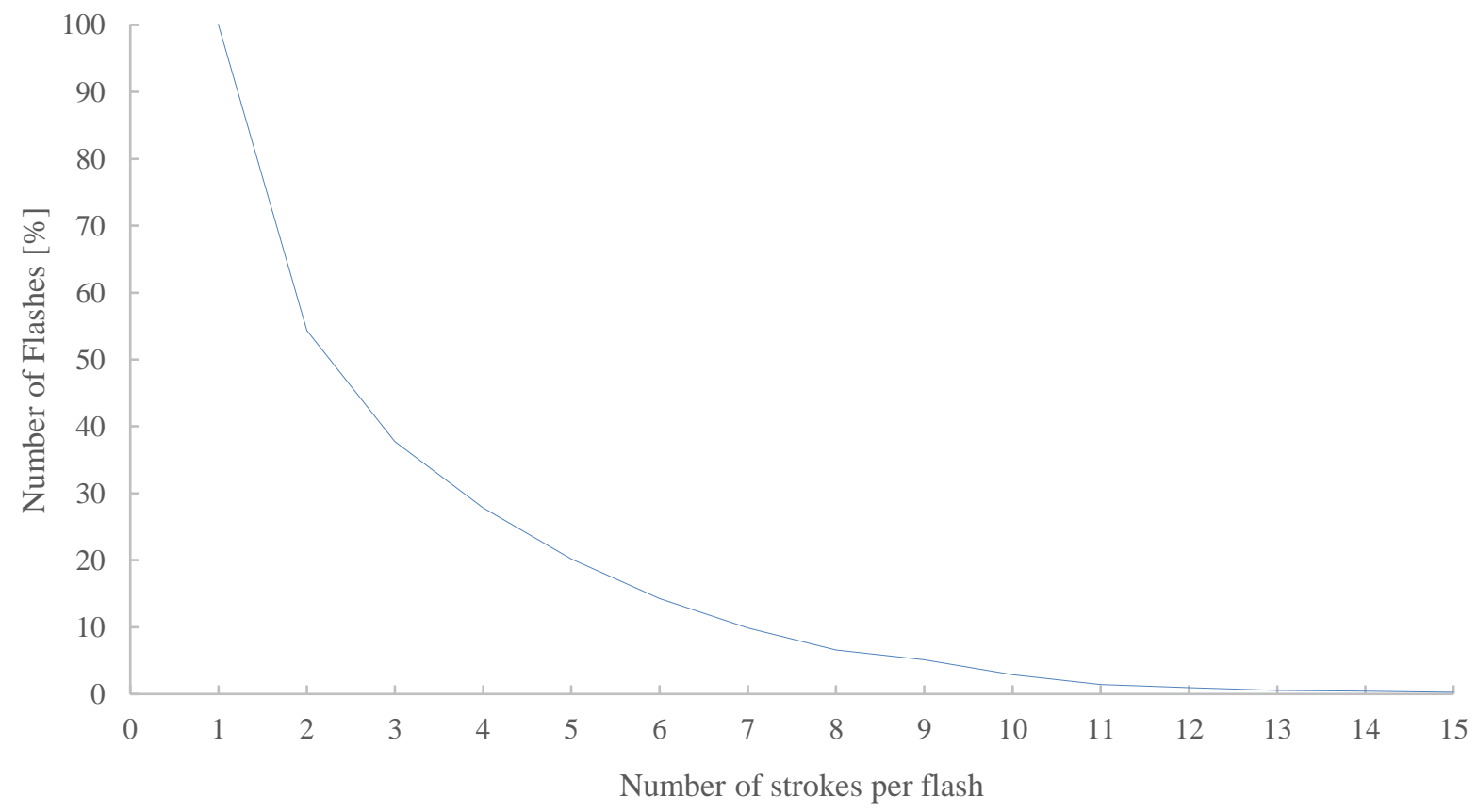

Figure 6.24 - Cumulative distribution of flash multiplicity for 758 flashes within $20 \mathrm{~km}$ from the tower, August 24, 2011. 
On August 24, 2011, out of the 32 flashes which were recorded at the CN Tower, only 8 were single-stroke flashes. Figure 6.25 displays the cumulative probability distribution (CPD) of flash multiplicity of CN Tower flashes, represented by the red line. On the other hand, the CPD of flash multiplicity of non-CN Tower flashes is represented by the blue line. The number of strokes in each of CN Tower flashes varies between 1 and 7, while it varies between 1 and 15 for non-CN Tower flashes.

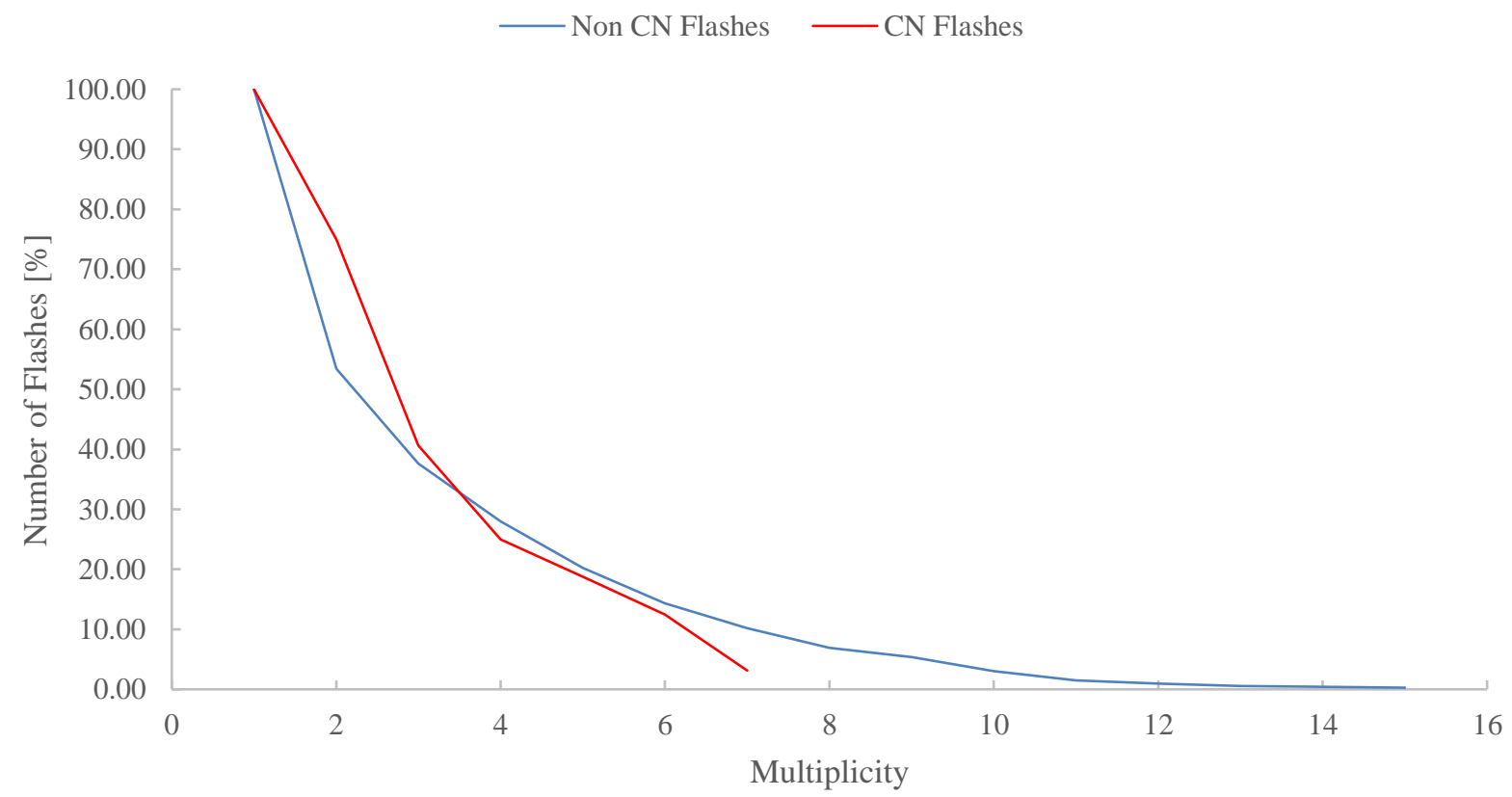

Figure 6.25 - Cumulative distribution of flash multiplicity for $\mathrm{CN}$ Tower and non-CN Tower flashes, August 24, 2011.

The flash duration of multi-stroke flashes is defined as the time between the first and the last strokes within one flash. Figure 6.26 is showing the CPD of flash duration of CN Tower and nonCN Tower flashes in milliseconds, represented by red and blue lines, respectively. The flash duration of CN Tower flashes varies between 14 and 824 milliseconds, with an average of $248 \mathrm{~ms}$. While it varies between 0 and 997 milliseconds with an average of $359 \mathrm{~ms}$ for the non-CN Tower flashes. 


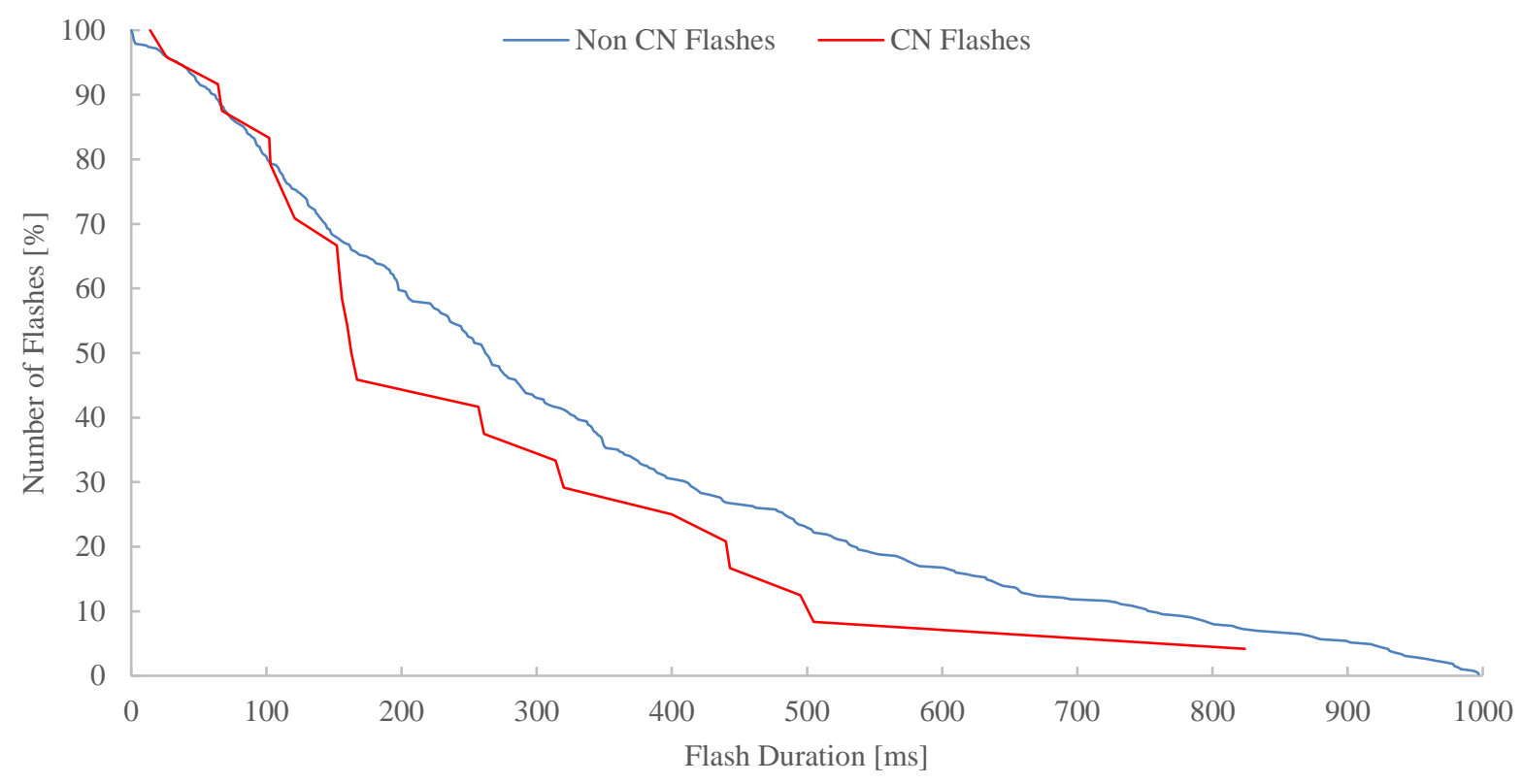

Figure 6.26 - Cumulative distribution of flash duration for multi-stroke flashes, August 24, 2011.

Furthermore, the CPDs of flash duration for non-CN Tower negative and positive/bipolar flashes are displayed in Fig. 6.27. This data set includes 379 negative flashes and 9 positive/bipolar flashes, with average flash durations of 356.5 and $301.8 \mathrm{~ms}$, respectively.

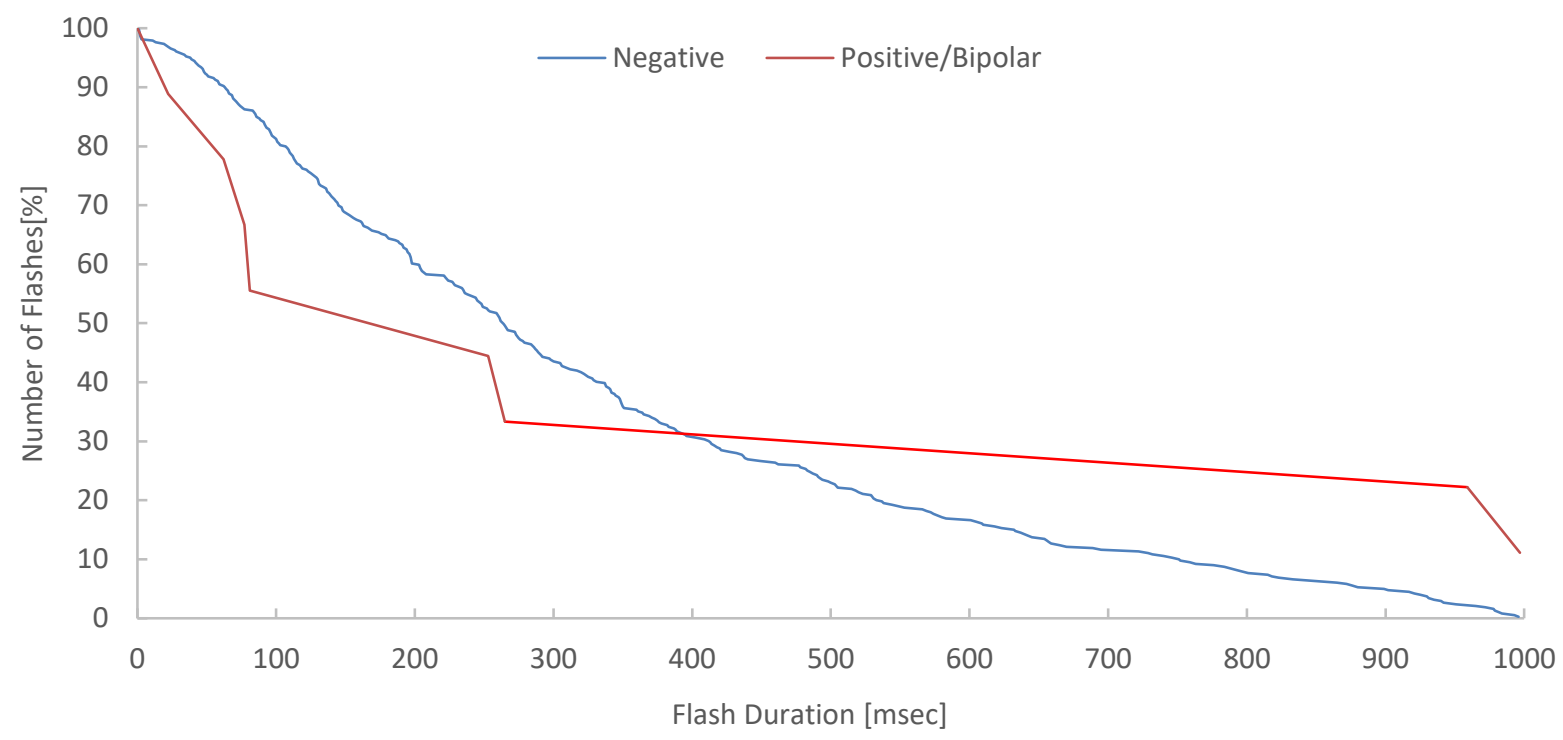

Figure 6.27 - Cumulative distribution of flash duration for non-CN Tower flashes, August 24, 2011. 
For non-CN Tower flashes, the CPDs of the estimated peak current for negative, positive and bipolar flashes are shown in Fig. 6.28. NALDN detected 5 positive (solid red line), 4 bipolar (dotted black line) and 379 negative (solid blue line) non-CN Tower flashes within $20 \mathrm{~km}$ from the tower on August 24, 2011. Even though positive flashes were very few (5), the estimated peak current values of positive flashes are generally higher than that of bipolar and negative flashes.

The estimated peak currents vary between $10.5 \mathrm{kA}$ and $33.5 \mathrm{kA}$ for bipolar flashes (4 flashes), and between $21.1 \mathrm{kA}$ and $82.3 \mathrm{kA}$ for positive flashes (5 flashes). While the average peak current of the 379 negative non-CN Tower flashes is found to be $23.8 \mathrm{kA}$.

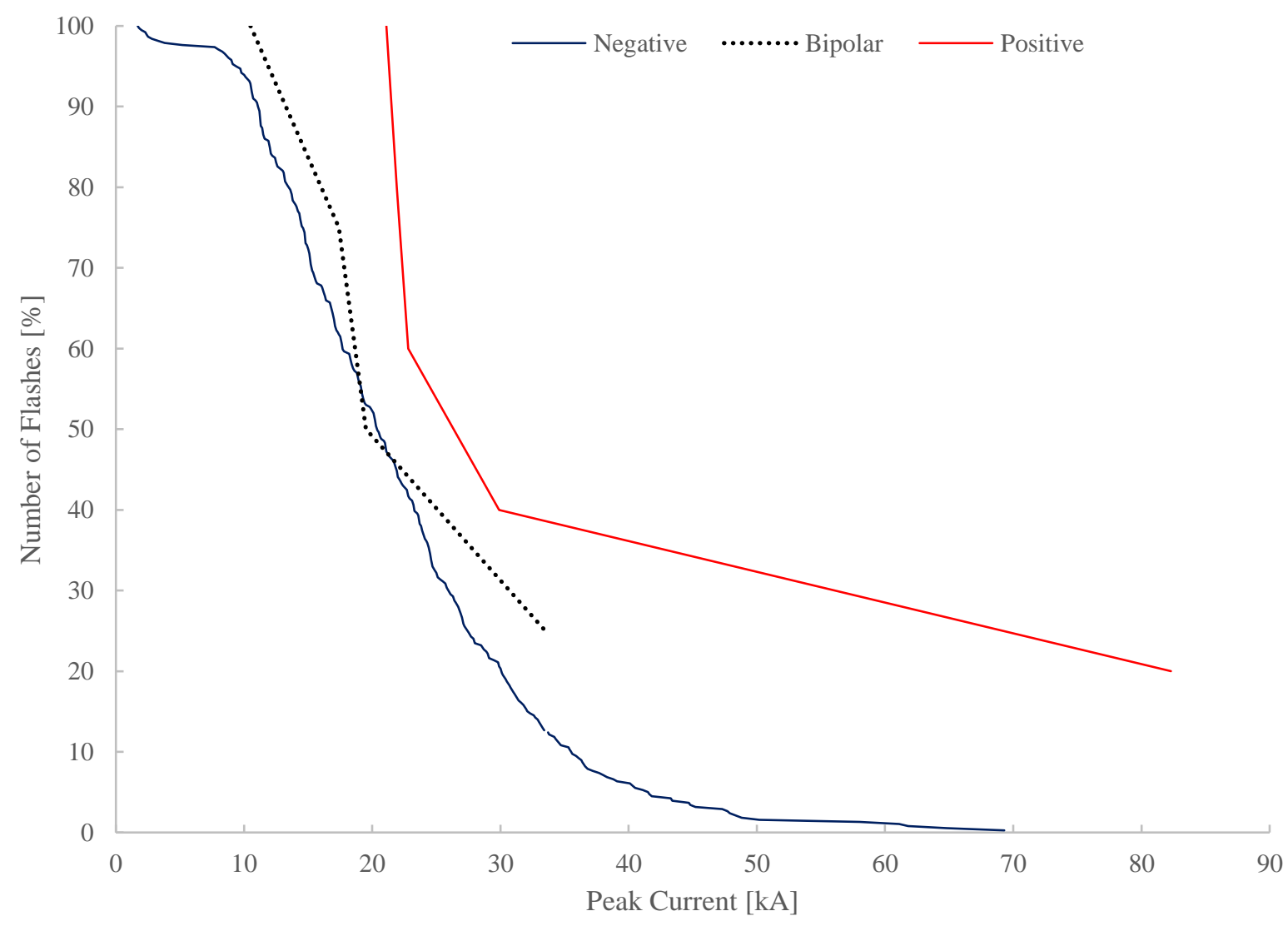

Figure 6.28 - Cumulative distribution of non-CN Tower flashes peak current; positive (red), bipolar (black dotted) and negative (blue) flashes. 


\section{Chapter 7}

\section{Conclusions}

\subsection{Conclusions}

The existence of the Toronto CN Tower, standing at 553-m tall, presents such an amazing opportunity to collect lightning data and study the characteristics of tall-structure lightning. Such opportunity was pivotal for the emergence of this thesis. Based on the North American Lightning Detection Network (NALDN) data and the return-stroke currents recorded at the tower, the lightning environment has been thoroughly investigated within up to $100 \mathrm{~km}$ from the CN Tower, especially while the tower was struck with major storms in 2005 and 2011.

Based on the current derivative signals recorded on August 24, 2011, representing the most intense storm that has ever been observed at the CN Tower and the acquired NALDN data, this thesis emerged. Although video records show that the tower was struck with 52 flashes within 84 minutes and 6.9 seconds, the $\mathrm{CN}$ Tower current derivative measurement system recorded only 32 flashes, containing 161 return strokes. The remaining 20 flashes did not trigger the current derivative measurement system indicating that they did not contain return strokes. Fortunately, before the advent of the 2011 severe storm, a large-memory digitizer (NI PCI 5114) was installed at the tower to continuously record, for the first time, the current derivative of every flash for two seconds. 
Using the 2011 North American Lightning Detection Network (NALDN) data for the area of up to $100 \mathrm{~km}$ from the tower, the lightning environment characteristics in the vicinity of the tower were thoroughly studied, including the determination of flash multiplicity, stroke location and density, monthly and daily variation of stroke density, polarity, and peak current estimate. It was also possible to compare the characteristics of $\mathrm{CN}$ Tower flashes, which are upward initiated, with flashes occurring in its vicinity that are expected to be mostly downward-initiated. Furthermore, an opportunity materialized to study the lightning environment around the tower while the tower was heavily struck with 52 flashes within about 84 minutes, during the most intense storm ever recorded at the tower.

Flash multiplicity of CN Tower lightning during the most intense storm is found to be5.03, which is markedly higher than that of non-CN Tower flashes that was determined to be 2.83 during the day of August 24, 2011.

Positive flashes in the vicinity of the tower are found to be much fewer and have generally lower multiplicity than those for negative flashes. However, peak currents of positive strokes are mostly higher than those for negative strokes.

On August 24, 2011 and during the 104-minute time window, within which the tower was heavily struck with lightning, the NALDN detected non-CN Tower 15 positive and 309 negative strokes, within $20 \mathrm{~km}$ from the tower (The number of positive strokes is only $4.6 \%$ of the total number of detected strokes). The average peak current of positive non- $\mathrm{CN}$ Tower strokes is found to be $28.01 \mathrm{kA}$, which is $52 \%$ higher than that for negative strokes.

During August 19, 2005 storm, which lasted for 90 minutes and 4 seconds, the NALDN detected 546 negative and 206 positive non-CN Tower strokes within $20 \mathrm{~km}$ from the tower. The average peak current of positive strokes is found to be $11.29 \mathrm{kA}$ and that for negative strokes is $16.96 \mathrm{kA}$. However, the maximum current peak of negative strokes is $89.3 \mathrm{kA}$, more than three time higher than that of the highest positive stroke ( $26.8 \mathrm{kA}$ ), proving that the August 19, 2005 storm was quite different from August 24, 2011 storm, at least in the vicinity of the tower. The average estimated peak currents for CN Tower strokes are calculated to be $24.95 \mathrm{kA}$ and 23.93 kA during August 24, 2011 and August 19, 2005. 
It is worth mentioning that on August 24, 2011, the tower started to be hit by lightning at the decaying part of the storm, whereas on August 19, 2005, it was hit at the very beginning of the storm.

The average number of sensors reporting a lightning stroke in the vicinity of the CN Tower during the August 242011 storm is found to be 8.8, indicating high location accuracy data.

NALDN is a commercial lightning detection network that is more focused on cloud-toground lightning. This produced some discrepancies in terms of tall-structure lightning.

\subsection{Future Research and Recommendations}

The importance of lightning studies, as it impacts human life and infrastructures, has been expanding worldwide towards the improvement of lightning detection, which leads to proper protection.

It is recommended to acquire higher quality NALDN data. The GPS timing of lightning events can be obtained with a resolution of 1 nanosecond, which will make the time-matching process with the $\mathrm{CN}$ Tower-measured lightning events more precise. Also, knowing the number of sensors that record each lightning event would impact the accuracy of its estimated location and peak current. Moreover, acquiring the location coordinates with the fifth decimal place would substantially improve the location accuracy to $1.1 \mathrm{~m}$ resolution. Analyzing more successive yearly lightning data and correlating it with the solar cycle is of interest and may open avenues to prediction of lightning activities.

On the other hand, it is recommended to improving the $\mathrm{CN}$ Tower current measurement system in terms of time resolution and memory. Also the acquisition of a high-speed digital camera $(100,000$ frames/sec $)$ is a requirement for understanding tall-structure lightning based on current and video records.

Finally, it is recommended to study the electromagnetic interference in the vicinity of the tower resulting from $\mathrm{CN}$ Tower lightning strikes. 


\section{References}

[1] Martin A. Uman, “Lightning,” Pittsburgh PA: McGraw Hill, 1969.

[2] Canadian Lightning Fatalities and Injury Statistics, https://ec.gc.ca/foudrelightning/default.asp?lang=En\&n=5D5FB4F8-1.

[3] Lightning and forest fires, Environment and Climate Change Canada, http://www.ec.gc.ca/foudre-lightning/default.asp?lang=En\&n=48337EAE-1.

[4] V.A. Rakov and M.A. Uman, "Lightning: Physics and Effects," Cambridge University Press, August 2003

[5] Martin A. Uman, "The Lightning Discharge," Orlando, FL: Academic Press Inc., 1987.

[6] E.R. Williams, "The Electrification of Thunderstorms," Scientific American, November 1988, pp. 88-99.

[7] Martin A. Uman, "The Art and Science of Lightning Protection," New York: Cambridge University Press, 2008.

[8] Environment Canada, "Lightning in Canada" http://www.ec.gc.ca/foudrelightning/default.asp?lang=En\&n=73364E34-1.

[9] Video records obtained from Mr. P. Weiss and Mr. W. See-Tho. 
[10] W. Janischewskyj, A.M. Hussein, V. Shostak and P. Dzurevych, "Characterization of the Current Wavefront Parameters of Lightning Strikes to the CN Tower in Toronto," $8^{\text {th }}$ International Symposium on High Voltage Engineering, August 23-27, Yokohama, Japan, 1993.

[11] Nag, A., M. J. Murphy, W. Schulz, and K. L. Cummins, 2015: "Lightning locating systems: Insights on characteristics and validation techniques," Earth Space Sci., 2, 65-93, doi:10.1002/2014EA000051.

[12] Rakov, V. A., "Lightning electromagnetic environment: From continuing-current fields to X-rays," in Intl. Conf. on Grounding and Earthing \& 3rd Intl. Conf. on Lightning Phys. and Effects, Florianopolis, Brazil, 2008.

[13] K.L. Cummins and M.J. Murphy, “An Overview of Lightning Locating Systems: History, Techniques, and Data Uses, With an In-Depth Look at the U.S. NLDN," IEEE Trans. on Electromagnetic Compatibility, Vol. 51, No. 3, pp. 499-518, August 2009.

[14] LPATS IV Installation, Operation, and Maintenance Manual, Global Atmospherics, Inc., USA, 1998.

[15] Cummins, K.L.. M.J. Murphy, J.V. Tuel, "Lightning detection methods and meteorological applications," IV International Symposium on Military Meteorology, Malbork, Poland, September 25-28, 85-100, 2000.

[16] A. Lafkovici, A.M. Hussein, W. Janischewskyj and K. Cummins, "Evaluation of the performance characteristics of the North American Lightning Detection Network based on tall-structure lightning," IEEE Trans. on EMC, vol. 50, no. 3, pp. 630-641, August 2008.

[17] P.J. Lewis, "Winter Lightning in the Maritime Provinces of Canada," 16th International Lightning Detection Conference, Global Atmospherics, Inc. Tuscon, Arizona, November 7-8, 2000. 
[18] A. Lafkovici, "A Performance Analysis of the North American Lightning Detection Network using CN Tower Lightning Data," M.A.Sc. Thesis, Ryerson University, Toronto, Ontario, Canada, 2005.

[19] K.L. Cummins, M.J. Murphy, E.A. Bardo, W.L. Hiscox, R.B. Pyle, and A.E. Pifer, “A Combined TOA/MDF Technology Upgrade of the U.S. National Lightning Detection Network," Journal of Geophysical Research, vol. 103, no. D8, pp. 9035-9044, April 1998.

[20] Nag, A., M. J. Murphy, A. E. Pifer, and J. A. Cramer, "Performance Characteristic Improvements of the U.S. National Lightning Detection Network," Abstract 4.5, $6^{\text {th }}$ Conference on the Meteorological Applications of Lightning Data, 93 ${ }^{\text {rd }}$ American Meteorological Society Annual Meeting, Austin, Texas, January 05 - 10, 2013.

[21] A. Nag, M.J. Murphy, K.L. Cummins, A.E. Pifer, J.A. Cramer, "Recent Evolution of the U.S. National Lightning Detection Network," $23^{\text {rd }}$ International Lightning Detection Conference, Vaisala, Arizona, USA, March 2014.

[22] Personal Communication from Meteorologist Lyn Mainwaring of Environment Canada.

[23] CN Tower - Wikipedia, https://en.wikipedia.org/wiki/CN_Tower.

[24] A.M. Hussein, V. Todorovski, M. Milewski, K.L. Cummins and W. Janischewskyj, "Characteristics of lightning strikes at and in the vicinity of the CN Tower," International Conference on Lightning Protection, Uppsala, Sweden, 1c4: pp. 1-12, June 23-26, 2008.

[25] A.M. Hussein, S. Jan, V. Todorovski, M. Milewski, K.L. Cummins and W. Janischewskyj, "Influence of the CN Tower on the lightning environment in its vicinity," Proc., International Lightning Detection Conference, pp. 1-19, Orlando, FL, USA, April 19-20, 2010. 
[26] A.M. Hussein, "CN Tower Lightning Parameters," Invited Paper, Proceedings, $X$ International Symposium on Lightning Protection, pp. 107-133, Curitiba, Brazil, Nov. 9-13, 2009.

[27] A.M. Hussein, M. Milewski, W. Janischewskyj, "Correlating the characteristics of the $\mathrm{CN}$ Tower lightning return-stroke current with those of its generated electromagnetic pulse," IEEE Trans. on Electromagnetic Compatibility (EMC), vol. 50, no. 3, pp. $642-$ 650, August 2008.

[28] A.M. Hussein, S. Kazazi, M. Anwar, M. Yusouf and P. Liatos "CN Tower Lightning Characteristics, Based on Current-Recorded Flashes," Proc., International Conference on Lightning Protection, pp. 2028-2034, Shanghai, China, October 13-17, 2014.

[29] A.M. Hussein and S. Kazazi, "Characteristics of a Tall-Structure Severe Lightning Storm," Proc., International Symposium on lightning Protection, pp. 146-151, Belo Horizonte, Brazil, Oct. 7-11, 2013.

[30] M. Milewski, "Lightning Return-Stroke Transmission Line Modelling Based on the Derivative of Heidler Function and CN Tower Data," Ph.D. Thesis, Ryerson University, Toronto, Ontario, Canada, 2009.

[31] A.M. Hussein, S. Kazazi, M.P. Anwar, M. Yusouf, "Characteristics of the most intense lightning storm ever recorded at the CN tower," Journal of Atmospheric and SolarTerrestrial Physic, vol. 154, pp. 195-206, February 2017.

[32] N. Mansour and A.M. Hussein, "Lightning Environment in the Vicinity of the CN Tower During Major Storms," accepted for publication, The 10th Asia-Pacific International Conference on Lightning, May 16-19, Krabi, Thailand, 2017. 


\section{Glossary}

$\begin{array}{ll}\text { AGL } & \text { Above Ground Level } \\ \text { ARSI } & \text { Atmospheric Research Systems, Inc. } \\ \text { CG } & \text { Cloud-to-ground } \\ \text { CLDN } & \text { Canadian Lightning Detection Network } \\ \text { CMC } & \text { Canadian Meteorological Centre } \\ \text { CPD } & \text { Cumulative Probability Distribution } \\ \text { DE } & \text { Detection Efficiency } \\ \text { DL } & \text { Dart Leader } \\ \text { DSL } & \text { Digital Subscriber Line } \\ \text { EVDO } & \text { Evolution Data Optimized } \\ \text { GPS } & \text { Global Positioning System } \\ \text { IMPACT } & \text { IMProved Accuracy from Combined Technology } \\ \text { LF } & \text { Low Frequency } \\ \text { LLS } & \text { Lightning Location System } \\ \text { LPATS } & \text { Lightning Position And Tracking Sensor } \\ \text { MDF } & \text { Magnetic Direction Finding } \\ \text { NALDN } & \text { North American Lightning Detection Network }\end{array}$


NLDN National Lightning Detection Network

RS Return Stroke

SL Stepped Leader

TOA Time-of-Arrival

VCC Vaisala Control Centre

VHF Very High frequency

VLF Very Low Frequency

VPN Virtual Private Network 